\title{
REPORT ON GROUPED PEER REVIEW OF SCHOLARLY JOURNALS IN MATHEMATICS AND SCIENCE
}

Committee on Scholarly Publishing in South Africa

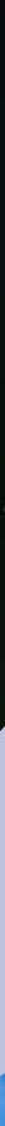




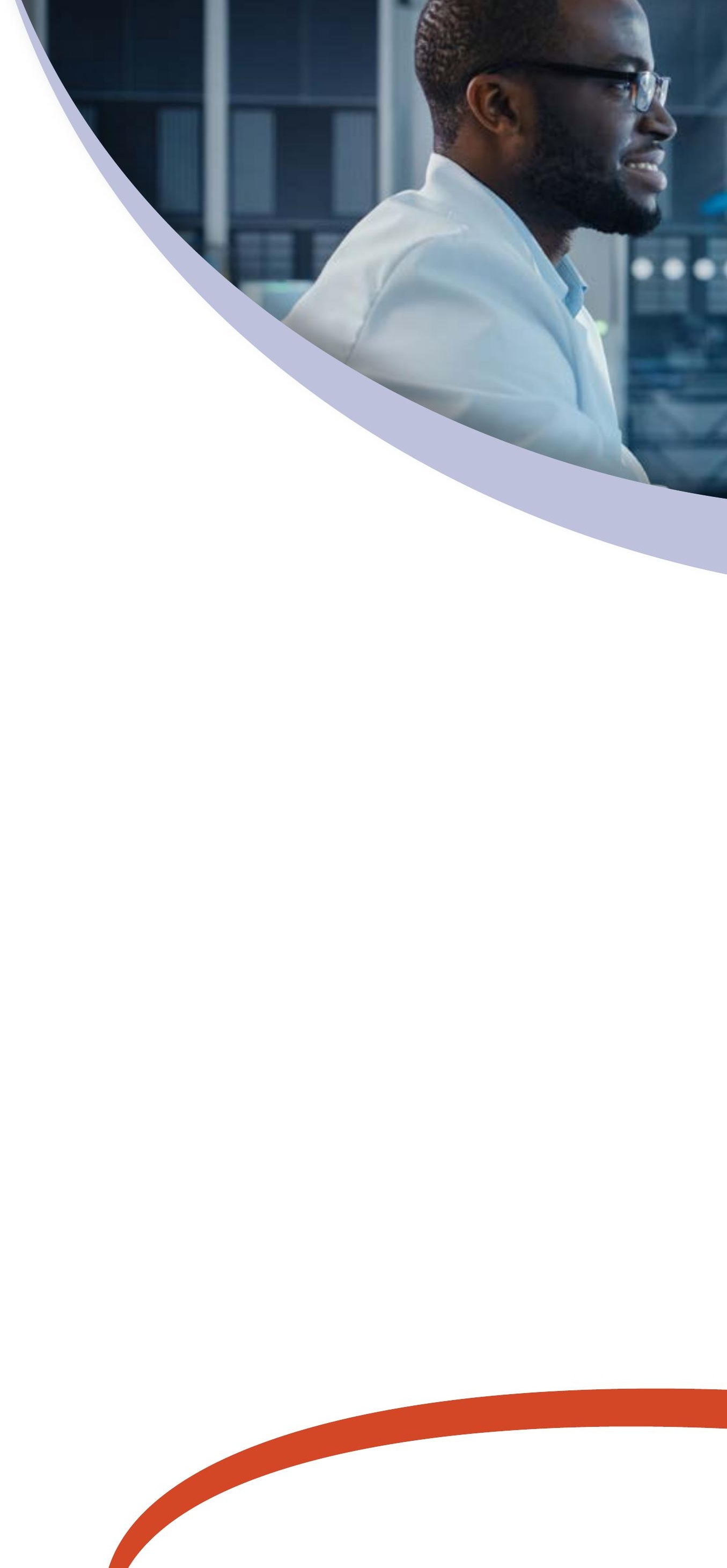





\section{Table of Contents}

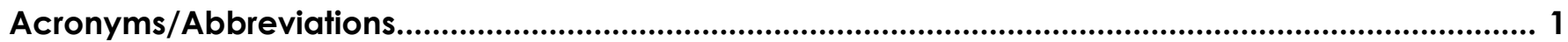

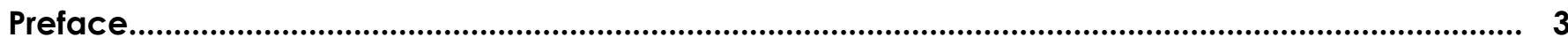

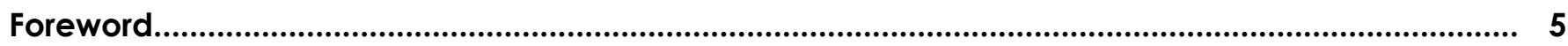

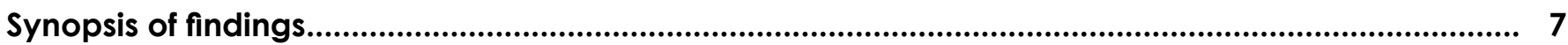

1. Periodic Peer Review of South African Scholarly Journals: Approved Process Guidelines and Criteria

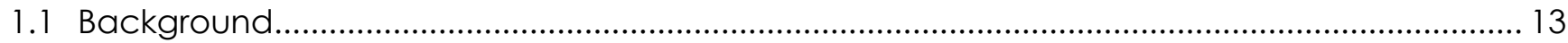

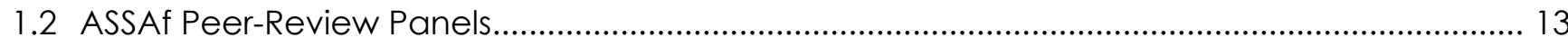

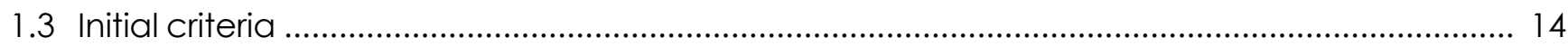

1.3.1 Editorial Process-Related Criteria: Generally Based on ASSAf's Code of Best Practice in Scholarly Journal Publishing, Editing and Peer Review................................. 14

1.3.2 Business-related Criteria................................................................................................... 14

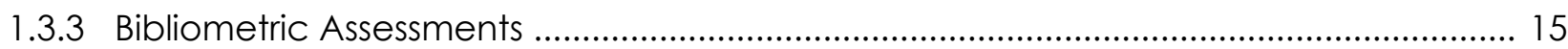

1.4 Process Guidelines for Setting up Panels, Peer Reviewers, Panel Meetings and Reports for the Subject Peer Review of Journals..................................................................................... 15

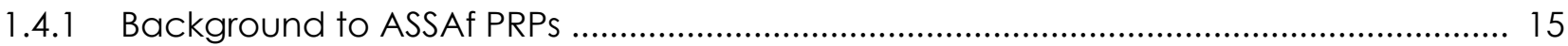

1.4.2 Role of the Scholarly Publishing Unit (SPU) ................................................................. 15

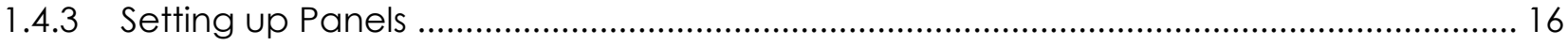

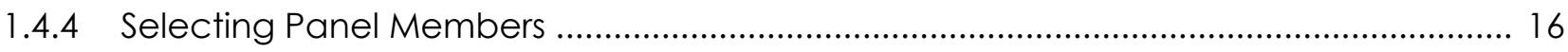

1.4.5 Criteria for Membership .............................................................................................. 16

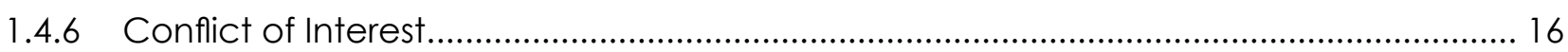

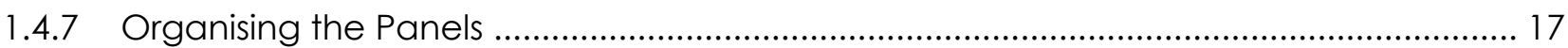

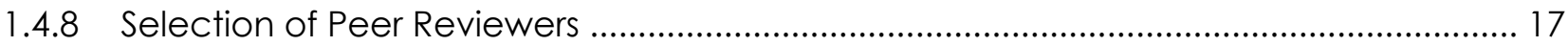

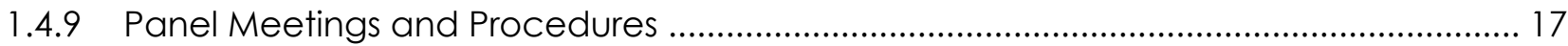

1.4.10 Post-meeting Procedures and Panel Reports ............................................................. 18

2. Special Considerations Concerning South African Mathematics and Science Journals.................. 19

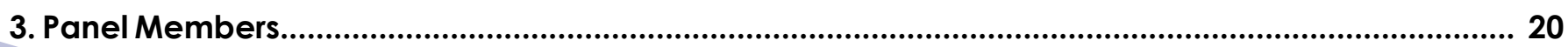

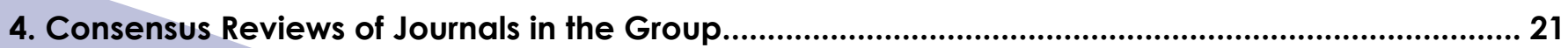

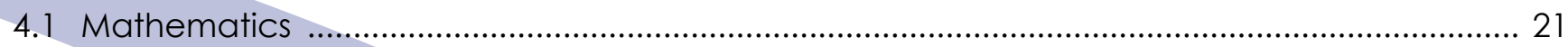

4.1.1 ORiON: Journal of the Operations Research Society of South Africa............................ 21

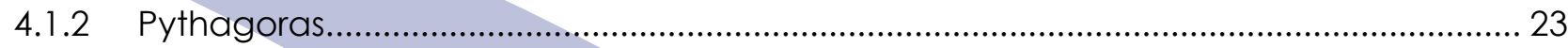

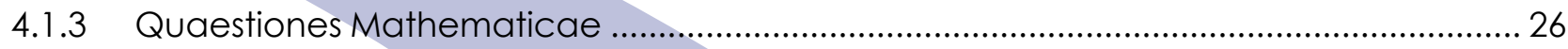




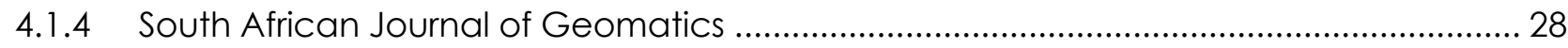

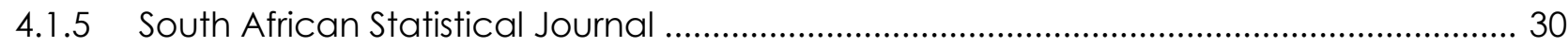

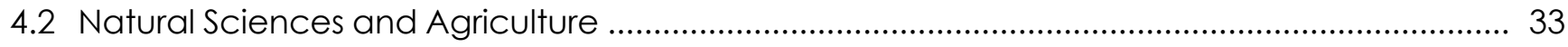

4.2.1 African Journal of Agricultural and Resource Economics ......................................... 33

4.2.2 African Journal of Aquatic Science .............................................................................. 35

4.2.3 African Journal of Marine Science .............................................................................. 38

4.2.4 Ostrich: Journal of African Ornithology ....................................................................... 42

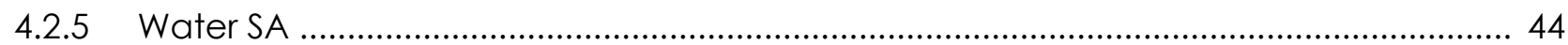

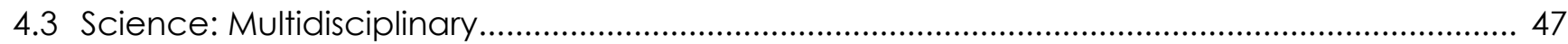

4.3.1 African Journal of Science, Technology, Innovation and Development .................... 47

4.3.2 Journal for New Generation Sciences ........................................................................ 50

4.3.3 Journal for Transdisciplinary Research in Southern Africa ............................................. 54

4.3.4 South African Journal of Chemistry ................................................................................. 58

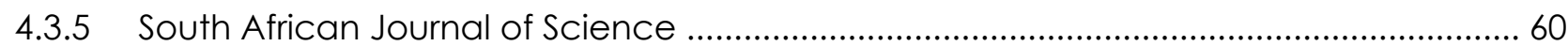

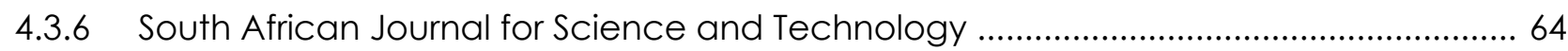

4.3.7 Transactions of the Royal Society of South Africa .........................................................68

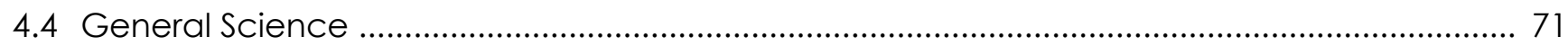

4.4.1 Annals of the Ditsong National Museum of Natural History ........................................... 71

4.4.2 Durban Natural Science Museum Novitates ................................................................ 74

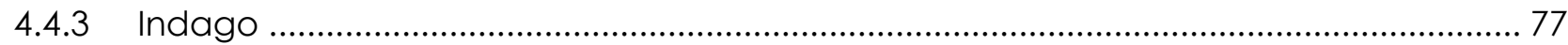

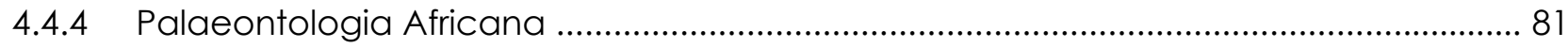

4.4.5 South African Archaeological Bulletin ......................................................................... 84

Appendix A: Questionnaire sent to Editors of Journals under review ............................................. 87

Appendix B: Requests to Independent Peer Reviewers ................................................................. 91 


\section{Acronyms/Abbreviations}

AFROS AGORA

AJAS

AJOL

AJSTID

AMESA

ASAPA

ASSAf

CC BY

CC BY-NC-ND

CHE

CONSAS

COPE

Covid-19

CSPISA

CUT

CV

DEFF

DHET

DOAJ

DOI

DSI

EBSCOhost

$\mathrm{ESCl}$

HEQC

IBSS

INASP

IR

JNGS

$\mathrm{KZN}$

$M C Q$

MIT

$\mathrm{NC}$

ND

NISC

NRF

NSEF

OARE

OJS

ORSSA

PDF
African Federation of Operational Research Societies

Access to Global Online Research in Agriculture

African Journal of Aquatic Science

African Journals Online

African Journal of Science, Technology, Innovation and Development

Association for Mathematics Education of South Africa

Association of Southern African Professional Archaeologists

Academy of Science of South Africa

Creative Commons Attribution 4.0 International licence

Creative Commons Attribution-NonCommercial-NoDerivatives

International licence

Council on Higher Education

Conference for Southern African Surveyors

Committee on Publication Ethics

Severe acute respiratory syndrome coronavirus 2 (SARS-CoV-2)

Committee on Scholarly Publishing in South Africa

Central University of Technology

Curriculum Vitae

Department of Environment, Forestry and Fisheries

Department of Higher Education and Training

Directory of Open Access Journals

Digital Object Identifier

Department of Science and Innovation

Elton B. Stephens Company (EBSCOhost) research platform

Emerging Sources Citation Index

Higher Education Quality Committee

International Bibliography of the Social Sciences

International Network for the Availability of Scientific Publications

Institutional Repository

Journal for New Generation Sciences

KwaZulu-Natal

Mathematical Citation Quotient

Multidisciplinary, interdisciplinary or transdisciplinary

Non-Commercial

No Derivative works

National Inquiry Services Centre

National Research Foundation

National Scholarly Editors' Forum

Online Access to Research in the Environment

Open Journal Systems

Operations Research Society of South Africa

Portable Document Format 
SA

SAAS

Sabinet

SACI

SADC

SAJC

SAJG

SAJS

SARChl

SASJ

SAYAS

SCIELO SA

SNIP

TUT

UK

Unisa

USA

VAT

Wits

WoS

WRC

$X M L$

HTML
South Africa

South African Archaeological Society

South African Bibliographic and Information Network

South African Chemical Institute

Southern African Development Community

South African Journal of Chemistry

South African Journal of Geomatics

South African Journal of Science

South African Research Chairs Initiative

South African Statistical Journal

South African Young Academy of Science

Scientific Electronic Library Online South Africa

Normalised Impact per Paper

Tshwane University of Technology

United Kingdom

University of South Africa

United States of America

Value Added Tax

University of the Witwatersrand

Web of Science

Water Research Commission

Extensible Markup Language

HyperText Markup Language 


\section{Preface}

\section{Committee on Scholarly Publishing in South Africa Discipline-grouped Peer-review Reports on South African Scholarly Journals}

This is the 12th in the series of discipline-grouped evaluations of South African scholarly journals. Eventually, it is hoped that all scholarly journals published in South Africa will have been subjected to independent, multiple peer review as part of a quality-assurance process initiated by the Academy of Science of South Africa (ASSAf). The quality-assurance process is a precursor to the identification of journal titles to be loaded on to the open-access platform, Scientific Electronic Library Online South Africa (SciELO SA). Only open-access journals of sufficiently high quality will be included in this fully indexed, free-online, multinational platform, now also directly featured on the Clarivate Analytics Web of Science (WoS) portal.

The traditional focus of peer review is on a single journal article, book chapter or book. It is less common to subject journals to independent, multiple peer review, as these are usually evaluated in qualitative reputational terms, or bibliometrically by means of impact factors.

The peer-review of South African scholarly journal titles required the development of a new methodology that was piloted successfully with the first two discipline-grouped peer review reports, published in 2010, on the Social Sciences and Related Fields and the Agricultural and Related Basic Life Sciences. This work was not achieved without difficulty, as the process was unfamiliar to reviewers accustomed to reviewing single articles.

ASSAf has confidence in this ambitious programme, which is aimed at ensuring that the bulk of South African scholarly journals are of good quality. The process goes beyond the familiar journal assessment approaches by providing concrete recommendations to enable the editor(s) of journals, especially those not deemed to be of a sufficient standard, to take corrective action. The process also provides an opportunity for editors to reapply for evaluation.

The process centred on multi-perspective, discipline-based evaluation panels appointed by the ASSAf Council on the recommendation of ASSAf's Committee on Scholarly Publishing in South Africa (CSPiSA); journal editors were requested to complete specially designed questionnaires, and peer reviewers were selected from a spectrum of scholars in relevant fields. Each editor was asked to provide answers to a set of questions, which were used to address the scope and focus of the journals under review, the scope of the authorship, and the presence or absence of enrichment features such as editorials, topical reviews, book reviews, and news and views articles. (The editors' questionnaire and peer reviewers' questions are appended to this report as Appendices A and B.)

Each discipline-based evaluation panel met to discuss the individual peer reviews and questionnaires and consolidated them into a consensus review for each journal. Final formulations and recommendations were prepared, including suggestions for improvement from both the peer reviewers and the panel. The responsible editors were given an opportunity to check the accuracy of the information in each individual journal report, and the final version of the report was submitted for approval to CSPiSA and the ASSAf Council.

In this report, the latest in the series of reports on the review of discipline groups of journals, it is evident that much has been learned from the review of previous discipline groups, and that in future the process will become more streamlined, such that subsequent reports will follow in rapid succession. 
I would like to thank the chair of the panel, Prof Don Cowan, and members of the evaluation panel, and to particularly acknowledge Prof Robin Crewe, who is responsible for overseeing ASSAf's peerreview panel activities, for his leadership in this quality-assurance process. I acknowledge the important role played by ASSAf staff in supporting the process, in particular Mrs Susan Veldsman, Director of the Scholarly Publishing Unit, and the project officer who worked under her direction, Ms Mmaphuthi Mashiachidi. Finally, I acknowledge the contribution of the many individual peer reviewers who have each contributed towards strengthening the quality of South African scholarly journals.

\section{Prof Himla Soodyall}

Executive Officer: Academy of Science of South Africa 


\section{Foreword}

The Department of Higher Education and Training (DHET) welcomes yet another scholarly journals peer-review report by the Academy of Science of South Africa (ASSAf). These reviews auger well for the health and integrity of our science system, especially the higher education sector which communicates its scholarly knowledge largely through the journals medium. We wish ASSAf strength and the very best as they continue to improve the quality of journals in the South African higher education system, thereby influencing the standard of research conducted in the various scientific disciplines. Certainly, these reviews uplift the reliability and integrity of our science system at large and that of scholarly publications, as the ASSAf's processes and methodology are rigorous. Besides, the process is developmental as it is iterative and interactive with the journals' editors-in-chief.

The DHET supports the work of ASSAf in ensuring that only quality publications from the higher education system are circulated and utilised within the higher education system and the practitioners at large. The DHET views the work of ensuring quality publications as a collective effort of everyone involved in the knowledge production value chain, from researchers to publishers, practitioners and to users of knowledge. Our effort is supported by the joint statement on ethical research and scholarly publishing practises issued jointly by ASSAf, CHE, DHET, NRF and USAF, which states that the key role players on ensuring the right behaviour and attributes in the publishing of research outputs are the editors, peer reviewers, editorial boards, authors, and higher education institutions.

In addition to the technical criteria in the Research Output Policy of the DHET to determine if a journal qualifies for inclusion in the DHET list of South African journals, ASSAf contributes immensely to the provision of a professionally managed process that mobilises expertise for further assessment of scholarly quality of each new journal addition. Moreover, these periodic reviews help to maintain high standards of the DHET-listed journals. Government subsidy for research relies heavily on this valuable contribution by ASSAf which ensures that the DHET continues to successfully deliver on its stated mission of supporting only publications of high quality leading to the successful implementation of the Research Output Policy.

Over the past few years, the open access and open science movement has intensified. The DHET has heeded the call and supports open access to quality knowledge. As such, in addition to the Scientific Electronic Library Online South Africa (SciELO - SA) which is managed by ASSAf, the DHET has recently included the Directory of Open Access Journals (DOAJ) as one of the indexes approved for the purposes of research subsidy from published articles by academics at the South African universities. Over and above the effort to broaden the scope of journals for South African academics, the DHET hopes to also send a message about the unjustifiable high costs of publishing and accessing knowledge meant to uplift our society, and that open access knowledge can be both freely accessible and of high quality at the same time.

As we continue to explore various means to support the improvement of quality of publications and as the Research Outputs Policy indicates, the DHET together with representatives from the sector, is working on other improvements of quality of research outputs from the higher education system of South Africa. As stated above, this effort requires active vigilance of everyone involved to maintain high quality of knowledge produced by academics in our higher education system. We hope that everyone involved in the knowledge production line will find this ASSAf review report valuable and make use of its recommendations for the betterment of our higher education system.

Congratulations to ASSAf on yet another achievement.

Mr Mahlubi Mabizela and Ms Fhumulani Maanda

Higher Education Policy and Research Development

Department of Higher Education and Training 


$$
\begin{aligned}
& R=\frac{1}{L}=\lim _{n \rightarrow \infty} 10 \\
& \left.\sum_{-3 \pi}^{T}\right|_{0} ^{4} \pi-\pi \\
& \frac{4-1}{3 v^{2}} \\
& \mid x y^{2 n^{\prime}} \\
& =\int^{\beta}\left(\sum_{n=1}^{\infty} u_{n}(x)\right) d x=\sum_{n=1} \int_{\mathcal{L}} u_{n}(x) d x_{1} \\
& K_{\nu}(x)=7 \lim _{n \rightarrow 0} V_{n}=\lim _{\lambda \rightarrow 0} \sum_{i=1}^{n} f\left(\xi_{i}\right. \\
& =2 n \\
& \lim _{\lambda \rightarrow 0} \sum_{n=1}^{n} \Delta \sigma_{i} \\
& \text { m } \frac{0}{a_{n}}=0 \\
& \lim _{i=1} \sum_{i=1}^{\infty} f\left(\xi_{i},\right. \\
& J(u, v)=\int_{\frac{\partial u}{\partial u}}
\end{aligned}
$$




\section{Synopsis of findings}

The process of reviewing a journal comprises a thorough evaluation by peers of questionnaires completed by the respective editors and three independent reviews, based on a defined subset of published issues of the journal. The peer reviewers' reports are reviewed by the panel and then synthesised into an appraisal of the journal accompanied by recommendations. In concluding the peer-review process, the panel makes recommendations regarding continued inclusion of the journal on the DHET 'List of approved South African journals', as well as recognition by ASSAf for inclusion on the SCiELO SA platform. The recommendations with respect to each of the journals reviewed are summarised in the following table.

\begin{tabular}{|c|c|c|c|c|}
\hline Journal title & $\begin{array}{l}\text { Indexed } \\
\text { in }\end{array}$ & $\begin{array}{l}\text { Recommended } \\
\text { for continued } \\
\text { DHET } \\
\text { accreditation }\end{array}$ & $\begin{array}{l}\text { Recommended } \\
\text { for SciELO SA }\end{array}$ & Summary of recommendations \\
\hline $\begin{array}{l}\text { ORION: } \\
\text { Journal of the } \\
\text { Operations } \\
\text { Research } \\
\text { Society of South } \\
\text { Africa }\end{array}$ & $\begin{array}{l}\text { DHET and } \\
\text { DOAJ }\end{array}$ & Yes & No & $\begin{array}{l}\text { The editor-in-chief and members } \\
\text { of the board should improve their } \\
\text { international standing; board } \\
\text { members of high international } \\
\text { reputation should be included. } \\
\text { The quality of the papers needs to } \\
\text { be improved, and the number of } \\
\text { papers should be increased. The } \\
\text { average time between submission } \\
\text { and final publication could be } \\
\text { shortened. Publishing special issues } \\
\text { and inviting guest editors might be } \\
\text { helpful. }\end{array}$ \\
\hline Pythagoras & $\begin{array}{l}\text { DHET, } \\
\text { DOAJ } \\
\text { and } \\
\text { Scopus }\end{array}$ & Yes & Yes & $\begin{array}{l}\text { The editor should consider } \\
\text { widening the membership of } \\
\text { the board to include more } \\
\text { international members, as most } \\
\text { of the current members are South } \\
\text { African. Improving international } \\
\text { exposure and international author } \\
\text { participation would also be } \\
\text { beneficial. }\end{array}$ \\
\hline $\begin{array}{l}\text { Quaestiones } \\
\text { Mathematicae }\end{array}$ & $\begin{array}{l}\text { DHET, } \\
\text { Scopus, } \\
\text { WoS and } \\
\text { DOAJ }\end{array}$ & Yes & $\begin{array}{l}\text { Recommended } \\
\text { for SciELO SA } \\
\text { platform should } \\
\text { it become } \\
\text { open access. }\end{array}$ & $\begin{array}{l}\text { The aims and scope of the journal } \\
\text { need to be revised and updated } \\
\text { to attract more quality work. } \\
\text { Applied mathematics is currently } \\
\text { not adequately represented in the } \\
\text { journal. Since this is the only journal } \\
\text { published by the South African } \\
\text { Mathematical Society, the society } \\
\text { should encourage more articles } \\
\text { in applied mathematics, and this } \\
\text { should be reflected in the scope of } \\
\text { the journal. }\end{array}$ \\
\hline
\end{tabular}




\begin{tabular}{|c|c|c|c|c|}
\hline Journal title & $\begin{array}{l}\text { Indexed } \\
\text { in }\end{array}$ & $\begin{array}{l}\text { Recommended } \\
\text { for continued } \\
\text { DHET } \\
\text { accreditation }\end{array}$ & $\begin{array}{l}\text { Recommended } \\
\text { for SciELO SA }\end{array}$ & Summary of recommendations \\
\hline $\begin{array}{l}\text { South African } \\
\text { Journal of } \\
\text { Geomatics }\end{array}$ & DHET & Yes & Yes & $\begin{array}{l}\text { The journal needs to develop } \\
\text { editorial and conflict-of-interest } \\
\text { guidelines and policies. Scholarly } \\
\text { features should be considered as } \\
\text { useful additions to the journal. The } \\
\text { editor should consider inviting well- } \\
\text { known international authors to } \\
\text { publish. The list of editorial board } \\
\text { members should be increased } \\
\text { to include local, continental and } \\
\text { international researchers in a wider } \\
\text { variety of fields. }\end{array}$ \\
\hline $\begin{array}{l}\text { South African } \\
\text { Statistical } \\
\text { Journal }\end{array}$ & $\begin{array}{l}\text { DHET and } \\
\text { Scopus }\end{array}$ & Yes & $\begin{array}{l}\text { Recommended } \\
\text { for SciELO SA } \\
\text { platform should } \\
\text { it become } \\
\text { open access. }\end{array}$ & $\begin{array}{l}\text { The editorial board should be } \\
\text { expanded. The journal should } \\
\text { consider publishing four issues each } \\
\text { year. International scholars should } \\
\text { be invited to publish. The webpage } \\
\text { where the journal is hosted needs } \\
\text { to be updated. }\end{array}$ \\
\hline $\begin{array}{l}\text { African Journal } \\
\text { of Agricultural } \\
\text { and Resource } \\
\text { Economics }\end{array}$ & $\begin{array}{l}\text { DHET and } \\
\text { Scopus }\end{array}$ & No & No & $\begin{array}{l}\text { It is recommended that the } \\
\text { editorial board should have more } \\
\text { representation from the African } \\
\text { continent. The journal should } \\
\text { improve its website and follow } \\
\text { the design models of other good } \\
\text { international journals. }\end{array}$ \\
\hline $\begin{array}{l}\text { African Journal } \\
\text { of Aquatic } \\
\text { Science }\end{array}$ & $\begin{array}{l}\text { DHET and } \\
\text { Scopus }\end{array}$ & Yes & $\begin{array}{l}\text { Recommended } \\
\text { for SciELO SA } \\
\text { platform should } \\
\text { it become } \\
\text { open access. }\end{array}$ & $\begin{array}{l}\text { Scholarly features such as reviews } \\
\text { and more special issues should } \\
\text { be considered as useful additions } \\
\text { to the journal. Special issues with } \\
\text { invited contributions could boost } \\
\text { the citation records. }\end{array}$ \\
\hline $\begin{array}{l}\text { African Journal } \\
\text { of Marine } \\
\text { Science }\end{array}$ & $\begin{array}{l}\text { DHET and } \\
\text { Scopus }\end{array}$ & Yes & $\begin{array}{l}\text { Recommended } \\
\text { for SciELO SA } \\
\text { platform should } \\
\text { it become } \\
\text { open access. }\end{array}$ & $\begin{array}{l}\text { The citation rate of the articles } \\
\text { seems to be low and should be } \\
\text { improved. It is suggested that } \\
\text { the number of review papers be } \\
\text { increased. The inclusion of news } \\
\text { and views could highlight exciting } \\
\text { articles in the issue and provide } \\
\text { additional press for the authors. }\end{array}$ \\
\hline
\end{tabular}

Ostrich: Journal of African Ornithology

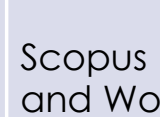
and WoS
Recommended for SCIELO SA platform should it become open access.
A faster turnaround time of manuscripts from acceptance to publication might help in attracting more authors to submit their manuscripts to the journal. 


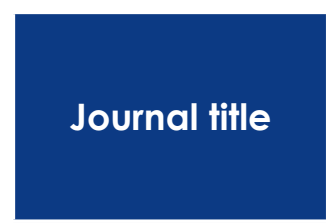

Indexed
in

Recommended

for continued

DHET

accreditation

\section{Recommended for SCIELO SA}

Summary of recommendations

$\begin{array}{llll} & \text { DOAJ, } & \\ \text { Water SA } & \text { SciELO } & \text { Already on } \\ & \text { SA, } & \text { Yes } & \text { the SciELO SA } \\ & \text { Scopus } & & \text { tatform. } \\ & \text { and WoS } & & \end{array}$

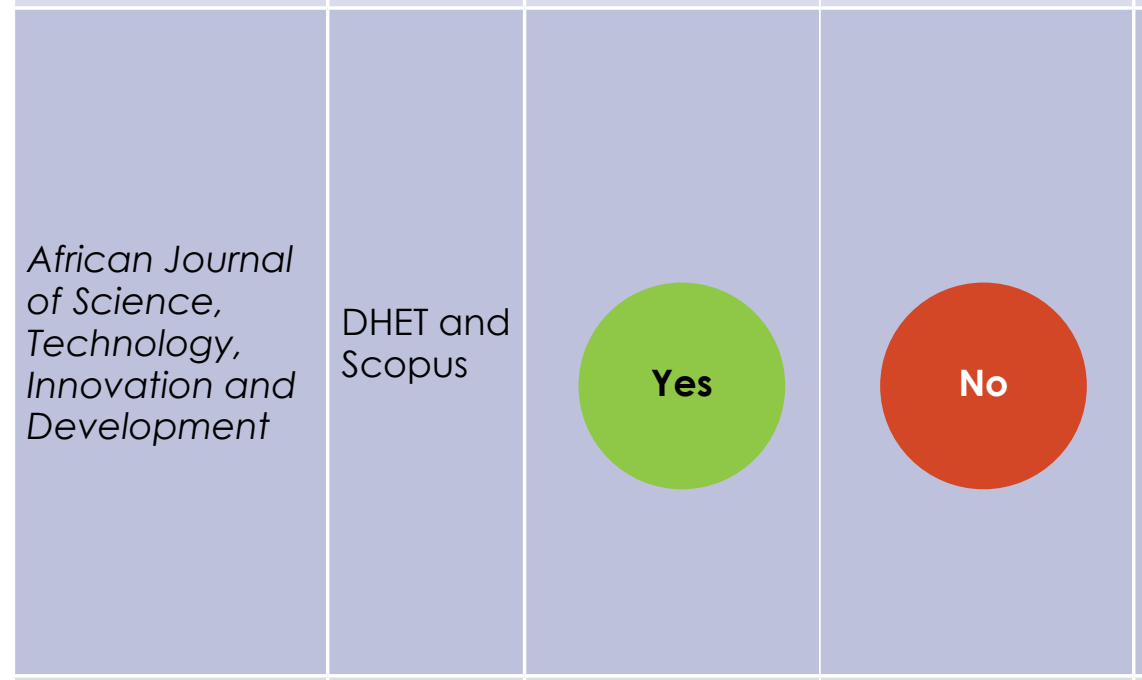

Journal for New Generation Sciences

Journal for Transdisciplinary Research in Southern Africa
Value-added features should be considered as useful additions to the journal. The journal should attempt to shorten the period between receipt of manuscripts and publication of articles.

The editor should strongly reconsider the issue of publishing papers of which he or other editorial board members are authors or coauthors. This constitutes a serious conflict of interest and contravenes acceptable codes of editorial practice. In addition, the panel recommends that the articles be placed in distinct categories to improve the impact and readability of the journal.Such categories could include: science, technology and engineering; process development and technology economics.

The panel has serious concerns about many aspects of the journal, including the current title, the composition of the editorial board, the ratio between acceptance and rejection of manuscripts, impact and citation figures for published papers, and the lack of alignment between the journal title and most of the content. The journal should seriously consider all the recommendations presented in this review.

The journal should seriously consider the recommendations of this review. In particular, the senior editors should refrain from publishing in 'their own journal', as this represents a conflict of interest. 


\begin{tabular}{|c|c|c|c|c|}
\hline Journal title & $\begin{array}{l}\text { Indexed } \\
\text { in }\end{array}$ & $\begin{array}{l}\text { Recommended } \\
\text { for continued } \\
\text { DHET } \\
\text { accreditation }\end{array}$ & $\begin{array}{l}\text { Recommended } \\
\text { for SciELO SA }\end{array}$ & Summary of recommendations \\
\hline $\begin{array}{l}\text { South African } \\
\text { Journal of } \\
\text { Chemistry }\end{array}$ & $\begin{array}{l}\text { DOAJ, } \\
\text { SCIELO } \\
\text { SA, } \\
\text { Scopus } \\
\text { and WoS }\end{array}$ & Yes & $\begin{array}{l}\text { Already on } \\
\text { the SciELO SA } \\
\text { platform. }\end{array}$ & $\begin{array}{l}\text { The journal should consider inviting } \\
\text { some of the leading academic } \\
\text { chemists in South Africa to } \\
\text { contribute reviews. This might } \\
\text { encourage a wider readership } \\
\text { and further citations. If successful, } \\
\text { invitations to some leading } \\
\text { international scholars with whom } \\
\text { these local authors have close ties } \\
\text { could then follow. }\end{array}$ \\
\hline $\begin{array}{l}\text { South African } \\
\text { Journal of } \\
\text { Science }\end{array}$ & $\begin{array}{l}\text { DHET, } \\
\text { DOAJ, } \\
\text { SciELO } \\
\text { SA, } \\
\text { Scopus } \\
\text { and Wos }\end{array}$ & Yes & $\begin{array}{l}\text { Already on } \\
\text { the SciELO SA } \\
\text { platform. }\end{array}$ & $\begin{array}{l}\text { The editorial team might consider } \\
\text { the introduction of thematic issues } \\
\text { and soliciting manuscripts from } \\
\text { leading national and international } \\
\text { (particularly African) scholars. This } \\
\text { concept could be expanded to } \\
\text { invited contributions by talented } \\
\text { early-career researchers under } \\
\text { specific themes (e.g. 'Young } \\
\text { Investigator Awards' or the like), } \\
\text { providing a platform to showcase } \\
\text { research of up-and-coming } \\
\text { researchers based in Africa. The } \\
\text { editorial team could also consider } \\
\text { partnering with other African } \\
\text { science societies. }\end{array}$ \\
\hline $\begin{array}{l}\text { South African } \\
\text { Journal for } \\
\text { Science and } \\
\text { Technology }\end{array}$ & $\begin{array}{l}\text { DHET and } \\
\text { DOAJ }\end{array}$ & Yes & Yes & $\begin{array}{l}\text { It is recommended that the editorial } \\
\text { board should be diversified in } \\
\text { terms of country and institutional } \\
\text { representation in the relevant } \\
\text { disciplines, tointroduceinternational } \\
\text { standards and approaches to } \\
\text { the journal. The editorial team } \\
\text { should also be expanded to reflect } \\
\text { the multidisciplinary approach } \\
\text { of the journal, while retaining its } \\
\text { relevance to the natural sciences } \\
\text { and technology. }\end{array}$ \\
\hline
\end{tabular}




\begin{tabular}{|c|c|c|c|c|}
\hline Journal title & $\begin{array}{l}\text { Indexed } \\
\text { in }\end{array}$ & $\begin{array}{l}\text { Recommended } \\
\text { for continued } \\
\text { DHET } \\
\text { accreditation }\end{array}$ & $\begin{array}{l}\text { Recommended } \\
\text { for SciELO SA }\end{array}$ & Summary of recommendations \\
\hline $\begin{array}{l}\text { Transactions } \\
\text { of the Royal } \\
\text { Society of South } \\
\text { Africa (RSSA) }\end{array}$ & $\begin{array}{l}\text { DHET and } \\
\text { Scopus }\end{array}$ & Yes & $\begin{array}{l}\text { Recommended } \\
\text { for SciELO SA } \\
\text { platform should } \\
\text { it become } \\
\text { open access. }\end{array}$ & $\begin{array}{l}\text { The editorial board should consider } \\
\text { enlarging the remit of the journal } \\
\text { to cover articles from all over the } \\
\text { world. However, the published } \\
\text { works do not normally match } \\
\text { up to this standard. In order to } \\
\text { increase its standing, the journal } \\
\text { could potentially expand its } \\
\text { invited reviews to RSSA fellows and } \\
\text { scientists working at the National } \\
\text { Research Foundation (NRF) Centres } \\
\text { of Excellence or research chars } \\
\text { under the South African Research } \\
\text { Chairs Initiative (SARChl). }\end{array}$ \\
\hline $\begin{array}{l}\text { Annals of } \\
\text { the Ditsong } \\
\text { National } \\
\text { Museum of } \\
\text { Natural History }\end{array}$ & DHET & Yes & No & $\begin{array}{l}\text { The panel noted that, in its current } \\
\text { form and with its current mode of } \\
\text { management and production, } \\
\text { the journal does not align with the } \\
\text { requisites for DHET accreditation. } \\
\text { However, the panel also noted } \\
\text { that the new editor has committed } \\
\text { to most of the suggested changes } \\
\text { and improvements which, when } \\
\text { completed, would align the journal } \\
\text { with the requirements for DHET } \\
\text { accreditation. }\end{array}$ \\
\hline $\begin{array}{l}\text { Durban Natural } \\
\text { Science } \\
\text { Museum } \\
\text { Novitates }\end{array}$ & DHET & No & No & $\begin{array}{l}\text { The panel recommends that the } \\
\text { journal should address the issues } \\
\text { that do not currently comply with } \\
\text { the requirements for either DHET } \\
\text { accreditation or inclusion on } \\
\text { the SciELO SA platform, namely, } \\
\text { the number of annual published } \\
\text { articles, and the high proportion } \\
\text { of articles that emanate (with or } \\
\text { without external co-authors) from } \\
\text { the host institution. In addition, the } \\
\text { panel believes, as indicated by the } \\
\text { editor, that it is critically important } \\
\text { to expand the breadth of content } \\
\text { of the journal both geographically } \\
\text { and in terms of subject matter. } \\
\text { Whether the journal can remain } \\
\text { viable without these changes } \\
\text { remains an issue of considerable } \\
\text { concern. }\end{array}$ \\
\hline
\end{tabular}

Recommended

DHET for SciELO SA

The editorial board should consider enlarging the remit of the journal to cover articles from all over the world. However, the published match to this standard in order to could potentially expand its invited reviews to RSSA fellows and scientists working at the National Research Foundation (NRF) Centres of Excellence or research chairs under the South African Research Chairs Initiative (SARChl).

The panel noted that, in its current form and with its current mode of management and production, the journal does not align with the requisites for DHET accreditation. However, the panel also noted (n) most of the suggested changes completed, $v$ with the requirements for DHET theditation. that do not currently comply with the requirements for either DHET accreditation or inclusion on the SciELO SA platform, namely, the number of annual published portion of articles that emanate (with or without external co-authors) from the host institution. In addition, the panel believes, as indicated by the editor, that it is critically important of the journal both geographically and in terms of subject matter. Whether the journal can remain viable without these changes concern. 


\begin{tabular}{|c|c|c|c|c|}
\hline Journal title & $\begin{array}{l}\text { Indexed } \\
\text { in }\end{array}$ & $\begin{array}{l}\text { Recommended } \\
\text { for continued } \\
\text { DHET } \\
\text { accreditation }\end{array}$ & $\begin{array}{l}\text { Recommended } \\
\text { for SciELO SA }\end{array}$ & Summary of recommendations \\
\hline Indago & DHET & Yes & No & $\begin{array}{l}\text { The panel recommends that the } \\
\text { journal should address the issues } \\
\text { that do not currently comply } \\
\text { with the requirements for DHET } \\
\text { accreditation. The panel also } \\
\text { notes that the current editor, in } \\
\text { response to a range of criticisms, } \\
\text { has committed to addressing most } \\
\text { of these issues. Once completed, } \\
\text { such changes would align the } \\
\text { journal with the requisites for DHET } \\
\text { accreditation. }\end{array}$ \\
\hline $\begin{array}{l}\text { Palaeontologia } \\
\text { Africana }\end{array}$ & DHET & Yes & Yes & $\begin{array}{l}\text { It is recommended that the journal } \\
\text { should ensure that the pre-print } \\
\text { policy is clear to potential authors. } \\
\text { A clear policy on open data or the } \\
\text { availability of underpinning data is } \\
\text { advised. }\end{array}$ \\
\hline $\begin{array}{l}\text { South African } \\
\text { Archaeological } \\
\text { Bulletin }\end{array}$ & $\begin{array}{l}\text { DHET, } \\
\text { Scopus } \\
\text { and WoS }\end{array}$ & Yes & $\begin{array}{l}\text { Recommended } \\
\text { for SciELO SA } \\
\text { platform should } \\
\text { it become } \\
\text { open access. }\end{array}$ & $\begin{array}{l}\text { The panel recommends that the } \\
\text { journal should actively attempt } \\
\text { to involve more authors from } \\
\text { neighbouring southern African } \\
\text { countries. In addition, the pane } \\
\text { believes that the editorial board } \\
\text { could benefit from the involvement } \\
\text { of younger researchers. }\end{array}$ \\
\hline
\end{tabular}

\section{OVERALL SUMMARY}

While the reviewers of the South African mathematics and science journals were generally happy with the quality, structure and operations of the publications, some recurring themes were highlighted. Some criticisms were expressed about the composition of editorial boards, where either the balance between emerging and established researchers was not appropriate, or where processes for the appointment and turnover of editorial board members were either absent or not reliably implemented. While the difficulties associated with competing with international journals were noted, the need to attract a wider authorship base, from across the African continent and beyond, was a frequent recommendation. The identification of a few instances of weak editorial practice was a cause for some concern. The panel noted the many instances of positive feedback from editors in response to the comments and criticisms from reviewers.

Of the 22 journals evaluated, three were recommended for removal from the DHET-accredited list. Five journals were recommended to be invited to join SciELO SA, and seven were not endorsed for inclusion on the SCiELO SA platform. Seven journals were recommended for inclusion on the SciELO SA platform on condition that they implement an open-access model. Three journals were already listed on the SCIELO SA platform. 


\section{Periodic Peer Review of South African Scholarly Journals: Approved Process Guidelines and Criteria}

\section{$1.1 \quad$ Background}

During the launch meeting of the ASSAf-led National Scholarly Editors' Forum (NSEF) held on 25 July 2007, the 112 participants supported ASSAf and its CSPiSA in taking the lead in implementing Recommendation No. 5 of the 2006 ASSAf Report on a Strategic Approach to Research Publishing in South Africa. This recommendation dealt specifically with the need for a system of quality assurance for the more than 260 of the country's journals that are accredited by DHET (http://research.assaf.org. za/handle/20.500.11911/49):

Recommendation No. 5: that ASSAf be mandated jointly by the departments of Education, and Science and Technology to carry out external peer review and associated quality audit of all South African research journals in five-year cycles, probably best done in relation to groups of titles sharing a particular broad disciplinary focus, in order to make recommendations for improved functioning of each journal in the national and international system.

\subsection{ASSAf Peer-Review Panels}

The quality-assurance system for journals is conducted primarily through discipline-grouped peer reviews carried out by a series of purpose-appointed peer-review panels (PRPs) drawn from the ranks of researchers and other experienced scholars in and around the fields concerned in each case, as well as persons with practical (technical) publishing experience. The proposed PRPs are overseen by the CSPiSA but appointed by the ASSAf Council. Their draft reports are sent to relevant stakeholders for comment and input before finalisation by the PRP concerned, and ultimate consideration by the CSPiSA and then the ASSAf Council.

The following quote from the ASSAf report clarifies the approach to be followed in the review of the journals, and some aspects of the approach proposed:

The periodic, grouped quality assurance-directed peer review of South African research periodicals would function analogously to the quality audits of the Council on Higher Education (CHE) and Higher Education Quality Committee (HEQC), would be developed as an outcome of the Editors' Forum, and would focus on: the quality of editorial and review process; fitness of, and for purpose; positioning in the global cycle of new and old journals listed and indexed in databases; financial sustainability; and scope and size issues. The ASSAf panels carrying out the reviews would each comprise 6-8 experts, some of whom would not be directly drawn from the areas concerned, and would require data-gathering, interviews, and international comparisons, before reports with recommendations are prepared, approved, and released to stakeholders such as national associations, the departments of Science and Technology and of Education, the CHE/HEQC, the National Research Foundation and Higher Education South Africa (HESA), now Universities South Africa (USAf). 
It must be emphasised that the main purpose of the ASSAf review process for journals is to improve the quality of scholarly publication in the country in a manner that is consonant with traditional scholarly practices - primarily voluntary peer review. It is not an attempt to control these publications in any way. ASSAf respects the independence and freedom of researchers, and of the research process itself, as important preconditions for the critical and innovative production of new knowledge. At the same time, the work of South African researchers has to be assessed, both qualitatively and quantitatively, as part of the global community of scholars and scientists, and in this respect ASSAf has an obligation to contribute to improving the quality of such work where possible.

\subsection{Initial Criteria}

A number of criteria were explored in Chapter 4 of the ASSAf report, which dealt with the survey of the over 200 then-current editors of accredited South African scholarly journals. Other possible criteria were proposed in other sections of the report or have since been suggested by members of the CSPISA or the NSEF. These are grouped and listed below, and are consolidated in the questionnaire presented in Appendix A.

\subsubsection{Editorial process-related criteria, generally based on ASSAf's Code of Best Practice in Scholarly} Journal Publishing, Editing and Peer Review

- Longevity of the journal (continuous or discontinuous), in years.

- Number of original peer-reviewed papers published per year during the last five years, plus number of manuscripts submitted, plus number rejected out of hand or after peer review; average length of published papers; and 'author demography' of papers submitted and published.

- Number and nature of peer reviewers used per manuscript, and the overall number per year, including institutional and national or international spread, plus quality, according to ASSAf's Code of Best Practice in Scholarly Journal Publishing, Editing and Peer Review (previously the National Code of Best Practice in Editorial Discretion and Peer Review), and average length of peer-review reports.

- Average delay before publication of submitted manuscripts, and frequency of publication.

- Professional stature and experience of the editor; how the editor is selected; how long the editor has been in service; and the success or otherwise in addressing the major issues in the field, through commissioning of reviews or articles, editorial comment, etc.

- Number and professional stature/experience of editorial board members, plus selection processes, turnover and nature of involvement in the handling of manuscripts or other functions. If international members serve on the board (which is desirable), whether they are a mix from developed and developing countries.

- Existence and nature of editorial policy or guidelines, plus how often these are revised or updated; conflict-of-interest policy (e.g. how manuscripts are assessed when submitted by an editor or board member as author or co-author).

- Whether errata are published, and how many per year.

- Value-added features, such as editorials, news and views pieces, correspondence on papers, reviews, policy or topical forums, etc. - how many, and how they are generated. What proportion they constitute of the total pages in journal issues.

Any peer-review process of the journal already in place (e.g. by a professional association).

\subsubsection{Business-related Criteria}

- Frequency and regularity ('on time') of publication.

- Print runs (redundant stock, direct versus indirect distribution to readers). 
- Production model and service provider(s).

- Paid and unpaid advertising.

- Sponsorship and any quid pro quo arrangements.

- Paid and unpaid subscription base, and how this is marketed. Cost level of print and (if applicable) e-subscriptions.

- E-publication. If this is done, the website or portal, and access possibilities for users. Whether any evaluation is done, especially in respect of tagging and searchability.

- Whether there are HTML/XML and PDF versions, or only PDF, and whether multimedia is used.

- The portals for open access, if provided. If not e-published, whether this is being considered, and how.

- Total income and expenditure each year.

- Distribution to international destinations.

- Whether indexed in the Web of Science (WoS), the International Bibliography of Social Sciences (IBSS), or any other international database. If indexed, for how long and how continuously.

- Offers to purchase from multinational publishers.

- Copyright arrangements.

\subsubsection{Bibliometric Assessments}

- Citation practice - how many authors are listed?

- If applicable, what are the WoS-type impact factors (and various derivatives) over the last five years?

- Are reviews a regular or increasing feature?

- If articles are not in English, are English abstracts mandatory?

\subsection{Process Guidelines for Setting up Panels, Peer Reviewers, Panel Meetings and Reports for the Subject Peer Review of Journals}

\subsubsection{Background to ASSAf PRPs}

The quality-assurance system for journals is implemented primarily through discipline-grouped peer reviews carried out by a series of purpose-appointed PRPs drawn from the ranks of researchers and other experienced scholars in and around the fields concerned in each case, as well as persons with practical (technical) publishing experience. The proposed ASSAf PRPs are overseen by the CSPiSA but appointed by the ASSAf Council. Their draft reports are sent to relevant stakeholders for comment and input before finalisation by the PRP concerned, and final consideration by the CSPiSA and then the ASSAf Council.

\subsubsection{Role of the Scholarly Publishing Unit}

A project officer of the ASSAf Scholarly Publishing Unit is assigned to support each panel chair, but reports to the director of the Scholarly Publishing Unit in terms of review logistics and the production of draft and final review reports. The project officer is responsible for the following issues and activities:

selecting and appointing panel members;

obtaining completed questionnaires from editors;

organising panel activities, including meetings; selecting independent peer reviewers for each journal or groups of titles;

- drafting consolidated version 1 reports; and

- obtaining CSPiSA and ASSAf Council approval for final, publishable panel reports. 


\subsubsection{Setting up Panels}

The proposed PRPs are chaired by an ASSAf member and appointed by the Council, which assumes accountability for the work of the PRP in helping to develop a credible quality-assurance mechanism for South African scholarly journals.

\subsubsection{Selection of Panel Members}

- The process of appointing PRP members is managed by the chair of the CSPiSA until the panel and its chairperson have been appointed.

- CSPiSA members are asked to assist in preparing a list of at least 12 or 13 names, four or five of whom shall be considered to be alternates.

- A typical PRP consists of six to eight members.

- Each nomination must be accompanied by critical personal and career details, as well as a brief motivation, to enable the CSPiSA, and later the ASSAf Council, to give due consideration to the constitution of the best possible and most competent PRP.

- The draft list of potential members is published on the ASSAf website and is also circulated for comment to members of the NSEF at least two weeks before the Council meeting at which the appointments are to be made.

- All comments received are noted in making the final decision.

- All provisionally listed persons are required to complete and submit conflict-of-interest forms prior to the Council's consideration of the list of names.

\subsubsection{Criteria for Membership}

- The individuals selected to serve on a PRP should have experience and credibility in the disciplines under review, or in related disciplines, or be senior scholars who may be from a completely different discipline. Generally, the composition of a panel, in an approximate ratio of 3:3:2, should be a mix of disciplinary specialists, specialists in areas cognate to the broad disciplinary area concerned, and senior scholars who are knowledgeable in scholarly practices and drawn from any broad disciplinary area.

- The panel members should have demonstrable expertise and experience in both the editing and peer-review aspects of research journals.

- It is not necessary for all PRP members to be experts in both editing and peer-review aspects - a mix of senior academics and a few active editors (of journals not under review) is appropriate but all should have some appreciation of both journal editing and peer review.

- At least one member should have direct practical (technical) experience of publishing.

Persons selected as panel participants will typically be drawn from among ASSAf's membership, academic institutions, science councils and consultants.

\subsubsection{Conflicts of Interest}

It will be necessary to take care to avoid real or perceived conflicts of interest.

Committee expertise, balance and conflicts of interest are discussed at the first meeting of the PRP (and may be discussed again at any subsequent meeting), and recommendations to resolve problematic issues can be presented to the ASSAf Council through the Scholarly Publishing Unit (ASSAf Secretariat) for possible amendment of the composition of PRPs.

- Panel members are requested to submit written conflict-of-interest statements and are bound to report any new potential sources of conflict of interest during the quality-review process. 
The organisation of the panel is conducted by its chair and supported by the assigned project officer. The activities related to organisation typically include:

- planning and costing the review and panel activities;

- obtaining completed questionnaires from each editor or equivalent (concerning publishing logistics);

- identifying suitable peer reviewers for each journal or group of titles (concerning content quality);

- assembling hard copies of journals, or providing access to the journal online;

- setting dates for panel meetings, assigning tasks, and collating materials;

- preparing and distributing pre-meeting and post-meeting materials (e.g. draft version 1 reports, assembled peer reviews and editors' questionnaires in template form);

- taking responsibility for post-meeting activities, including draft version 2 report preparation, circulation for comment to panel members and editors and preparation and processing of final reports; and

- evaluating panel processes.

\subsubsection{Selection of Peer Reviewers}

- At least two, but preferably three, independent peer reviewers, as well as alternative reviewers, must be agreed upon by the panel for each title or group of similar titles.

- Members of the CSPiSA and ASSAf's membership in general will be given an opportunity to volunteer to serve as panel reviewers through a specific written call.

- Other candidates will be sought from reviewer lists of the NRF and from among active science council research staff.

- The process of selection is overseen by the panel chair. The final agreed appointments of willing volunteer reviewers are made by the panel itself.

- Conflicts of interest must be avoided - thus current or former editors cannot become peer reviewers of the journals concerned; this also applies to current members of editorial boards.

- The project officer must arrange access for the peer reviewers to hard copies or e-copies of the journals under review.

- The core questions to be addressed in respect of each journal must be provided to peer reviewers, who should be asked to ensure that all these questions are covered in their reviews.

\subsubsection{Panel Meetings and Procedures}

\subsubsection{Preparations}

- The ASSAf project officer is responsible for drawing up the version 1 report on each journal. Each reviewer's answers should be consolidated under the standard headings of the draft, with each input as a separate paragraph. The editor's questionnaire should also be inserted as a single item under 'questionnaire' and 'business aspects'.

- The documentation (editors' questionnaires, peer-review reports) should be sent by email to all panel members at least two weeks prior to the panel meeting. If the peer reviews are not all available by that stage, they should be made available by the date of the meeting, for tabling on the day.

- Panel members should be informed that hard copies of all documentation will be available at the meeting in bundles containing the completed editor's questionnaire and reviewers' reports for each journal title. 
- Conveners of subsets of journals should be alerted to their role at the forthcoming panel meeting: to present the journals in the set, and to make recommendations for discussion and elaboration. Any panel member who is unable to attend should be asked to submit written notes for presentation to the panel by the convener.

- Ideally, hard copies of issues of journals to be considered should be available at the meeting, but this can be dispensed with if it is not logistically possible.

- A quorum of at least two-thirds of the members of PRPs must be guaranteed at any meeting, otherwise a new date must be sought.

\subsubsection{Meetings}

- Journal titles should be considered in subsets.

- Consensus on each of the criteria should be agreed seriatim, as per a convener's spoken summary, and noted by the project officer in attendance.

- Particular attention should be paid to reaching agreement on recommendations in respect of:

(a) An invitation to the publisher or editor to join the SciELO SA platform (if the journal is open access and meets the special criteria with respect to frequency of publication and annual number of peer-reviewed original articles).

(b) A recommendation to DHET with respect to accreditation on its list of South African journals in which any article is considered as a valid research output.

(c) Suggestions for improvement that would facilitate an invitation or recommendation under (a) or (b), if not yet recommended.

(d) Suggestions for improvement or general enhancement of functions.

\subsubsection{Post-Meeting Procedures and Panel Reports}

- When producing a version 2 report, the three paragraphs in each item must be consolidated to produce a consensus version.

- A detailed and motivated draft version 2 report of each peer review panel's findings and recommendations is prepared by the assigned project officer, working closely with the panel chair.

- The project officer and convener should reach agreement on the record of the meeting in respect of all outcomes within no more than two weeks.

- The meeting record should be sent to all panel members for comment and ratification (including those who were not able to attend the meeting), and responses should be received within one week.

- The convener should prepare a final version of the meeting record and submit a copy of each journal-specific item as a privileged communication to the editor concerned for written comment within no more than two weeks.

- The convener should identify any comments by the editor that might materially change the recommendations in the record and submit these to the panel for consideration and decision.

- The record, as it is finally agreed upon, should be submitted to the CSPiSA for approval before submission to the ASSAf Council and public release. 


\section{Special Considerations Concerning South African Mathematics and Science Journals}

This ASSAf review of Mathematics and Science journals included 22 journals across the categories of general science (five journals), mathematical science (four journals), natural sciences and agriculture (seven journals) and multidisciplinary science (six journals). The phased review process, in which two or three senior national or international researchers reviewed each journal, is described in the introductory chapter of this report and included feedback from the editors of the respective journals. Where there were differences of opinion between reviewers on any journal, an additional reviewer was asked to adjudicate.

The scholarly journals under review varied widely in their age; some (such as the Transactions of the Royal Society of South Africa) have a publication history of more than a century, while others have been established for less than two decades. The journals covered by this review have varied origins, many having been established by a society (such as ASSAf) or research organisation (such as a museum). Some of the newer journals were established by individuals or university departments. The stated purposes of the journals vary equally widely; some were established principally as vehicles to disseminate the research outputs of a single organisation or institution, while others aim to bring together disparate themes in an interdisciplinary context, or to service the African science community. The complexities of this review process were possibly compounded by the fact that the journals reviewed covered a wide range of disciplines, from broad (such as the Journal of Transdisciplinary Research in South Africa) to rather narrow in scope (such as the Ostrich Journal of African Ornithology) and represented a diversity of different bodies and stakeholder groups.

The ASSAf review of national Mathematics and Science journals took place in the context of the rapidly evolving landscape of science publishing, particularly the dramatic rise over the past two decades of fully online publishing platforms. This evolution has been associated with considerable benefits to the research community, including the speed of publication, the ease of access to published research and the globalisation of research outputs. Sadly, this evolution has also been accompanied by substantial negative impacts, particularly the scourge of 'predatory' publishers and journals, where the objectives of economic gain take precedence over publication standards. In addition, the dramatic rise in the number of new online journals has put great pressure on the peer-review process, the primary benchmark by which all journals are judged, and there is growing evidence of international peer-reviewer 'fatigue'.

The technical complexity of the review process, involving many senior members of the South African science community, was in no way assisted by the effects, from early 2020, of the global Covid-19 pandemic, which severely disrupted academic activities for more than a year.

Across the 22 journals reviewed, the conclusions of the reviewers were generally positive. There was consensus agreement across the review process that all the journals that had been reviewed served a valuable purpose within their disciplinary spheres. In most cases, the reviewers found that the structures, systems and processes associated with the publication pipelines were robust, with sound handling systems, acceptable peer-review processes, and reliable and timeous publication schedules. In general, the quality of the published articles was judged to be good to excellent, and technical aspects, such as data presentation and figure quality, were mostly of international standard. It was noted by reviewers that the numbers of papers published in the various journals varied widely, presumably due to field-specific factors and the size of the local research communities. It was repeatedly noted by editors that national journals could not compete with high-profile international journals, nor could they be expected to. 
Among the criticisms of some journals expressed by reviewers, three areas were highlighted in particular, and have subsequently formed the basis of recommendations returned to the editorial boards of the journals in question. These were (a) journal management and editorial board structures that appear not to have changed for long periods, (b) journals that published either infrequently or intermittently, and (c) specific instances of journals where the senior editor or members of the editorial board appear to publish too frequently in their own journal. In all these instances, the responses received from the senior editors, on receipt of the ASSAf review panel recommendations, suggest that the journals have already made appropriate changes, or will take rapid steps to do so.

The panel was independently provided with a table indicating which of the journals reviewed are indexed by the major international reference platforms, namely Scopus and WoS. Of the 22 journals, 14 are indexed by Scopus and eight by the more stringent WoS. It was noted that the museum journals (Annals of the Ditsong National Museum of Natural History, Durban Natural Science Museum Novitates and Indago) and the relatively recently established interdisciplinary journals (Journal for New Generation Sciences and Journal for Transdisciplinary Research in Southern Africa) are not included on either of these indexing platforms. A consistent comment by the panel was that, where possible, successful applications to these platforms would have large and positive impacts on the journals' international exposure and impact.

After considerable discussion, and taking into account the feedback from some editors, it was recommended that 19 of the 22 journals should maintain their accreditation status, and two were conditionally recommended for the DHET-accreditation list. Three of the journals were already listed on the SciELO SA platform, five have been recommended to join, seven to join conditionally (in the event that they become open-access journals), and seven have not been recommended.

The work was undertaken by two ASSA staff members, six expert panel members and 73 expert scholars. The two ASSAf staff members involved were Mrs Susan Veldsman (Director, Scholarly Publishing Unit) and Ms Mmaphuthi Mashiachidi (Project Officer, Scholarly Publishing Unit).

Note: Panel members who were directly involved with any of the journals being reviewed did not contribute to the reporting or the recommendations for those particular journals.

\section{Panell Members}

1. Prof Anthony Afolayan, Research Professor, Department of Botany, University of Fort Hare, https:// orcid.org/0000-0002-9111-6695

2. Prof Roumen Anguelov, Professor and Head of Department of Mathematics and Applied Mathematics, University of Pretoria, https://orcid.org/0000-0001-5456-0466

3. Prof Don Cowan, Director of Genomics Research Institute, and Centre for Microbial Ecology and Genomics, University of Pretoria, https://orcid.org/0000-0001-8059-861X

4. Prof Maryke Labuschagne, Professor of Plant Breeding, Faculty of Natural and Agricultural Sciences, University of the Free State, https://orcid.org/0000-0003-0593-2678

5. Prof Natasha Sacks, Professor of Advanced Manufacturing, Department of Industrial Engineering, Stellenbosch University, https://orcid.org/0000-0001-7769-7588

6. Prof Edilegnaw Wale Zegeye, Professor of Agricultural Economics, School of Agricultural, Earth and Environmental Sciences, University of KwaZulu-Natal, https://orcid.org/0000-0003-4705-7971 


\section{Consensus Reviews of Journals in the Group}

\subsection{Mathematics}

\subsubsection{ORiON: Journal of the Operations Research Society of South Africa}

\section{Focus and scope:}

\section{(Purpose of journal, positioning, focus, scope, readership)}

ORION is the official journal of the Operations Research Society of South Africa (ORSSA) and is published biannually. The focus of the journal is limited to the broad discipline of operations research. Some problems in operations research are unique to South Africa, but also of interest to the international operations research community. Operations research problems frequently stem from challenges facing communities, industries or the government of a country. South Africa's status as a developing country, with diverse communities unevenly spread over a large geographical area, presents many economic, sociological, logistical and other challenges to scholars of operations research that do not exist in first world countries.

ORION provides a vehicle for academics and practitioners of operations research to publish scholarly studies addressing such problems. There are no other operations research journals from developing countries on any major international index. ORiON fills this gap of addressing unique problems with an international interest from the context of a developing country. Articles published in ORiON also lead to the advancement of research in related fields such as statistics, data science, computer science, applied mathematics and industrial engineering.

Until 2012, ORION's primary audience was local scholars and practitioners of operations research. Since 2013, the editorial board has put considerable effort into internationalising ORiON's contributing authors and readership. ORiON's target audience has widened and become more international in recent years.

The growing interest in operations research in several African countries has also prompted the editorial board to actively target scholars from other countries in Africa. One of the strategies identified to achieve this is to promote ORION through the newly established African Federation of Operational Research Societies (AFROS). A strategic decision was taken to start the process of elevating ORiON to the journal for AFROS, much as the International Transactions in Operational Research is the operations research journal for the International Federation of Operational Research Societies (IFORS). ORION is accessed by 17 libraries (12 international), 289 individuals (15 international) and five institutions (international).

\section{Editing functions:}

\section{(Standing, local institutional spread, international participation)}

Consensus review: There is no evidence of significant reputational standing and recognition of the editor-in-chief or members of the editorial board.

\section{Questionnaire:}

(Editorial process-related criteria)

ORiON was established in 1985 and has been published without interruption since then. All the issues are available online at http://orion.journals.ac.za/pub/index. The journal is published biannually. The first issue of a volume appears in July, and the second in December each year. The number of times 
a PDF copy of a paper is downloaded is recorded on ORION's online system based on Open Journal Systems (OJS). This figure does not include downloads from EBSCOhost, ProQuest, South African Bibliographic and Information Network (Sabinet), African Journals Online (AJOL), Directory of Open Access Journals (DOAJ) or ABI/INFORM. Because ORION is an open-access journal, it can be read freely all over the world.

Over the three-year review period, 35 full articles and one review article have been published. The number of manuscripts received over the same period was 114 full articles and one review article. The rejection rate of manuscripts without peer review was $30.6 \%$, and $35.7 \%$ of manuscripts were rejected after peer review. The proportion of peer-reviewed papers that had at least one author with a nonSouth African address was $16 \%$.

Three to four peer reviewers are usually approached for each submitted manuscript. Peer reviewers are selected based on their expertise. Over the years, ORION has built up a list of reviewers together with their fields of expertise. Peer review is conducted in a 'double-blind way'. Valid reviewer critique and article improvement are rigorously implemented. Peer reviewers receive follow-up information. Reviewer performance is assessed, and information is captured in a database. A total of 147 peer reviewers were used in one year over the review period, about $47 \%$ of whom had a non-South African address. The peer-review reports were accessibly retained in the journal's records. The average period between receipt of a manuscript and publication is 60 weeks in print, and 62 weeks online.

The editor-in-chief has been in office for seven years and is in the process of handing over to a new editor-in-chief. The editor-in-chief is elected to office by ORSSA for a term of one year. Associate editors handle manuscripts in their field of expertise, or if there might be a conflict of interest for the editor-in-chief in respect of any manuscript. All past editors are invited to serve on the editorial board after their term. The term of office for members of the editorial board ranges from two months to 30 years. Members of the editorial board are invited from inside and outside the country to provide specific topical expertise and are reappointed annually.

The journal has appropriate editorial guidelines. The conflict-of-interest policies are embedded in the journal's 'Publication ethics and publication malpractice statement' on the journal website. The statement explicitly states the responsibility of editors, authors and reviewers to declare any conflict of interest. The journal guidelines are aligned with ASSAf's Code of Best Practice in Scholarly Journal Publishing and Peer Review. The journal publishes errata.

ORION has not published any value-added features, but authors and readers are invited to submit letters to the editor for publication. The percentage of pages in each issue that represents peerreviewed original material is $100 \%$.

\section{Content:}

(Quality, focus, spread within domain, sample of best work in South Africa, enrichment features)

Consensus review: The quality of some of the published papers is good, but not all compare favourably with international standards. The number of papers each year is low. The authors are mostly from South Africa.

\section{Essential technical features:}

(English abstracts, errata, citation practice, presentation)

Consensus review: There are acceptable abstracts for all articles. Presentation, design, layout, style and copy-editing interventions are acceptable to good, and images are used in an ethical manner. The citation practice is acceptable but could be improved in some articles. There are no general review papers. 
Usefulness in capacity development, and international comparability:

Consensus review: The journal is suitable as a general ongoing stimulus for local graduate students and young staff in the discipline. However, the impact of published articles is low.

\section{Business aspects:}

(Business-related criteria; Bibliometric assessments)

The journal is owned and published by ORSSA. The regular print run is 300 hard copies. Production and distribution are not outsourced. The journal does not carry advertising and receives no sponsorships. All costs are covered by ORSSA.

The number of paying subscribers is 311 (22 institutions and 289 individuals), 32 of which are international. There are no page fees or charges, or article-processing charges. The journal currently uses an online management system but uses a manual system for loading articles on to the website for the management of editorial workflow. Access is free online, without password protection.

There have been no offers from multinational publishers to purchase the journal. Because of a Creative Commons Attribution 4.0 International (CC BY) licence arrangement, the journal only requests authors to cite and acknowledge the original paper. Authors may archive their articles in open-access repositories as post-prints.

ORION is included on AJOL, DOAJ, EBSCOhost, ProQuest, Sabinet and SUNScholar. Impact factors have not been determined. There are altmetric indicators. The 'front details' for papers and English abstracts are mandatory. The journal is currently under review for inclusion in Scopus.

\section{Suggested improvements:}

Consensus review: The editor-in-chief and the members of the board should improve their international standing and include board members of high international reputation.

Having special issues and inviting guest editors might be helpful.

The quality of papers needs to be improved. The volume of publications should be increased.

The average time between submission and final publication could be shortened.

\section{Panel's consensus view:}

i. The journal should continue to be listed on the DHET-accredited list.

ii. The journal should not be invited to join the SciELO SA platform.

iii. The editor should seriously consider the suggested recommendations for improvement.

\subsubsection{Pythagoras}

\section{Focus and scope:}

(Purpose of journal, positioning, focus, scope, readership)

Pythagoras is a scholarly research journal that provides a forum for the presentation and critical discussion of current research and developments in mathematics education both nationally and internationally. Pythagoras publishes articles that significantly contribute to the understanding of mathematics teaching, learning, assessment and curriculum studies, including reports of research (experiments, case studies, surveys, philosophical and historical studies), critical analyses of school mathematics curricular and teacher development initiatives, literature reviews, theoretical analyses, exposition of mathematical thinking (mathematical practices) and commentaries on issues related to the teaching, learning and assessment of mathematics at all levels of education. 
Pythagoras is the only South African research journal focusing on mathematics education. It publishes only original high-quality research articles and has the largest readership on mathematics education in the country. The journal serves the South African mathematics education research community with quality, open-access publications and through promotion of the discipline of mathematics education.

The primary target audiences are national and international scholars. The journal has three main sources of readership: (a) Pythagoras is an online open-access journal published by AOSIS since 2011, and has a worldwide audience of mathematics education researchers and authors; (b) Pythagoras has been published as a printed paper edition by its owner, the Association for Mathematics Education of South Africa (AMESA) since 1980, and is distributed free to all individual and institutional members as a benefit of membership (AMESA currently has approximately 2500 members); (c) Pythagoras is also available online to subscribers of Sabinet African Journals. Currently, 67 local and international university libraries buy access to Pythagoras through a Sabinet subscription.

\section{Editing functions:}

\section{(Standing, local institutional spread, international participation)}

Consensus review: The chief editor, associate editors and most of the editorial board represent many of the most important and significant mathematics educators in South Africa and include international representation from some countries. The chief editor is appointed competitively for a five-year term, which may be (and has been) extended, subject to performance review, as consistent with best practice.

\section{Questionnaire:}

\section{(Editorial process-related criteria)}

Pythagoras was established in 1980 and publishes at least one issue per year. Individual articles are published on a rolling basis (i.e. individual articles are published online as soon as they are ready for publication by adding them to the table of contents of the current volume and issue). Articles are accessible online at http://www.pythagoras.org.za/. According to the records of the journal from 2011 to 2018, the number of visits was 148265 and the downloads 534 426. The journal is read in 198 countries worldwide, including 46 African countries. It is not pre-scheduled to appear on given dates, and there have been no significant interruptions.

During the three-year review period, 28 full articles and one book review were published. The number of manuscripts received was 77 full articles and one book review. There were 28 manuscripts rejected without peer review, and 20 after peer review. The proportion of peer-reviewed papers that had at least one author with a non-South African address was 10\% in 2017.

A minimum of three peer reviewers are usually approached for each submitted manuscript. Reviewer selection is critical to the publication process, and the editors base their choice on many factors, including expertise, reputation, specific recommendations and their own previous experience of a particular reviewer. Peer review is conducted in a 'double-blind way'. Valid reviewer critique and article improvement are rigorously implemented. Reviewer performance is assessed, and information is captured in a database. In 2016, 62 peer reviewers were used, 14.5\% of whom had a non-South African address. The peer-review reports are accessibly retained in the journal's records. The average period between receipt of a manuscript and its publication online is 181 days. The printed edition of the journal is compiled annually at the end of a volume.

The editor-in-chief has been in office since June 2008. Members of the editorial board have been in office for periods varying between six and seven years. The board handles peer review and advises on editorial policies and practices. The board is appointed from inside and outside the country to provide specific topical expertise. 
The journal has editorial guidelines and a conflict-of interest policy. The guidelines are aligned with ASSAf's Code of Best Practice in Scholarly Journal Publishing and Peer Review. Errata are published when necessary. Value-added features include critical editorials, critical topical reviews and analytical book reviews. The percentage of pages in each issue that represents peer-reviewed original material is about $99 \%$.

\section{Content:}

(Quality, focus, spread within domain, sample of best work in SA, enrichment features)

Consensus review: About 12 articles are published each year. The journal meets all applicable research standards with respect to the ethics of experimentation and research integrity. There is a strong focus on local and regional issues and concerns, as evidenced both in the reported studies (a vast majority of which are set in the South African context) and the list of authors. The publications have few non-South African authors (ranging from 8-14\% between 2015 and 2017). All articles published between 2015 and 2017 had at least one South African author, and none were authored entirely outside of South Africa.

\section{Essential technical features:}

\section{(English abstracts, errata, citation practice, presentation)}

Consensus review: The abstracts are well written. No poor citation practices are apparent. The articles are presented in an intelligible and logical manner and are written in clear and unambiguous English. The layout of the articles is aesthetically pleasing and easy to read. The use of figures and images is good.

\section{Usefulness in capacity development, and international comparability:}

Consensus review: The journal is suitable as an ongoing stimulus for local graduate students and young staff in the discipline concerned. The content covers a wide range of topics and interests, most of them firmly grounded in appropriate theoretical frameworks. A wide range of theories is presented, and readers receive a good introduction to the discipline of mathematics education research. The time-to-publication rate is better than that of many leading journals. The level of theoretical and methodological rigour is comparable to leading international journals.

\section{Business aspects:}

\section{(Business-related criteria; Bibliometric assessments)}

The title owner is AMESA, and the publisher is AOSIS. The regular print run is about 2500 copies. The distribution of the print copy is managed by AMESA. The journal carries unpaid advertising. AMESA subsidised $45 \%$ of the costs in 2018 (compared with $60 \%$ in 2011 ).

There are no paying subscribers for online open access. The print copy is distributed free of charge to AMESA members. AMESA has about 500 institutional members, and Pythagoras has about 70 institutional subscribers through Sabinet. The journal charges article-processing charges of R652 per page (excluding VAT). The editorial workflow is managed through the online management system. The journal is free online and is part of a non-commercial e-publication mechanism.

There have not been any offers from multinational publishers to purchase the journal. Authors retain copyright of work published by AOSIS, unless otherwise specified. In terms of the licensing agreement, the authors of work published by AOSIS are required to grant AOSIS unlimited rights to publish the definitive work in any format, language or medium, for any lawful purpose. AOSIS requires journal authors to publish their work in open access under the CC BY 4.0 licence.

The journal is accredited by DHET and included in the AOSIS Library Index; DOAJ; EBSCOhost; Gale Cengage Learning; Norwegian Register for Scientific Journals, Series and Publishers Level 1; ProQuest; 
Sabinet; Scopus; and Clarivate Analytics WoS Emerging Sources Citation Index (ESCI). The impact factor on Scopus Citescore was 0.22 in 2018. There are altmetric indicators. 'Front details' for papers and English abstracts are mandatory. The journal was previously reviewed by DOAJ.

\section{Suggested improvements: exposure and international author participation would also be beneficial. \\ Panel's consensus view: \\ i. The journal should continue to be listed on the DHET-accredited list. \\ ii. The journal should be invited to join the SciELO SA platform.}

Consensus review: The editor should consider broadening the editorial board to include more international members, as most of the current members are South African. Improving international

\subsubsection{Quaestiones Mathematicae}

\section{Focus and scope:}

(Purpose of journal, positioning, focus, scope, readership)

Quaestiones Mathematicae publishes research articles from a wide range of mathematical fields. Long expository papers of exceptional quality are also considered. The journal is published in English and receives contributions from authors worldwide, serving as an important reference source for anyone interested in mathematics. It publishes research papers on a wide range of mathematical topics that often reflect current mathematical research interests in South Africa. There is also strong interest in representing leading international areas of research.

The readership of the journal consists primarily of discipline-specific specialists in the mathematical sciences, particularly from the areas of pure and applied mathematics. These specialists are based at universities and research institutes, which are the main subscribers.

\section{Editing functions:}

(Standing, local institutional spread, international participation)

Consensus review: This journal is published by the South African Mathematical Society. It is of a high standard and compares favourably with similar journals published by other mathematical societies. Members of the editorial board are selected carefully from among national and international experts in pure and applied mathematics.

\section{Questionnaire:}

\section{(Editorial process-related criteria)}

Quaestiones Mathematicae was established in 1960. Six issues were published in 2015, and eight issues each year after 2016. It is available online through the Taylor \& Francis platform at http://www.tandfonline.com/ tama. The journal has received more than 65433 page views (including the issues list, table of contents, abstracts and references), 4752 full-text downloads in 2014 and 2926 in 2015 . The journal was read in more than 79 countries in 2014, including 14 African countries. It is pre-scheduled to appear in given months, and there have been no significant interruptions.

Over the three-year review period, all the articles that were published were peer-reviewed. Approximately $40 \%$ of the manuscripts were rejected without peer review, and about $50 \%$ after peer review. The proportion of peer-reviewed papers that had at least one author with a non-South African address was about $77 \%$.

Two peer reviewers are usually approached for each submitted manuscript that the editor or any of the four associate editors deems worthy of consideration. Peer reviewers are selected by members of 
the editorial board. The board has 26 members of high international standing in the fields of pure and applied mathematics, 18 of whom are based at leading institutions outside South Africa. Peer review is conducted in a 'blind way'. The implementation of valid reviewer critique and article improvement is rigorous. Revision papers are returned to the editorial board members handling the papers as well as the reviewers, who make recommendations on acceptance or rejection. The final recommendation is made by editorial board members, and the implementing decision is made by the associate editor or editor handling the paper. Peer reviewers do not receive follow-up information. Reviewer performance is assessed, and information is captured in a database. Just over 200 peer reviewers were used in 2016. The proportion of reviewers who had a non-South African address was $85 \%$. The peer-review reports were accessibly retained in the journal's records. The average period between receipt of a manuscript and its publication is between 18 months and two years in print, and 12 months online.

The editor, appointed by the council of the South African Mathematical Society, has been in office for 14 years. The appointment was initially for a five-year period, with the possibility of renewal. Members of the editorial board handle peer review and advise on editorial policies and practices. The term of office for current members of the editorial board is between three and 20 years, and the estimated average is 12 years. The board is appointed by invitation, in consultation with, and with the approval of the council of the South African Mathematical Society. The period of appointment is open ended. The board members were appointed from both inside and outside the country, with the aim of providing specific topical expertise.

The journal has editorial guidelines that are not specifically aligned with ASSAf's Code of Best Practice in Scholarly Journal Publishing and Peer Review, but nevertheless follow conventional practice for such journals. Quaestiones Mathematicae is a WoS-indexed journal with a good impact factor. The copublishers of the journal, National Inquiry Services Centre (NISC), make available on the journal webpage a document entitled 'Ethical considerations in research publication', which includes considerations of conflict of interest. In addition, the co-publisher, Taylor \& Francis, is a member of the Committee of Publication Ethics (COPE). Errata are published, although this happens rarely and depends on the value to be added to the original work. Errata are also peer reviewed. The journal does not publish any valueadded features. All pages in each issue represent peer-reviewed original material.

\section{Content:}

\section{(Quality, focus, spread within domain, sample of best work in SA, enrichment features)}

Consensus review: The general quality of publications is good, comprising interesting papers in a broad range of mathematics subjects, and representing a good sample of the best work done in the discipline. The number of articles each year is satisfactory. Although the main focus of the journal is national research, it attracts contributions from around the world. No additional scholarly features, such as editorials, topical reviews, book reviews or scholarly correspondence, are published.

\section{Essential technical features:}

\section{(English abstracts, errata, citation practice, presentation)}

Consensus review: All articles are published in English and have proper abstracts. Based on MathSciNet records of the American Mathematical Society, during the period 201 1-2015, Quaestiones Mathematicae published 218 papers, 66 of which were cited, giving a Mathematical Citation Quotient (MCQ) rating of 0.30. This was, for example, higher than the Bulletin of the Iranian Mathematical Society (0.18) or the Journal of the Egyptian Mathematical Society (0.11), but lower than the Journal of the Australian Mathematical Society (0.50) or the Bulletin of the Brazilian Mathematical Society (0.62). The citation practices are comparable with those of the best journals in the field. The presentation, design, layout, style and copy-editing interventions are good, and images are used in an ethical manner. 
Usefulness in capacity development, and international comparability:

Consensus review: The journal is suitable as a reference source for local graduate students and young staff in the various disciplines of mathematics. In some areas, the quality of articles is comparable with leading international journals in the field.

\section{Business aspects:}

\section{(Business-related criteria; Bibliometric assessments)}

The owner of the journal is the South African Mathematical Society, which has a contract agreement with NISC SA for publication. The regular print run is 80 copies per issue. All production and distribution activities are done in-house at NISC. The journal does not carry advertising and is not supported financially.

The number of paying subscribers is 49 , comprising 33 non-African institutions, 13 African institutions and three individuals. There are no page fees or article-processing charges. The editorial workflow is managed through an online management system. The journal is not open access, although a gold open-access option is available to authors through payment of an article-processing fee.

The journal is co-published with a multinational publisher. Submission of a manuscript implies the transfer of the copyright for the accepted article to the publisher and any media that the journal considers suitable for dissemination of the work. However, authors retain the right to disseminate their own work subject to standard restrictions. Standard publishing involves copyright transfer to the publisher; however, copyright retention licences are available to meet funder requirements, and on author request. Authors may elect to publish under a paid open-access licence that uses CC-BY as default, and CC BY-NC-ND on request.

The journal is included in Journal Citation Reports, Science Citation Index Expanded and Scopus. The journal had an impact factor of 0.463 in 2016 and 0.381 in 2017. Altmetric indicators are determined, and both the number of article views and a social media altmetric score are provided for each article on the journal website. The 'front details' for papers and English abstracts are mandatory. The journal has not been independently peer reviewed before.

\section{Suggested improvements:}

Consensus review: The aim and scope of the journal need to be revised and updated to attract more quality work. Applied mathematics is currently not adequately represented in the journal. Since this is the only journal of the South African Mathematical Society, the society should encourage more publications in applied mathematics, and this should be reflected in the scope of the journal.

\section{Panel's consensus view:}

i. The journal should continue to be listed on the DHET-accredited list.

ii. The journal should be invited to join the SciELO SA platform should its relationship with its publishers change and it becomes open access.

\subsubsection{South African Journal of Geomatics}

Focus and scope:

(Purpose of journal, positioning, focus, scope, readership)

The South African Journal of Geomatics (SAJG) publishes peer-reviewed original papers within the broad discipline of geomatics (including surveying techniques, technology and applications, mine surveying, hydrographic surveying, cadastral systems, land tenure, development planning, GIS, photogrammetry and remote sensing). The journal is designed to serve as a reference source and archive of advancements in these disciplines. 
The focus of the journal is on papers relevant to the South African and African contexts but is not restricted to these areas. This includes both technological developments as well as social adaptations appropriate to the needs of geomatics in Africa. Geomatics is a broad discipline with multidisciplinary links, and hence the SAJG accepts interdisciplinary submissions with a geomatics focus.

The SAJG is the only peer-reviewed journal available in South Africa, and possibly the whole of Africa, for geomatics content. The journal has an African focus but has some international reviewers and readers. It is freely subscribed to by individuals. There are currently more than 500 registered users.

\section{Editing functions:}

\section{(Standing, local institutional spread, international participation)}

Consensus review: The national reputation of the editorial board is high, but the coverage could be more multidisciplinary.

\section{Questionnaire: \\ (Editorial process-related criteria)}

The SAJG builds upon a long history of survey literature in South Africa. It represents the revival (with a name change) of the South African Journal of Surveying and Geo-Information, which has been dormant for several years. That journal, in turn, was based upon the South African Survey Journal, which was founded in 1923. The SAJG is published biannually, with occasional special editions. The journal can be accessed online at www.sajg.org.za. The visit and download records, as well as the number of countries in which the journal is read, are unknown. The journal is pre-scheduled to appear on given dates. There have been no significant interruptions to publication.

Over the three-year review period, 102 full articles have been published. The number of full-article manuscripts received over the same period was 193. The rejection rate of manuscripts without peer review was $10 \%$, and about $25 \%$ after peer review. The proportion of peer-reviewed papers that had at least one author with a non-South African address is unknown.

Between two and four peer reviewers are usually approached for each submitted manuscript. Peer review is conducted in a 'blind-way'. Valid reviewer critique and article improvement are rigorously implemented. Authors are required to submit a summary of all editorial changes made and how they have addressed reviewer comments as part of their revised submission. Peer reviewers do not receive follow-up information. Reviewer performance is assessed, and information is captured in a database. The peer-review reports are accessibly retained in the journal's records. The average period between receipt of a manuscript and its publication online is four months.

The editor has been in office for six years and was not appointed competitively. The period of appointment is indefinite. The members of the editorial board have been in office since the inception of the journal in 2012. The board handles peer review and advises on editorial policies and practices. The board members were not appointed competitively, and their period of appointment is indefinite. They were appointed from both inside and outside South Africa to provide specific topical expertise.

The journal does not have editorial guidelines or a conflict-of-interest policy. However, there is an errata policy. There are no value-added features. The percentage of pages in each issue that represents peerreviewed original material is $100 \%$.

\section{Content:}

(Quality, focus, spread within domain, sample of best work in SA, enrichment features)

Consensus review: The accepted and published articles are of good quality and focus on a wide range of issues. The authors come from South Africa and beyond, including other African countries. There are no useful additional scholarly features. 


\section{Essential technical features:}

(English abstracts, errata, citation practice, presentation)

Consensus review: The English language used is appropriate. There is adequate publication of errata. Adequate citation practices are followed and are consistent with international practice. The published articles exhibit good presentation, layout, style and image quality.

\section{Usefulness in capacity development, and international comparability:}

Consensus review: The journal is a good vehicle for publishing articles by students, and younger academic and research staff. The standard of the journal is comparable with other journals of applied geodesy and geomatics focusing on local and regional issues.

\section{Business aspects:}

(Business-related criteria; Bibliometric assessments)

The CONSAS Foundation is the owner and publisher of the journal. There is no regular print run, and production and distribution are not outsourced. The journal does not carry advertising but receives financial sponsorship from the CONSAS Foundation.

There are no paying subscribers, and no page fees or article-processing charges. The journal currently uses an online management system for the editorial workflow. Access is free online, without password protection. There have been no offers from multinational publishers to purchase the journal. There is a copyright notice and licence agreement with authors.

The journal is accredited by DHET. The impact factors and altmetric indicators are unknown. The 'front details' for papers and English abstracts are mandatory. The journal has not been independently peer reviewed before.

\section{Suggested improvements:}

Consensus review: The journal must develop editorial and conflict-of-interest guidelines and policies. Scholarly features should be considered as useful additions to the journal. The editor should consider inviting well-known international authors to publish in the journal. The list of editorial board members should be increased to include local, continental and international researchers in a wider variety of fields.

\section{Panel's consensus view:}

i. The journal should continue to be listed on the DHET-accredited list.

ii. The journal should be invited to join the SciELO SA platform.

\subsubsection{South African Statistical Journal}

\section{Focus and scope:}

\section{(Purpose of journal, positioning, focus, scope, readership)}

As the official journal of the South African Statistical Association, the South African Statistical Journal (SASJ) seeks to publish innovative contributions to the theory and application of statistics, as well as authoritative review articles on topics of general interest to the statistical community. Articles of a general or non-technical nature are also considered, provided that the topic is of current interest to the theory, application or teaching of statistics.

The primary focus of the journal is statistical theory and applications. The journal provides a platform for the research community to publish new and innovative research ideas in theoretical or applied statistics and serves as a resource of knowledge that researchers can use in their endeavours to solve new problems. The primary target audience is predominantly local scholars, but there is also some international interest in the journal. 
The journal has 612 subscriptions, 79 of which are international subscribers; 134 are institutions and 478 are individuals. The number of members who receive the journal in hard copy is 478 in total, 450 of whom are local, 21 are overseas and seven are from other African countries. The number of libraries that receive the journal in hard copy is 65 in total, 10 of which are local and 55 are overseas. The number of electronic subscriptions (through Sabinet), all of which are libraries or institutions, is 69 in total, 61 of which are local, three are overseas and five are from other African countries.

\section{Editing functions:}

\section{(Standing, local institutional spread, international participation)}

Consensus review: The editor-in-chief, associate editors and members of the editorial board generally have a high national or international standing in the discipline. The board is rather small, with few international members. Since there is a critical shortage of academics in the discipline of statistics in South Africa, more leading international researchers should be invited to join the board.

\section{Questionnaire:}

\section{(Editorial process-related criteria)}

The South African Statistical Journal was established in 1967 and publishes two issues each year. The issues published since 2001 can be accessed through the Sabinet platform at http://reference.sabinet. co.za/sa epublication/sasj. Older issues (before 2001) can be accessed at https://journals.co.za/ content/journal/sasj/browse?page=archive-issues. For the period 2015-2017, the download record was 726 in 2015, 1089 in 2016 and 7333 in 2017. The journal is pre-scheduled to appear on given dates, and there have not been any significant interruptions.

During the three-year review period, 51 full articles and one review article were published. The number of manuscripts received over the same period totalled 274 full articles and one review article. No manuscripts were rejected without peer review, and 174 full articles were rejected after peer review. About 26 of the 52 papers published in the period 2015-2017 (50\%) listed at least one author with a nonSouth African address.

An associate editor, who is an expert in the relevant field, is usually approached for each submitted manuscript. The associate editor then submits the manuscript to one or two reviewers. The journal makes use of both local and international associate editors, who are approved by the executive committee of the South African Statistical Association. Reviewers are selected according to their field of expertise, with attention to ensuring that some are non-South African. The associate editors receive the names of the authors and institutions. They then select reviewers who are not from the same institution as the author(s) to prevent any conflict of interest. The associate editor may choose to 'blank' the name of the authors of the paper when sending it to the reviewers. Valid reviewer critique and article improvement are rigorously implemented. No manuscript is accepted for publication until the associate editor and editor are satisfied that the corrections and changes indicated by the reviewers have been adequately addressed. Peer reviewers receive follow-up information. The editor assesses reviewer performance. Poor or unacceptable reviewer performance is brought to the attention of the executive committee of the South African Statistical Association and, if a decision is taken to relieve a reviewer of their duties, the reviewer is no longer used. A total of eight associate editors and 52 reviewers were used in one year over the three-year review period. The proportion of these reviewers who had a non-South African address was three of the eight associate editors, and 30 of the 52 reviewers. The peer-review reports are accessibly retained in the journal's records. The average period between receipt of a manuscript and its publication in print is 10 to 11 months, and the online version is published simultaneously.

The editor has been in office for four years. The process of selecting the editor for the journal involves the executive committee of the South African Statistical Association first compiling a list of potential 
candidates and then voting to make the final selection. The term of office of the editor is five years. Associate editors handle peer review through the editor and may give advice on editorial policies and practices. The term of office of editorial board members varies: some have served for only two years, while others have been serving for seven years. The period of appointment is indefinite. The editorial board members are appointed from both inside and outside South Africa to provide specific topical expertise.

The editorial guidelines appear inside the front cover of the journal and are available on the website of the South African Statistical Association. There is no conflict-of-interest policy, and the guidelines are not aligned with ASSAf's Code of Best Practice in Scholarly Journal Publishing and Peer Review. The journal publishes errata. The journal does not publish any value-added features apart from review articles on certain fields of interest, with comments from invited authors. Approximately $100 \%$ of the pages in each issue represent peer-reviewed original material.

\section{Content:}

(Quality, focus, spread within domain, sample of best work in SA, enrichment features)

Consensus review: The journal publishes articles that meet standard criteria for scientific excellence. The quality of published articles varies between average and good compared with international publication standards. The journal publishes an adequate number of articles. The journal is well established and highly regarded in the statistics community. The annual selection by the South African Statistical Association of the 'best' published articles may act as a motivation for submission to the journal. One of the shortcomings of the journal is the lack of articles dealing with local and regional problems and their statistical solutions, and the absence of invited articles or reviews based on local and regional needs.

\section{Essential technical features:}

\section{(English abstracts, errata, citation practice, presentation)}

Consensus review: There are proper English-language abstracts for all articles. No errata were published in the three editions under review. The conventional citation style for international statistics journals is used. The journal generally exhibits good presentation, design, layout, style and copyediting interventions, and images are used in an ethical manner (although one reviewer noted that the graphs in one edition were not of high quality).

\section{Usefulness in capacity development, and international comparability:}

Consensus review: The journal is suitable as a general ongoing stimulus for local graduate students and young staff in the discipline. The SASJ follows the model of well-established statistical theory and methods journals, such as the Significance journal published by the American Statistical Association and the Royal Statistical Society, and Communications in Statistics Theory and Methods, among others. Due to competition with these journals, it is not easy for the SASJ to attract many manuscripts from high-profile authors, or ground-breaking studies in theory and methods. As a local journal, the SAJS is not readily comparable with leading international journals in the field.

\section{Business aspects:}

\section{(Business-related criteria; Bibliometric assessments)}

The owner and publisher of the journal is the South African Statistical Association. All copies of a single issue are printed in a single batch. There are no repeat runs or 'second printings' of an issue. The printing and distribution are done by Spektrum Printing based in Pretoria. The journal does not carry advertising, and does not receive any financial sponsorship.

There are no page fees or article-processing charges. Currently the journal uses a manual system for editorial workflow. Articles are not freely accessible online, and article availability is part of a commercial e-publication service. 
There have been no offers from multinational publishers to purchase the journal. The South African Statistical Association holds copyright for the content. A licensing agreement with authors is not yet in place. However, the journal is in the process of drafting a document for authors related to copyright.

The journal is accredited by DHET and indexed by Scopus. The impact factors for the three-year review period are not available. Altmetric indicators are monitored by Sabinet. The 'front details' for papers and English abstracts are mandatory. The journal has not been independently peer reviewed before but is in the process of applying for WoS indexing.

\section{Suggested improvements:}

Consensus review: The editorial board should be expanded. The journal should consider publishing four issues each year. International scholars should be invited to publish in the journal.

The current Annual Proceedings of the South African Statistical Association Conference could be channelled through this journal, perhaps as a special issue.

Book reviews, topical reviews and invited papers could form part of the journal. Special issues on particular topics could help to establish a larger global footprint and improve the impact of the journal.

The webpage where the journal is hosted is outdated and needs to be updated.

\section{Panel's consensus view:}

i. The journal should continue to be listed on the DHET-accredited list.

ii. The journal should be invited to join the SciELO SA platform should its relationship with publishers change and it becomes open access.

iii. The editor should seriously consider the suggested recommendations for improvement.

\subsection{Natural sciences and agriculture}

\subsubsection{African Journal of Agricultural and Resource Economics}

\section{Focus and scope:}

(Purpose of journal, positioning, focus, scope, readership, etc.)

The focus and scope of the journal are agricultural and resource economics in Africa. The journal serves the South African research community by integrating South African researchers with researchers in the rest of Africa.

The primary target audience is African agricultural and resource economists, as well as those further abroad working on African agricultural economics. The journal is open access.

\section{Editing functions:}

(Standing, spread, international participation, peer review, etc.)

Consensus review: The editor-in-chief has high-level international standing. The editorial board is composed of experienced researchers from different parts of the world, including Europe and the USA, all of whom have an excellent reputation in the agricultural economics community.

\section{Questionnaire:}

(Editorial process-related criteria)

The journal was established in 2005 and is published quarterly. It is available online at www.afjare.org. 
The visit and download records were not available at the time of the review. The journal is available globally and is read in 54 African countries. Issues are pre-scheduled to appear in March, June, September and December. There was a significant interruption between 2011 and 2012 due to a change of editorship, and some issues appeared late.

During the three-year review period, 71 full articles were published. The number of full article manuscripts received over the same period was 422 . A total of 304 manuscripts were rejected without peer review, and 42 were rejected after peer review. The proportion of peer-reviewed papers that had at least one author with a non-South African address was $90 \%$.

Three peer reviewers are usually approached for each submitted manuscript. The selection of peer reviewers is based on the editor's networks and repeat requests. Peer review is conducted in a 'doubleblind way'. There is rigorous implementation of valid reviewer critique and article improvement. Peer reviewers receive follow-up information. Reviewer performance is assessed, and information is captured in a database. Thirty peer reviewers were used in one year over the review period. About $66 \%$ had a non-South African address. Peer-review reports are retained in the journal's records and are kept confidential by the editor. The average period between receipt of a manuscript and its publication online is six months.

The editor has been in office for six years and was appointed competitively. The period of appointment was five years, and the term was due to expire in 2019. Members of the editorial board handle peer review only in the case of a conflict of interest when one of the editors submits an article. They also provide advice on editorial policies and practices. Members of the editorial board are currently appointed for a four-year term, with the possibility of renewal for a maximum of one year. Members are appointed from outside South Africa to provide specific topical expertise.

The editorial guidelines are accessible online at www. afjare.org and are aligned with ASSAf's Code of Best Practice in Scholarly Journal Publishing and Peer Review. A second editor is available to handle papers published in French. If either of the editors wishes to publish in the journal, the manuscript is handled by a member of the editorial board. The code of ethics appears on the website. There is an errata policy in place.

The journal publishes value-added features such as correspondence on published articles. The percentage of pages in each issue that represents peer-reviewed original material is approximately $100 \%$.

\section{Content:}

(Quality, focus, spread within domain, sample of best work in SA, enrichment features, etc.)

Consensus review: The average quality of the accepted and published articles is good. Since 2013, the journal has regularly published four issues each year, each containing six to eight articles. The authors of published papers are predominantly from Africa or affiliated with African organisations, but the coauthors often come from other parts of the world. A few of the papers also come from lead authors in the USA or Europe. The journal clearly reflects the best work done on the African continent. All parts of Africa are included. Most of the papers in the journal are standard research papers. Editorials are occasionally included. The website also mentions book reviews, but these seem to be rare.

\section{Essential technical features:}

(English abstracts, errata, citation practice, presentation)

Consensus review: Over $90 \%$ of the papers are published in English and include English abstracts. The language usage in most articles is appropriate. A few papers are published in French; in such cases, 
in addition to the French version, the title and abstract are also provided in English. No errata have been published recently. The citation practice follows international standards. The journal exhibits good presentation, design, layout, style and copy-editing interventions, and images are used in an ethical manner.

Usefulness in capacity development, and international comparability:

Consensus review: The topics covered by this journal are suitable for graduate students in the field of agricultural economics, and the journal is an excellent resource for both academics and students. The journal is open access, making it accessible to all. The quality of the journal is comparable with other regional and national journals in agricultural economics.

\section{Business aspects:}

(Business-related criteria; Bibliometric assessments)

The African Association of Agricultural Economists, an association incorporated in Kenya, is both the owner and publisher. The journal is not printed. Production and distribution are not outsourced. The journal does not carry advertising. The journal receives financial sponsorship from the Bill and Melinda Gates Foundation through the African Association of Agricultural Economists.

The journal is open access and does not have paying subscribers. There are no page fees or articleprocessing charges. Editorial workflow is managed manually. There have not been any offers to purchase the journal from multinational publishers. Copyright is retained by authors, and there is no licensing agreement.

The journal is accredited by DHET and indexed by ESCl and Scopus. There is currently no impact factor. Altmetric indicators have not yet been determined. The 'front details' for papers and English abstracts are mandatory. The journal has been reviewed by Clarivate Analytics and Scopus.

\section{Suggested improvements:}

Consensus review: The journal is published by the African Association of Agricultural Economists, which is based in Kenya. Both of the senior editors are from Washington, USA. The seat of publication is Nairobi, Kenya. There is only one South African on the editorial board. Other editorial board members are from the USA, Australia, Belgium, Italy and Kenya. It is recommended that the editorial board should have more representation from the African continent.

The journal website is not user-friendly. It takes several clicks to find issues and get access to the papers. The right-hand frame of the website, with updates, recent publications and news is misleading, as the links lead to unexpected content. The journal should improve its website and follow the design models of other good international journals.

\section{Panel's consensus view:}

i. The journal should not continue to be listed on the DHET-accredited list, as this is not a South African journal.

ii. The journal should not be invited to join the SCiELO SA platform.

\subsubsection{African Journal of Aquatic Science}

Focus and scope:

(Purpose of journal, positioning, focus, scope, readership)

The African Journal of Aquatic Science (AJAS) is an international journal devoted to the study of the aquatic sciences, covering all African inland and estuarine waters. The journal publishes peer- 
reviewed original scientific papers and short articles in all fields of aquatic science, including limnology, hydrobiology, and estuarine and coastal marine science. Among the topics covered in this journal are ecology, conservation, biomonitoring, management, water quality, ecotoxicology, biological interactions, physical properties, and human impacts on aquatic systems. The AJAS is supported by the Southern African Society of Aquatic Scientists and serves as a reference source for those interested in understanding the valuable aquatic resources of Africa.

The journal aims to focus on freshwater and estuarine aquatic science. It is the only journal published in South Africa to focus exclusively on freshwater biological research. The primary target audience is aquatic scientists from the whole African continent.

In 2018, 149 individuals (98\% South African) and 2955 institutions had access to the journal, either with a subscription or through a library package (including most South African universities). Additional readership through AJOL, Research4Life, EBSCOhost and the International Network for the Availability of Scientific Publications (INASP) is more difficult to measure, as there are many thousands of institutions and hundreds of thousands of users with potential access through these portals, although most usage still comes through subscriptions and packages.

\section{Editing functions:}

\section{(Standing, local institutional spread, international participation)}

Consensus review: Overall, the editor and the members of the editorial board are of good international standing. The gradual rise of the impact factor of the AJAS over recent years bears testimony to a dedicated, competent and respected editorial team.

\section{Questionnaire:}

\section{(Editorial process-related criteria)}

The AJAS was established in 1971 under its original name, Southern African Journal of Aquatic Sciences, and was renamed in 2000. The journal publishes four issues per year. It is available online through a Taylor \& Francis platform at www.tandfonline.com/taas. The journal received more than 80000 page views and 10649 full-text downloads in 2018 on Taylor \& Francis Online. The journal is read on various platforms in over 100 countries and has probably been read in most countries around the world. It is pre-scheduled to appear on given dates. There have not been any significant interruptions.

Over the three-year review period, 108 original articles were published, as well as one letter, eight review articles and four book reviews. Other published papers over the review period included 24 short notes, one guest editorial, one opinion piece, two obituaries and three corrigenda. The overall number of manuscripts received over the three-year period was 594. A total of 102 manuscripts were rejected without peer review, and 318 were rejected after peer review. There were 74 peer-reviewed papers that had at least one author with a non-South African address.

Between two and 16 peer reviewers are usually approached for each submitted manuscript. Peer reviewers are selected based on their specialist expertise. Peer review is conducted in a 'single-blind way'. The journal rigorously implements valid reviewer critique and article improvement. Peer reviewers receive follow-up information. Reviewer performance is assessed, and information is captured in a database. A total of 211 peer reviewers were used in 2018, 76 of whom had a non-South African address. The peer-review reports are retained in the journal's records. The average period between receipt of a manuscript and its publication online is 265 days, and print copies appear within three weeks after going online. 
Editorship is currently held jointly by two scientists, who were nominated as co-editors in $2018 / 2019$. The appointments are for four years, with the option of extending the period. The appointments were not competitive. Members of the editorial board handle peer review and advise on editorial policies and practices. They have been in office for periods varying between one and nine years and were also not competitively appointed. Members of the board have been appointed for a three-year period, with the possibility of extension, and are appointed from both inside and outside South Africa to provide specific topical expertise.

The journal has 'Instructions to authors' and a conflict-of-interest policy, which can be viewed at http://www.nisc.co.za/products/2/journals/african-journal-of-aquatic-science\#downloads. The guidelines are not explicitly aligned with ASSAf's Code of Best Practice in Scholarly Journal Publishing and Peer Review, as they pre-date the ASSAf code, but the journal policies are in keeping with this document and those of COPE, of which the journal's co-publisher, Taylor \& Francis, is a member. The journal publishes errata.

Value-added features are occasionally published in the journal, including analytical book reviews, critical editorials and critical topical reviews. Correspondence on published articles is published if offered. About $98 \%$ of the pages in each issue represent peer-reviewed original material.

\section{Content:}

(Quality, focus, spread within domain, sample of best work in SA, enrichment features)

Consensus review: The published work is of good quality. The average number of articles (around eight to ten) per issue is adequate. The majority of the papers are original research, as well as a few reviews, opinions or book review papers. The AJAS represents some of the best work of South African aquatic scientists. There is a focus on local and regional materials and problems. A significant portion of papers also have authors from other African countries. Some papers are co-authored from countries outside Africa.

\section{Essential technical features:}

\section{(English abstracts, errata, citation practice, presentation)}

Consensus review: Proper abstracts in good English are provided for all articles. Good citation practice is employed. The journal exhibits good presentation, design, layout, style and copy-editing interventions, and images are used in an ethical manner.

\section{Usefulness in capacity development, and international comparability:}

Consensus review: The diversity of topics, taxa, freshwater ecosystems and geographic contexts covered provides excellent material for graduate students to gain exposure to the aquatic sciences. The journal is also a good option for early career aquatic scientists to gain publication experience. The journal is comparable with similar types of journals from other countries.

\section{Business aspects:}

\section{(Business-related criteria; Bibliometric assessments)}

The journal is owned by the Southern African Society of Aquatic Scientists and is published by NISC. The regular print run is 30 copies. All production and distribution processes are done in-house by NISC. The journal does not carry advertising and does not receive financial sponsorship.

The number of paying subscribers was 178 in 2018, excluding those with access through package sales. Access numbers for 2018 were 149 members (94.3\% South African), 18 institutional subscriptions ( 10 South African), one personal subscription (in South Africa), and over 2900 institutions with access through a package. The journal levies article-processing charges of R200 (excluding VAT) per page. 
The journal uses an online management system for the management of editorial workflow. Access is not free online and is part of a commercial e-publication service.

The journal is licensed for publication to multinational publishers, but they do not own the journal. The submission of a manuscript implies the transfer of the copyright for the accepted article to the publisher and any media considered suitable for dissemination of the work. However, authors retain the right to disseminate their own work, subject to standard restrictions (see www.nisc.co.za/products/ journals/authors). Standard publishing involves copyright transfer to the publisher; however, copyright retention licences are available to meet funder requirements and on author request. Authors may elect to publish under a paid open-access licence that uses CC BY as default, or CC BY-NC-ND on request.

The journal is indexed in BIOSIS Previews; Fish, Fisheries and Aquatic Biodiversity Worldwide; Journal Citation Reports; Science Citation Index Expanded; Scopus; Water \& Oceans Worldwide; Zoological Record and other minor indexes. The impact factor was 0.670 in 2016 and rose to 0.750 in 2018 . There are altmetric indicators. The 'front details' for papers and English abstracts are mandatory. The journal was previously peer reviewed by ASSAf.

\section{Suggested improvements:}

Consensus review: Scholarly features such as reviews and more special issues should be considered as useful additions to the journal. Special issues with invited contributions might boost the citation records.

\section{Panel's consensus view:}

i. The journal should continue to be listed on the DHET-accredited list.

ii. The journal should be invited to join the SciELO SA platform should its relationship with publishers change and it becomes open access.

\subsubsection{African Journal of Marine Science}

\section{Focus and scope:}

\section{(Purpose of journal, positioning, focus, scope, readership, etc.)}

The African Journal of Marine Science provides an international forum for the publication of original scientific contributions or critical reviews involving oceanic, shelf or estuarine waters, including oceanography, studies of organisms and their habitats, and aquaculture. Papers on the conservation and management of living resources, relevant social science and governance, or new techniques are all welcomed. Priority is given to rigorous, question-driven research, rather than descriptive research. Contributions of studies from African waters, including the Southern Ocean, are particularly encouraged, although not to the exclusion of those from elsewhere that have relevance for the African context. Submissions may take the form of a paper or a short communication.

The journal aims to achieve a balanced representation of subject areas, but also publishes proceedings of symposia in dedicated issues, as well as guest-edited suites on thematic topics in regular issues. All views expressed are those of the authors and not necessarily those of the editors or the title owner of the journal, the Department of Environment, Forestry and Fisheries (DEFF).

The focus of the journal is the marine and estuarine environment, and a wide range of research is published within that context. As the only regional journal dedicated to marine and estuarine science, the African Journal of Marine Science provides the South African marine research community with a specialist and internationally prominent platform for the publication of their research findings. It should be noted that the geographical scope of the journal is continent-wide, and hence the journal serves the African research community. 
The target audience is both South African and international, with a focus on researchers working in African waters. Most libraries access the journal as part of a large package of related titles, with relatively few purchasing a traditional single core subscription. The journal is available on (a) Taylor \& Francis Online, (b) EBSCOhost, (c) free of charge in over 3500 libraries through philanthropic initiatives such as Research4Life and INASP and (d) free of charge in low-income regions through AJOL, which has more than 150000 registered users.

The journal has 53 institutional paid subscribers, and the journal owner, DEFF, has 63 geographically distributed institutional exchange subscribers. In addition, there are nine individual South African paid subscribers.

\section{Editing functions:}

(Standing, spread, international participation, peer review, etc.)

Consensus review: The editorial team of this journal comprises highly regarded marine scientists who are well respected in local, African and international communities.

\section{Questionnaire:}

\section{(Editorial process-related criteria)}

The African Journal of Marine Science was established in 1983. Four issues are published each year. The journal is available online through the Taylor \& Francis platform at http://www.tandfonline.com/ tams. Taylor \& Francis Online hosts the version of record, to which the DOI points. There were 19370 full-text downloads and 131537 page views in 2014. Statistics are available only for Taylor \& Francis Online usage, with some philanthropic usage included. The journal was read in 194 countries during 2014,44 of which were African countries.

The journal is pre-scheduled to appear in March, June, September and December. There was a delay in the appointment of a publisher in 2017, which resulted in delays in publication, but all four quarterly issues were published by the end of the year.

During the three-year review period, 160 peer-reviewed articles were published, including 16 short communications. Seven peer-reviewed review articles, one book review, three editorials, one preface, one comment and three tributes were also published. A total of 395 manuscripts, including 39 short communications, were received. About 180 full-article manuscripts (including 14 short communications) and seven review articles were rejected without peer review. This represents $45.6 \%$ of the total received in this category. About 23 full-article manuscripts (including one short communication) were rejected after peer review. This represents $10.7 \%$ of the total manuscripts reviewed in this category. About $51 \%$ of the published papers had at least one author with a non-South African address.

Each manuscript submitted is reviewed by a minimum of two reviewers. Reviewers are selected in a number of ways, including: (a) from the list provided by the authors; (b) from those who have reviewed similar manuscripts previously; (c) from suggestions solicited from members of the editorial board; (d) from the list of potential reviewers generated by the WoS database; or (e) by perusing the reference list of the submitted manuscript. The journal uses a single-blind system, where the reviewers know the names of the authors and their institutions, but the authors do not know the names of the reviewers unless the reviewers explicitly indicate that they do not wish to remain anonymous. Valid reviewer critique and article improvement are rigorously implemented. Other than minor input of an editorial nature, all suggestions made by the reviewers require a response from the authors. Peer reviewers receive follow-up information. Reviewer performance is assessed, and information is captured in a database. In 2017, 138 reviewers were used, 55\% of whom had a non-South African address. The peerreview reports were accessibly retained in the journal's records. The average period between receipt of a manuscript and its publication online, including author revision, has been 10 months for the last 
12 issues. The articles appear in print approximately six weeks after going online. Articles that make an early appearance online must wait longer to appear in print.

The editor-in-chief has been running the journal since March 2013 and was appointed competitively and permanently. Members of the editorial advisory board do not handle peer review but advise on editorial policies and practices. The members of the advisory board have been appointed since mid-2013. Their appointment was not competitive, and the period of appointment was indefinite. The associate editors are all from South Africa, but there is a mix of local and foreign editorial advisory board members. Members of the advisory board were appointed to provide specific topical expertise. The journal has 'Instructions to authors' on its webpage. The submission of a manuscript implies that the material has not previously been published, nor is it being submitted elsewhere for publication. Contributions are accepted on the understanding that the authors have the authority for publication. The co-publisher of the journal, NISC, makes available on the journal webpage a document entitled 'Ethical considerations in research publication', which includes considerations of conflict of interest. The document is available under 'Author information' at http://www.nisc.co.za/products/3/journals/ african-journal-of-marine-science. The co-publisher, Taylor \& Francis, is a member of COPE (see http:// journalauthors.tandf.co.uk/preparation/ethics.asp). The guidelines for the journal are not aligned with ASSAf's Code of Best Practice in Scholarly Journal Publishing and Peer Review. The journal has a protocol in place for publishing errata and corrigenda (http://journalauthors.tandf.co.uk/publication/ corrections.asp).

The journal publishes value-added features such as critical editorials, analytical book reviews and correspondence on published articles in the form of formal comments. About $100 \%$ of the pages in each issue represent peer-reviewed original material.

\section{Content:}

(Quality, focus, spread within domain, sample of best work in SA, enrichment features, etc.)

Consensus review: The papers are of good quality. There are about 12 articles per issue (four issues per year), which include up to two reviews, approximately 10 research papers and other articles such as tributes or short communications. Papers are sourced both locally and regionally, particularly from southern Africa. There is strong representation from South Africa (about half), with additional representation from Indian Ocean countries and several other African countries. The authorship of papers reflects strong international collaboration, with many co-authors from countries in Europe or elsewhere in Africa.

\section{Essential technical features:}

(English abstracts, errata, citation practice, presentation)

Consensus review: The published articles are generally written in good English, with good presentation, design, layout, style and copy-editing interventions. Images are used in an ethical manner. The articles generally have a clear, uncluttered layout, are easy to follow, and contain high-quality yet simple figures and tables. Few errata are published. Good citation practice is followed.

\section{Usefulness in capacity development, and international comparability:}

Consensus review: The journal is used mainly by young and upcoming researchers and is useful for capacity development. It compares well internationally, but is not especially well supported by established researchers, who may prefer to publish in higher-impact journals.

\section{Business aspects:}

(Business-related criteria; Bibliometric assessments)

The title owner is DEFF. The journal is co-published by NISC and Taylor \& Francis. The regular print run of 
the journal is 230 copies per issue. Production and distribution are handled internally by the publisher. The journal carries unpaid advertising. DEFF employs the editor-in-chief and the editorial assistant, and also pays for a number of subscriptions to the journal. The costs of production, distribution and marketing, as well as online hosting, are borne by the publishers in return for retention of the bulk of the subscription income.

There are about 200 paying subscribers. The number of subscribing organisations includes 50 institutional subscribers, 140 print subscriptions (funded by DEFF) for institutional exchange, editorial board members and DEFF staff. There are nine individual subscribers. More than 2000 libraries access the journal as part of a large package of related titles. Contributions submitted to the journal are liable for charges at the rate of R250 per page for African contributors (excluding VAT for South Africans) or US $\$ 45$ per page for other contributors. Illustrations can be reproduced in colour, but only when essential, and subject to approval by the editor-in-chief. Non-essential use of colour is charged at R900 (excluding VAT) per page for African contributors, and US\$150 per page for contributors from elsewhere. Authors who do not receive a subsidy from their institution may apply to the publisher to have their page charges waived.

The journal uses a commercial online manuscript submission and review system (ScholarOne Manuscripts) and proprietary production and hosting software to manage the publication workflow. The journal is not open access, and is part of a commercial e-publication service.

The journal is licensed for publication to multinational publishers, but they do not own the journal. The submission of a manuscript implies the transfer of the copyright for the accepted article to the publisher and any other media that the journal considers suitable for dissemination of the work. However, the authors retain the right to disseminate their own work, subject to standard restrictions. Standard publishing involves copyright transfer to the publisher; however, copyright retention licences are available to meet funder requirements and on author request. Authors may elect to publish under a paid open-access licence that uses CC BY as default, or CC BY-NC-ND on request.

The journal is indexed and abstracted in BIOSIS; CAB Abstracts; Fish, Fisheries and Aquatic Biodiversity Worldwide; Journal Citation Reports; Science Citation Index Expanded; Scopus; Water \& Oceans Worldwide; Zoological Record and other minor indexes. In terms of Journal Citation Reports metrics for 2014, the two-year impact factor was 1.000, and the five-year impact factor was 1.253. The Eigenfactor Score was 0.00156 , and the Article Influence Score was 0.376 . The source normalised impact per paper (SNIP) was 0.499, and the SClmago Journal Rank (SJR) was 0.81. There are altmetric indicators. The 'front details' for papers and English abstracts are mandatory. The journal was reviewed by Clarivate Analytics to qualify for inclusion in the Science Citation Index (and related products), and by Elsevier for inclusion in Scopus, and was accepted for both indexes at the first attempt.

\section{Suggested improvements:}

Consensus review: The citation rate of the articles seems to be low and should be improved. It is suggested that the number of published review papers be increased. The inclusion of news and views could highlight exciting articles in the issue and provide additional press for the authors. The editor should consider adding this type of feature.

\section{Panel's consensus view:}

i. The journal should continue to be listed on the DHET-accredited list.

ii. The journal should be invited to join the SCiELO SA platform should its relationship with its publishers change and it becomes open access. 
Focus and scope:

(Purpose of journal, positioning, focus, scope, readership)

Ostrich: Journal of African Ornithology is the leading ornithological journal in Africa and publishes peer-reviewed scientific papers and short communications on all aspects of ornithology conducted in Africa and its associated islands and marine habitats. Contributions on avian behaviour, breeding, conservation, demography, ecology, migration, morphology and systematics are welcome, and review articles are particularly encouraged. Extended taxonomic papers may be considered for publication, particularly if they include relevant discussion of behavioural, ecological or biogeographic criteria. The journal also publishes book reviews. Articles published in Ostrich are expected to be of value to ornithologists, ecologists, conservationists and interested birdwatchers. Ostrich is the scientific journal of BirdLife South Africa. It is published by NISC and hosted by Taylor \& Francis. It focuses on ornithology and bird conservation. The primary target audiences are both local and international scholars.

For 2017, 48 individuals (69\% South African) and over 2000 institutions had access to the journal either with a subscription or through a library package (including most South African universities). Additional readership through AJOL, Research4Life, EBSCOhost and INASP is more difficult to measure, as there are many thousands of institutions and hundreds of thousands of users with potential access through these portals, although most usage still comes through subscriptions and packages.

\section{Editing functions:}

(Standing, local institutional spread, international participation)

Consensus review: The editor-in-chief, members of the editorial board and associate editors are wellrecognised researchers working in the fields of ecology and ornithology. Seventy-five per cent of them are based in Africa, and the rest in the USA, Belgium, the UK, Australia, Sweden and New Zealand.

\section{Questionnaire:}

\section{(Editorial process-related criteria)}

Ostrich was established in 1930 and published three issues per year until 2017. Four issues were published during 2018. The journal is accessible online through the Taylor \& Francis and NISC platforms at http://www.tandfonline.com/tost and http://www.nisc.co.za/products/11/journals/ostrich-journal-ofafrican-ornithology. The journal received more than 107510 page views and 9878 full-text downloads in 2017 on Taylor \& Francis Online. The journal is read on various platforms in over 100 countries, and has probably been read in most counties around the world. It is pre-scheduled to appear on given dates. The journal has produced issues in every year of its existence, and there have been no significant interruptions in recent times.

Over the three-year review period, 82 full articles, two letters and five book reviews were published. Other published peer-reviewed items included seven short notes, 22 short communications, one erratum, one corrigendum, two obituaries, one guest editorial, one perspective paper and three 'ornithological legends' papers. The number of manuscripts received over the same period was 145 original articles, two reviews and 56 short communications. The rate of manuscripts rejected without peer review was $18.4 \%$, and $25 \%$ of manuscripts were rejected after peer review. The proportion of peer-reviewed papers that had at least one author with a non-South African address was $54.4 \%$.

A minimum of two peer reviewers are usually approached for each submitted manuscript. The journal makes use of the reviewer selection tool available through ScholarOne Manuscripts, which suggests reviewers based on keywords and author expertise. At the end of 2019, a decision was taken to change the review process from single blind to double blind, which was initiated in 2020. Valid reviewer 
critique and article improvement are rigorously implemented. Peer reviewers do not receive followup information. Reviewer performance is assessed, and information is captured in a database. The total number of peer reviewers used in one year over the review period was 189. About 148 of these reviewers had a non-South African address. The peer-review reports were accessibly retained in the journal's records. The average period between receipt of a manuscript and its publication is six to 12 months online and in print.

The editor has been in office since 2016 and was appointed competitively. The period of appointment is unlimited. Members of the editorial board have been in office for more than ten years. They were not appointed competitively, and the period of their appointment is unlimited. The editorial advisory board was established in 2017. Members were appointed from both inside and outside South Africa to provide specific topical expertise. A panel of volunteers also translates titles and abstracts into French.

The journal has 'Instructions to authors', which can be accessed at http://www.nisc.co.za/ products/11/journals/ostrich-journal-of-african-ornithology\#downloads. The publisher of the journal, NISC, makes available on the journal webpage a document entitled 'Ethical considerations in research publication', which includes considerations of conflict of interest. The document is available under 'Author information' at http://www.nisc.co.za/products/11/journals/ostrich-journal-of-africanornithology\#downloads. The journal guidelines are not aligned with ASSAf's Code of Best Practice in Scholarly Journal Publishing and Peer Review. They pre-date the ASSAf code of best practice, but the journal policies are in keeping with this document and those of COPE, of which the co-publisher of the journal, Taylor \& Francis, is a member. The journal publishes errata.

Ostrich publishes value-added features such as critical editorials, critical topical reviews, analytical book reviews and correspondence on published articles. Other features include perspectives, obituaries and 'ornithological legends', which are published by invitation. Between $85 \%$ and $95 \%$ of the pages in each issue represent peer-reviewed original material.

\section{Content:}

\section{(Quality, focus, spread within domain, sample of best work in SA, enrichment features)}

Consensus review: The journal generally publishes good-quality articles. The published articles represent a good overview of ornithological research conducted in Africa. The journal reflects a focus on regional topics. More than half of the peer-reviewed papers have at least one author with a nonSouth African address. South African authors are well represented, together with researchers from other African countries and from the rest of the world.

\section{Essential technical features:}

(English abstracts, errata, citation practice, presentation)

Consensus review: Proper English-language abstracts are present for all articles. The citation practice follows international standards. The published articles exhibit good presentation, design, layout, style and copy-editing interventions, and images are used in an ethical manner.

\section{Usefulness in capacity development, and international comparability:}

Consensus review: Ostrich is an ideal journal for publication of the results of honours and master's projects as well as literature reviews. The journal has a worldwide following, and is therefore an excellent vehicle for disseminating the research output of young and developing researchers.

\section{Business aspects:}

\section{(Business-related criteria; Bibliometric assessments)}

Ostrich is owned by BirdLife South Africa, and has a contract agreement with NISC SA for publication. The regular print run of the journal is 140 copies per issue. Production and distribution are done inhouse at NISC. The journal carries unpaid advertising but does not receive financial sponsorship. 
There are page charges for the printing of non-essential colour pages and for open-access articles. Otherwise, there are no charges for authors. The journal uses an online management system for the management of editorial workflow. Access is not free online and is part of a commercial e-publication service.

The journal is co-published with a multinational publisher, but it does not own the journal. The submission of a manuscript implies the transfer of the copyright for the accepted article to the publisher and any media that the journal considers suitable for dissemination of the work. However, authors retain the right to disseminate their own work, subject to standard restrictions (see www.nisc.co.za/products/journals/ authors). Standard publishing involves copyright transfer to the publisher; however, copyright retention licences are available to meet funder requirements and on author request. Authors may elect to publish under a paid open-access licence that uses CC BY as default, or CC BY-NC-ND on request.

The journal is indexed or abstracted in Journal Citation Reports, Science Citation Index Expanded, Google Scholar, Scopus and other minor indexes. The impact factor was 0.833 in 2016 and 0.628 in 2019. The five-year impact factor was 0.662 in 2016 , and a record 0.813 for 2019. The Scopus CiteScore was 0.75 , and the SNIP was 0.647. There are altmetric indicators. The 'front details' for papers and English abstracts are mandatory. The journal has not been independently peer reviewed before.

\section{Suggested improvements:}

Consensus review: A faster turnaround time of manuscripts from acceptance to publication might help in attracting more authors to submit their manuscripts to this journal.

\section{Panel's consensus view:}

i. The journal should continue to be listed on the DHET-accredited list.

ii. The journal should be invited to join the SciELO SA platform should its relationship with its publishers change and it becomes open access.

\subsubsection{Water SA}

\section{Focus and scope:}

(Purpose of journal, positioning, focus, scope, readership)

Water SA publishes reviewed original work in all branches of water science, technology, engineering and policy. This includes water resource development, the hydrological cycle, surface hydrology, geohydrology and hydrometeorology, limnology, salinisation, treatment and management of municipal and industrial water and wastewater, treatment and disposal of sewage sludge, environmental pollution control, water quality and treatment, the impact of aquaculture on water resources, agricultural water policy, water economics, and water as a social good. Submissions of predominantly local interest, and submissions from outside southern Africa (defined for this purpose as including South Africa, Eswatini, Lesotho, Namibia, Botswana, Zimbabwe and Mozambique) are not considered.

The primary target audience is both local and international scholars in equal measure. Information on subscribers is not available. Information is available for the geographic location of website visitors: for 2015 (based on a snapshot of a visitor log of 11 days in February 2015), this was 38\% South African, with the remainder of visits being from 44 other countries.

\section{Editing functions:}

(Standing, local institutional spread, international participation)

Consensus review: The editorial board is composed of established researchers in South Africa and beyond, although most are South African. 


\section{Questionnaire:}

\section{(Editorial process-related criteria)}

Water SA was established in 1975 and is published quarterly (January, April, July and October). The journal is accessible online at http://www.wrc.org.za/WaterSA.htm. The visit and download records for Water SA on the Water Research Commission (WRC) website in 2014 were 136754 metadata views and 11453 downloads; on AJOL there were 155129 downloads in 2014; and on SciELO SA there were 161782 views or article requests in 2014. The number of countries in which the journal is read is unknown; however, the snapshot of visitor geographic location for Water SA pages on the WRC website was 45 countries in 2014, and 38 countries in 2013. There have been no significant interruptions in the publication schedule.

Over the three-year review period, a total of 198 full articles and nine review articles were published. Fifteen conference papers were also published in special editions. A total of 819 manuscripts were received over the same period. An average of $51.0 \%$ of submitted manuscripts were rejected without peer review, and $31.7 \%$ were rejected after peer review. The proportion of peer-reviewed papers that had at least one author with a non-South African address was 34.0\% in 2015 and 2016, and 36.0\% in 2017.

A total of two peer reviewers are usually approached for each submitted manuscript. Reviewers are selected from a reviewer database of all previous reviewers as well as those who ask to be considered as a reviewer. Internet searches, to find potential reviewers who have published on a similar topic or have used similar methods, are also conducted using Google Scholar. Authors are asked to nominate four suitable candidates, but usually no more than one of these is used as a reviewer and is only approached if their publication record reflects that they have the necessary expertise, and if they are not found to have been closely associated with any of the authors in the past. Peer review is not conducted in a 'blind way'. The authors and institutions are visible to the reviewer, as this assists them in identifying potential conflicts of interest and in checking for overlapping publications. Valid reviewer critique and article improvement are rigorously implemented, unless a satisfactory response is received (either by implementing the recommendation or addressing the concern directly in the text, or by providing a suitable motivation, in a separate response document, for why they have chosen not to do so), or the revised paper is not accepted for publication. If critical issues have been highlighted by a reviewer, then the revised paper and a written response to the comments by the author(s) is returned to the reviewer for re-review. Peer reviewers do not receive follow-up information unless they specifically request it. Reviewer performance is not formally assessed, and information is not captured in a database. In 2017, 184 peer reviewers were used, 46\% of whom had a non-South African address. Peer-review reports were accessibly retained in the journal's records. The average period between receipt of a manuscript and its publication online is 380 days.

The editor has been in office for five years as part of a full-time permanent position at the WRC. The position was advertised, and the editor was competitively selected. Members of the editorial board do not handle the peer-review process, but they provide advice on editorial policies and practices. The board has been in office since July 2014. Members of the editorial board are nominated by a nomination committee comprising research managers from the WRC, the editor and members of the outgoing editorial board. Nominees are shortlisted after a meeting of the selection committee. Members of the board were nominated from inside and outside the country with the aim of providing specific topical expertise.

There are editorial guidelines in the form of the 'Guide to authors'. There is no conflict-of-interest policy, but reviewers are asked to declare any conflicts of interest in their review reports. The journal guidelines are not specifically aligned with ASSAf's Code of Best Practice in Scholarly Journal Publishing and Peer Review. 
The journal contains value-added features such as critical editorials (in the context of special editions), critical topical reviews and correspondence on published articles (comments on published articles are published along with a response from the authors of the article being commented on). The percentage of pages in each issue that represents peer-reviewed original material is $100 \%$.

\section{Content:}

(Quality, focus, spread within domain, sample of best work in SA, enrichment features)

Consensus review: The quality of the articles accepted is good, with an adequate number of articles each year. The best research in the country in the relevant fields tends not to be published in this journal, as authors may prefer to target international journals. The journal focuses on the Southern African Development Community (SADC) region, and studies of predominantly local interest outside of southern Africa are not considered. Most of the authors are from South Africa.

\section{Essential technical features:}

\section{(English abstracts, errata, citation practice, presentation)}

Consensus review: An English-language abstract is mandatory for all articles. Errata are published only for important errors that might affect the communicated results of the research, which is in line with standard international practice. The journal has excellent citation practices, and exhibits excellent presentation, design, layout, style and copy-editing interventions. Images are used in an ethical manner.

\section{Usefulness in capacity development, and international comparability:}

Consensus review: The quality of the journal makes it suitable as a publication target and reference source for local graduate students and young staff in the discipline. The journal is comparable with broadly similar national journals from other countries around the world.

\section{Business aspects:}

\section{(Business-related criteria; Bibliometric assessments)}

The owner and publisher of the journal is the WRC. The journal is no longer printed. Layout is outsourced, and all other production and publication activities are done within the WRC. The journal does not carry advertising. The journal is fully funded by the WRC.

There are no paying subscribers, as the journal is fully open access. There are no page fees or articleprocessing charges. The journal uses a manual system for loading articles on to the website as part of the editorial workflow. The journal is in the process of moving to an online system based on OJS. The journal is open access with password protection, but open free of charge to anyone who registers. The login requirement prior to download will be removed in the next WRC website upgrade. All current articles are also published on the SCIELO SA and AJOL platforms and are not password protected. The journal is part of a commercial e-publication service that includes Gale Cengage Learning and ProQuest.

There have not been any offers from multinational publishers to purchase the journal. Currently, copyright is held by the journal (with certain re-use permissions granted by means of a CC BY licence), and authors transfer copyright to the journal, subject to acceptance for publication. Once an online submission system is in place, this will be changed to a system in which authors retain copyright.

The journal is indexed by WoS, Google Scholar and Scopus. The impact factor was 0.640 in 201410.962 over five years) and 0.809 in 2013 (0.993 over five years). Altmetric indicators are available on the WRC website, AJOL, SciELO SA and Sabinet. The 'front details' for papers and English abstracts are mandatory. The journal was reviewed for inclusion in WoS and the SCiELO SA platform. 


\section{Suggested improvements:}

Consensus review: Value-added features should be considered as useful additions to the journal. The journal should attempt to shorten the period between the receipt and publication of manuscripts. The current average period of over a year to publish an article is too long and may discourage potential authors.

\section{Panel's consensus view:}

i. The journal should continue to be listed on the DHET-accredited list.

ii. The journal is already on the SciELO SA platform.

\subsection{Science: Multidisciplinary}

\subsubsection{African Journal of Science, Technology, Innovation and Development}

\section{Focus and scope:}

(Purpose of journal, positioning, focus, scope, readership, etc.)

The African Journal of Science, Technology, Innovation and Development (AJSTID) is a multidisciplinary journal covering economics, science, engineering and technology, with a core focus on the economics of innovation and development. The AJSTID provides an outlet for research on the process and impact of science, technology and innovation at two levels, with the narrow objective of achieving industrial growth and the broader objective of achieving socio-economic development, particularly in Africa and other developing economies.

The AJSTID provides an outlet for research work by scientists, academics, engineers, practitioners, doctoral scholars and postgraduate students concerned with the impact of science, technology and innovation processes on industrial, economic and social development. The journal also aims to provide an opportunity to publish for emerging researchers in Africa and other developing countries. About $70 \%$ of submissions come from researchers in Africa and other countries of the developing world. The target audience includes both local and international scholars and researchers, but the main focus is on developing regions, as evident from the journal's reach across various countries.

The AJSTID is available to readers both in print and online. About 2302 international institutions and libraries have access to the journal as part of the Taylor \& Francis platform, and more than 2800 institutions across developing regions are able to access the journal through initiatives such as INASP, Access to Global Online Research in Agriculture (AGORA) and Online Access to Research in the Environment (OARE). There are also some institutions and individuals that subscribe independently. In $2017,45 \%$ of the full-text downloads were from African countries, $20 \%$ from European countries and $12 \%$ from the USA.

\section{Editing functions:}

\section{(Standing, spread, international participation, peer review, etc.)}

Consensus review: The journal has a large editorial panel of two editors-in-chief (with Google Scholar profiles of $\mathrm{H} 12$ or $\mathrm{H} 13$; both are affiliated to the Tshwane University of Technology [TUT] and have published together at least 30 times), five associate editors (with low $\mathrm{H}$ indices, two of whom are from TUT), an editorial board of 22 members, as well as four book editors. Most of the editorial panel members are from South Africa, and there are only three international members (based in Malaysia, Italy and Cameroon). The list of editorial advisors is much longer, and there is sufficient representation of international scholars to give the editorial panel an international flavour; however, it is not clear from the editors' questionnaire how actively they are drawn into the manuscript-handling processes of the journal. It is notable that this is a highly interdisciplinary journal, which is commendable, but this poses the risk of a lack of focus in the articles published. 


\section{Questionnaire:}

\section{(Editorial process-related criteria)}

The journal was established in 2009. In 2018, the AJSTID started publishing seven online issues and three print issues in each annual volume, which was an increase from six in 2017. The journal is accessible online through the Taylor \& Francis platform at www.tandfonline.com/rajs. In 2017, there were 31971 full-text downloads from 130 countries, 37 of which were from African countries. The AJSTID is prescheduled to appear in March, July and November. Papers are published online as soon as possible, and the papers are then assembled into an issue during the appropriate cover month. The journal has a good track record of meeting publication deadlines. There have been no interruptions in the publication schedule.

During the three-year review period, 191 full articles and nine conference papers were published. The number of manuscripts received over the same period was 604 full articles (including review articles) and nine book reviews. The average rejection rate was $35 \%$. This has been increasing annually, rising to more than $52 \%$ in 2017 due to increased submissions. Of the papers that are rejected, about half are rejected before peer review and half afterwards. In 2017, 40 of the total of 76 peer-reviewed published papers had at least one author with a non-South African address.

Three to four peer reviewers are usually approached for each submitted manuscript. Associate editors from relevant disciplines are appointed, and the editor-in-chief assigns each paper to one of them. The associate editors then invite three to four reviewers. The AJSTID generally follows a double-blind review system. Peer review may be single blind in exceptional cases, for example, in the case of highly specialised scientific papers. Valid reviewer critique and article improvement processes are rigorously implemented. The editors check that authors have duly addressed the reviewers' comments. In some cases, the editors refer the revised manuscript back to the concerned reviewer for their consent. Peer reviewers receive follow-up information. Reviewer performance is assessed, and information is captured in a database. Between 75 and 85 peer reviewers were used each year during the threeyear review period. Over $80 \%$ of these reviewers had a non-South African address. The peer-review reports are accessibly retained in the journal's records. The average period between receipt of a manuscript and publication is eight to 10 months in print, and six to eight months online.

The founding editors have been in office for 10 years and were not appointed competitively. There is no specific appointment period. The members of the editorial board handle peer review as part of their role, and advise on editorial policies and practices. Between $60 \%$ and $70 \%$ of the editorial board and editorial advisory board members have been in office since 2009, and others joined the board after 2013. The board members are appointed through selection, and their appointment period is indefinite. They were appointed from inside and outside the country to provide specific topical expertise.

The journal has instructions for authors on its webpage, accessible at http://bit.ly/2Xawavh. Conflict of interest is dealt with on a case-by-case basis, and in consultation with Taylor \& Francis where necessary. Authors and guest editors are required to sign a publishing agreement with Taylor \& Francis. Peer reviewers are also advised to disclose any conflicts of interest. The guidelines of the journal are aligned with ASSAf's Code of Best Practice in Scholarly Journal Publishing and Peer Review. It is the publisher's policy to publish errata, in line with the guidance of COPE.

The journal selectively publishes critical editorials, analytical book reviews and what are described as 'research notes' to accommodate work that has been categorised as critical topical reviews. Between $90 \%$ and $100 \%$ of the pages in each issue represent peer-reviewed original material. 


\section{Content:}

(Quality, focus, spread within domain, sample of best work in SA, enrichment features, etc.)

Consensus review: The articles are diverse, ranging from waste management to applied chemistry, cloud computing, small and medium enterprises (SMEs), policy, health and medicine, manufacturing and education. This is consistent with the content of a multidisciplinary journal. In general, the published content would be considered to be of adequate or good standing, but does not represent the best work done in the country in the relevant fields.

The average number of articles per issue in the seven annual online issues is about ten, with a total of about 70 articles each year.

The journal provides a vehicle for articles on African regional and local problems. Most of the authors are from Africa, with some international authors. The quality of the articles varies from low to acceptable to good, depending on the authors involved. There is some evidence of publications from international scholars of good standing.

Few additional scholarly features are published.

\section{Essential technical features:}

(English abstracts, errata, citation practice, presentation)

Consensus review: The English usage in the abstracts and articles is generally of a good standard. Errata may be included, although none were published between 2015 and 2018. The citation practice is appropriate. The general print quality of articles is excellent; all figures, design, layout and style elements are consistent with standards set by Taylor \& Francis.

\section{Usefulness in capacity development, and international comparability:}

Consensus review: The journal may be suitable as a general reference source for local graduate students and young staff in the relevant disciplines.

In the context of international multidisciplinary journals, the AJSTID is not highly rated and has a low profile. The Scopus impact factor is very low at 0.05. The journal is not listed in WoS, but the editor indicates that WoS indexing is a future goal. The journal is only poorly accessed by Google Scholar.

\section{Business aspects:}

\section{(Business-related criteria; Bibliometric assessments)}

The AJSTID is owned by TUT, and copyright is vested in the university. Taylor \& Francis holds the licence to publish the journal. There is a small regular print run of fewer than 100 copies. The production of the journal is done by NISC in collaboration with Taylor \& Francis. Hard-copy distribution in Africa is also managed by NISC, whilst electronic distribution is done by Taylor \& Francis. The journal does not carry any advertising. The South African Research Chairs Initiative (SARChI) Chair on Innovation Studies hosted by TUT and funded by the Department of Science and Innovation (DSI) and the NRF, has been supporting the journal.

Subscriptions to the AJSTID are mostly from institutions, with a negligible number of individual subscriptions. There are no page fees or article-processing charges, unless an author requests that a paper is published in open access. The management of editorial workflow is done through the online management system. The journal is not open access and is part of a commercial (pay-to-view and/ or pay-to-subscribe) e-publication service. 
The AJSTID has a co-publishing partnership with NISC and Taylor \& Francis, but TUT retains ownership and copyright of the journal. There has been some interest from other publishers (Africa World Press) to purchase the journal. Through a copyright agreement form, which all authors are asked to sign upon publication, authors transfer the copyright of their articles to TUT.

The AJSTID is accredited by DHET and indexed by Scopus, Cabell's International and ESCI. The Scopus Citescore impact factor is 0.05 . Altmetric indicators are administered by Taylor \& Francis. Data such as the number of views per article, citations and altmetric indicators are available on the journal's home page. The 'front details' for papers and English abstracts are mandatory. The journal has been independently reviewed before by DHET, Clarivate Analytics and Scopus.

\section{Suggested improvements:}

Consensus review: The Taylor \& Francis platform gives the journal a good basis from which to work. The journal has been sustained for a reasonable period of more than ten years and seems to have become well established among a selected niche of readers and contributors, and to attract reasonable quality papers, which are increasing in number. Ultimately, the quality of the articles will ensure the success of the journal and will depend on the editorial policy and editorial board, which should be continually reviewed. The research profiles of the editors and associate editors are not particularly strong.

The current impact of the journal is very low. If the articles were placed in distinct categories (e.g. science, technology and engineering, process development, and technology economics), the readability and impact of the journal could perhaps be enhanced.

The strategy to expand the circulation of the journal in more African countries could increase readership and citations. Extension of the book review section (e.g. one review per issue) could add value.

The addition of a correspondence section to develop interaction between scholars, businesspeople and policymakers could enhance the value of the journal. Notices of forthcoming conferences could also be a valuable feature in the online version.

The editorial panel should consider a revision of the journal title. At present, the title appears to be rather grandiose and all embracing, which is unfortunately a style commonly used by many predatory journals. A new title should emphasise 'development' as the focus of the journal.

The processes for peer review should be clearly stated on the appropriate platform.

\section{Panel's consensus view:}

i. The journal should continue to be listed on the DHET-accredited list.

ii. The journal should not be invited to join the SciELO SA platform.

iii. The editor should seriously reconsider the issue of publishing papers in the journal with himself and other editorial board members as authors or co-authors. This constitutes a serious conflict of interest and contravenes acceptable codes of editorial practice.

iv. The journal editors should consider each of the recommendations presented by the review panel.

\subsubsection{Journal for New Generation Sciences}

\section{Focus and scope:}

(Purpose of journal, positioning, focus, scope, readership)

The Journal for New Generation Sciences (JNGS) publishes papers in the technological sciences that deal with the development of knowledge through application and extend beyond disciplinary borders and subject-specific topics. 
The target audiences are (a) the various different types of universities in South Africa, (b) universities in Africa, (c) international universities and (d) national and international business, industry and associations. Over the period 2003-2017, a total of 650 papers were received. Manuscripts from South African sources were received from all 26 South African universities, a Technical and Vocational Education and Training (TVET) college, South African businesses and industry, and the Council for Scientific and Industrial Research (CSIR). Universities and polytechnics in eight other African countries submitted papers. Papers were also received from 26 international universities, institutes or corporations.

The JNGS is an open-access journal. The online editions date back to Vol. 2, No. 1. Prior to becoming an open-access journal, the JNGS was distributed to all research offices in South Africa, to the South African Technology Network, to a distribution list comprising identified scholars and institutions in South Africa and Africa, and to the international science community.

\section{Editing functions:}

\section{(Standing, local institutional spread, international participation)}

Consensus review: Currently, the members of the editorial board are not listed on the journal website or in the 'Guidelines' document (https://cms.cut.ac.za/Files/Froala/9d321200-af78-4328-ac4a02ca421c78ac.pdf). The editor-in-chief is of low academic standing: he has a Google H index of 10 and 412 citations in total, and most of his publications have appeared in South African journals. The editor-in-chief has been associated with this position since the inception of the journal. The editorial board consists of 12 members, five of whom are international and four of whom are associated with the host institution. The panel does not consider this ratio of membership to be particularly appropriate and recommends that the senior editor should reduce the reliance on members of the host institution serving on the editorial board.

The editor is the founder of the journal; he has been in office since 2003 and is due to serve as editor for another two years. The members of the editorial board assist with the identification of peer reviewers and advise on editorial policies and practices. The terms of office of board members vary, because of the dates when they were invited to serve on the board. Appointments are made on the basis of invitation in order to reflect expertise, relevant experience and the ability to assist in positioning the journal in the public domain. The period of appointment was not indicated. Members of the board were appointed from inside and outside the country. The task of the editorial board is to focus on three activities: (a) advising and taking decisions on editorial policy and practice; (b) quality assurance and assessment of fitness for purpose; and (c) shaping the identity of the journal.

From the information presented, there is no system for reviewing the performance of the reviewers who are used for articles, but according to the editor, this matter is being addressed. It appears that the journal has limited international contributions, and that most of the articles are contributed by four to five South African universities, together with the institution at which the journal is hosted. The contributions received from national universities come largely from those considered not to be research-intensive institutions. The conclusion is that the JNGS has only a very limited national reputation. The information from the editor with regard to contributions received suggests a much broader spectrum than that assessed for the last three years.

\section{Questionnaire:}

\section{(Editorial process-related criteria)}

The JNGS was first published in 2003. After a period of three years (in 2005) it was presented to the then Department of Education (DoE) for accreditation. The JNGS was subsequently accredited in 2006 for inclusion on the list of DoE-accredited publications. Two editions are published each year. A third edition (as a dedicated edition) was published between 2012 and 2016. The JNGS is available 
online on the following platforms: African Journal Archive via Sabinet African Journals open-access platform (http://journals.co.za/content/journal/newgen), Central University of Technology (Free State) Institutional Repository (CUT IR) (http://ir.cut.ac.za/) and CUT website (http://www.cut.ac.za/jngs). The visit and download records on the African Journal Archive are only available from 2012 when the new reference platform was implemented. The CUT IR has only recently added the JNGS to its collection, and no earlier statistics are available from this platform. Records from the African Journal Archive platform indicate that the journal is read in at least in nine countries (Australia, Botswana, Canada, Namibia, South Africa, Eswatini, the UK, the USA and Zimbabwe). The CUT IR platform indicates that the journal is read in at least ten countries or regions (South Africa, China, European Union, Norway, Nigeria, Germany, India, Australia, Bangladesh and Botswana).

The publication of papers is planned for July and December each year. Each edition usually comprises eight to ten papers. Dedicated editions are planned for particular dates. Since 2013, each edition has first been published as an e-edition, after which a limited number of printed copies are distributed to authors, legal repositories and a selected target audience. There have not been any significant interruptions.

During the three-year review period, 80 full articles were published. The number of full-article manuscripts received over the same period was 221 . About $15 \%$ of manuscripts were rejected without peer review, and about $50 \%$ after peer review. The proportion of peer-reviewed papers that had at least one author with a non-South African address was $10 \%$.

At least two external peer reviewers are usually approached for each submitted manuscript. Peer reviewers are selected based on their subject knowledge, with suggestions by the editorial board. Peer review is conducted in a 'blind way'. Valid reviewer critique and article improvement are rigorously implemented. Peer reviewers receive follow-up information, and reviewers' feedback is acknowledged, although they do not receive feedback on the final outcome of the paper. A new system has been initiated since 2017 to make all submissions and reviews online. The online system was supposed to be available in 2018, although in March 2021 the guidelines for submission (accessed at https://www.cut.ac.za/ings) still request the submission of a MSWord document to the editor. Reviewer performance is assessed, and information is captured in a database. In 2017, 64 peer reviewers were used, about $10 \%$ of whom had a non-South African address. The peer-review reports were accessibly retained in the journal's records. The average period between receipt of a manuscript and its publication in print is 12 months, and online is 10-12 months.

The editorial guidelines of the journal are aligned with ASSAf's Code of Best Practice in Scholarly Journal Publishing, Editing and Peer Review. There is a conflict-of-interest policy. No errata were published before the availability of online issues. The journal does not contain any value-added features. About $100 \%$ of the pages in each issue represent peer-reviewed original material.

\section{Content:}

\section{(Quality, focus, spread within domain, sample of best work in SA, enrichment features)}

Consensus review: The quality of the articles accepted is adequate. The published articles are related to both industry and education, with most (about two-thirds) being on education. Data for 2017 indicate that 34 submissions were received, 32 of which were published; data on the acceptance rates for other years were not available. This high acceptance rate is potentially a cause for concern and could indicate weak review processes and generally low publication quality.

There is some evidence that the JNGS has low impact. Few of the published papers have any impact: Google Scholar identified only six cited papers (cited only twice). This suggests that international interest in the journal is weak, possibly reflecting the limited international authorship. 
No useful additional scholarly features such as editorials, topical reviews, book reviews or scholarly correspondence are published.

\section{Essential technical features: \\ (English abstracts, errata, citation practice, presentation)}

Consensus review: English-language abstracts are provided for all articles. On occasion, the abstract does not adequately indicate the main findings of the study. No evidence of published errata could be found. Good citation practices are used. The journal generally exhibits good presentation, design, layout, style and copy-editing interventions. Images, where present, are used in an ethical manner.

\section{Usefulness in capacity development, and international comparability:}

Consensus review: The journal has the potential to be used as a vehicle for stimulating local graduate students and young staff to disseminate their knowledge. The articles, especially those in the field of education, are stimulating and may be of value to local graduate students and young staff.

The subject matter is mostly local, and the journal is thus not comparable with leading international journals in the field. The journal has shown some improvement in the quality of articles over the past three years. The editor noted that the download rate is good, but the impact, as measured by Google Scholar, was very low for the period between 2016 and 2018.

\section{Business aspects:}

\section{(Business-related criteria; Bibliometric assessments)}

The journal is owned and published by CUT. Before the online issues, there was a regular print run of 500 copies. The print run was reduced to 50 copies because journal has moved to open access. All editorial work is done within the university. Language review is outsourced. Professional layout and printing are outsourced based on the procurement policy of the university. No advertisements are carried in the journal. The university supports the journal financially.

In an effort to promote the journal to the widest possible audience, it is available free of charge. The journal is distributed to both individuals and organisations. Before 2016, page fees were not charged. The intention was that from 2016, the journal would be managed according to a business-based model, with page fees being charged, and a part-time administrative assistant appointed to deal with administrative matters. The journal website (https://www.cut.ac.za/jngs) currently states that a page charge of R500 per page is applied. The editorial workflow is managed through the online management system. The journal is freely accessible online without password protection and is part of a non-commercial e-publication mechanism.

There has been an offer to engage with a multinational publisher, and a request from a different university of technology to co-own the journal together with CUT. The institutional management decision was to keep the journal as a CUT-driven initiative. Copyright is transferred to CUT on acceptance of an article for publication. In terms of the licensing agreement, authors grant CUT the non-exclusive right to reproduce, translate and distribute submissions (including the abstract) worldwide and royalty free in print and electronic formats.

The JNGS is accredited by DHET and included in Google Scholar. The impact factor and altmetric indicators are determined by Google Scholar. 'Front details' for papers and English abstracts are mandatory. The journal was reviewed by DHET in 2005 when it applied for listing.

\section{Suggested improvements:}

Consensus review: The comments presented by the editor in the questionnaire address the challenges the journal faces and demonstrate that the editor has a good comprehension of what is required to improve the standing of the journal. 
Details of the editorial board should be provided on the journal website. Due to the transdisciplinary nature of the journal, a recommendation could be that a more diverse editorial board be constituted in terms of institutional and disciplinary representation.

To increase its national and international standing, additional scholarly features such as critical editorials, topical reviews, analytical book reviews or other scholarly correspondence should be included. The journal should attempt to incorporate more comparative studies that involve international perspectives, which could increase the citation metrics and visibility of the journal.

The number of papers downloaded seems healthy, but the citation of these papers is very low. The editorial board should actively address this through interventions aimed at increasing the impact of the published articles.

Promotion of the journal at conferences and symposia would be of value, as would strong and consistent visibility on social media platforms. The journal should leverage its multidisciplinary nature and reach out to universities, locally and internationally, especially in Africa.

The journal should try to reduce the 10-12 month period from receipt of a manuscript until publication.

The publication of errata is encouraged to maintain the integrity and credibility of the journal.

It is of particular importance for the journal to clarify its niche focus. The current focus on multidisciplinary, interdisciplinary and transdisciplinary topics might attract studies that fall between the domains of other disciplines, but it could also be seen as so diffuse that authors prefer to contribute to other more thematically focused journals.

Given that a large proportion of the content of the journal is not science (social science at best), a change in the title of the journal is recommended (perhaps Journal of Next Generation Studies).

\section{Panel's consensus view:}

i. The journal should not continue to be listed on the DHET-accredited list.

ii. The journal should not be invited to join the SciELO SA platform.

iii. The panel has serious concerns about many aspects of the journal, including the current title, the composition of the editorial board, the ratio between acceptance and rejection of manuscripts, the impact and citation figures for published papers, and the lack of alignment between the journal title and the bulk of the content.

iv. The journal should seriously consider the other recommendations in this review.

\subsubsection{Journal for Transdisciplinary Research in Southern Africa}

\section{Focus and scope:}

(Purpose of journal, positioning, focus, scope, readership)

The Journal for Transdisciplinary Research in Southern Africa is dedicated to promoting the concept of transdisciplinary research. The editorial team welcomes contributions of a theoretical nature, as well as material based on empirical research. Preference is given to southern Africa as a region of focus, but submitted articles that show potential to contribute towards the understanding of science beyond the confines of a single discipline would also be considered. Any multidisciplinary, interdisciplinary or transdisciplinary (MIT) research is potentially eligible for publication. 
The journal aims to attract submissions from researchers who work in more than one discipline and engage in community-based projects. Both African and international researchers have made contributions to the journal on the theoretical aspects of transdisciplinarity. In recent years, there has been growing interest among IT specialists to explore new technologies and to publish in this journal. The journal has attracted papers from academics in diverse fields, including educationalists, researchers in the field of music, and philosophers.

The type of material suitable for publication in the journal should typically deal with theoretical aspects of MIT and the methodology used in the research work. The journal has a worldwide audience, and the primary target audience comprises local and international scholars, NGOs, NPOs and specialists in transdisciplinarity. This is an open-access journal, which has been published by AOSIS since February 2016, and by North-West University before that.

\section{Editing functions:}

\section{(Standing, local institutional spread, international participation)}

Consensus review: The editorial board has not changed much in 13 years; most of the members are South African, but there are three internationally recognised scholars on the board. There is no clear evidence of high national or international standing among the majority of those with editorial responsibilities. It would seem that the chief editor has a weak publication record with only 323 citations on Google Scholar, and only 27 journal articles with any citations at all. Of his published articles, 25 have appeared in this journal, about 10 of which are uncited. Most members of the editorial board have limited publishing experience (with fewer than 200 Google Scholar citations), with the exception of three who have $\mathrm{H}$ indices in the 30 s and 40 s and citations in the thousands.

\section{Questionnaire:}

\section{(Editorial process-related criteria)}

The journal was founded in 2005 and published at least two issues each year before 2016, as well as intermittent special editions based on conference proceedings and research projects. Since AOSIS became the publisher in 2016, at least one issue has been published each year. Articles are published online when they are ready for publication, and then printed in an end-of-year compilation. Additional issues may be published for special events (e.g. conferences) or to address a special theme. The journal is accessible online at https://td-sa.net. Between 15 February 2016 and 31 January 2018, the visit statistics from Google Analytics were 7365 and the download statistics from OJS were 39 304. The journal is read in 128 countries, 37 of which are African countries. The journal is not pre-scheduled to appear on given dates. There have been significant interruptions on three occasions since the first edition appeared at the end of 2005. The early delays were related to hard-copy publications, and the delays in 2014 and 2015 were due to authors taking too long to complete recommended peerreview changes. In 2016, there was a change of publisher, and the publication frequency changed to a rolling publication.

Over the three-year review period, 84 full articles and one book review have been published. The number of manuscripts received over the review period was 152 full articles. About 33 manuscripts were rejected without peer review and 30 after peer review. The proportion of peer-reviewed papers that had at least one author with a non-South African address has been 2.2\% since 2015.

At least two peer reviewers are usually approached for each submitted manuscript. In cases where there are two or more specialist areas involved, the reviewers can be increased to three on average. If there is a split decision between two reviewers, a third reviewer is selected, and sometimes even a fourth. In terms of the selection of peer reviewers, a lead author is requested to provide a list of three names, one or two of whom are selected. External reviewers who can consider articles in a 
transdisciplinary context are appointed. Since the journal has been in the AOSIS digital publishing stable, it has been possible to build up a comprehensive network of reviewers across a broad spectrum of disciplines and transdisciplinary fields of focus. Peer review is conducted in a 'double-blind way'. Valid reviewer critique and article improvement are rigorously implemented. Reviewer performance is assessed, and information is captured in a database. In 2017, 82 peer reviewers were used, 9.75\% of whom had a non-South African address. The peer-review reports were accessibly retained in the journal's records. The printed edition of the journal is compiled annually at the end of a volume. The number of days to publication is calculated from the date of acceptance until the publication date.

The founding editor has been in office since 2005, without a specified appointment period. The members of the editorial board handle peer review and advise on editorial policies and practices. The editorial board members and the editorial advisory board members have been in office since the beginning in 2005, with only minor subsequent changes and no fixed term of office. These members were invited from inside and outside the country, based on their ability to provide specific topical expertise.

The journal's editorial guidelines are available at https://td-sa.net/index.php/td/pages/view/policies. Any relevant competing interests of authors must be disclosed during the review process and declared in the published work. The guidelines for the journal are aligned with ASSAf's Code of Best Practice in Scholarly Journal Publishing and Peer Review. Errata are published, and the policy is accessible at http://aosis.co.za/policies\#correcting record.

The journal publishes value-added features such as critical editorials, news and views, critical topical reviews, analytical book reviews and op-ed pieces. The percentage of pages in each issue that represents peer-reviewed original material was 98\% in 2017.

\section{Content:}

\section{(Quality, focus, spread within domain, sample of best work in SA, enrichment features)}

Consensus review: It is difficult to assess the quality of articles, given the wide range of disciplines represented. In general, the quality appears to be highly variable. For articles falling within the broad field of development studies, the quality is average. The articles have clearly been edited with care, resulting in consistency and professionalism in their presentation. From the information provided, it was difficult to ascertain the number of articles accepted and published.

It was difficult to assess whether the published work in general provides a sample of the best work being done in South Africa, given the wide range of disciplines represented and the variable quality of the articles. There is a strong focus on material from, or relevant to, South Africa; only a few of the articles focus on material of wider relevance within the region, although this may be changing. The authors are mostly from South Africa, with only a few from other countries. Most of the authors whose papers were published during the period under review appear to be based at a somewhat narrow band of South African institutions (North-West University, University of South Africa, University of Limpopo and University of Pretoria). Subsequent to the review period, authors from other institutions such as the University of KwaZulu-Natal, University of Fort Hare and University of the Free State have submitted articles. Only three editorials and one book review could be located. The editorials that are available are helpful in providing future orientation.

To assess the contribution of articles published in the journal to its transdisciplinary focus, a total of 97 articles that appeared between 2015 and mid-2018 were critically reviewed. Only a small minority (7.2\%) of the 97 articles that were assessed refer clearly and explicitly to transdisciplinarity as an important emerging approach. Some of the articles, while not explicitly discussing the issue of disciplinary boundaries, do consciously explore perspectives beyond the confines of a single discipline. Some of the articles could be classified as 'ambiguous' in that the potential contribution of transdisciplinary research is not discussed directly, but strongly implied. 
Overall, the review revealed that about $74 \%$ of the articles published in the journal over the review period of three and a half years cannot be said to fall within the focus of the journal. Many of these articles do report research that is relevant to social problems and may be said to embody a form of 'engaged science'. All the articles in this category could have been published in established journals in the respective disciplines of their authors. It is therefore sometimes questionable whether the journal contributes significantly to the emerging field of transdisciplinarity.

\section{Essential technical features:}

\section{(English abstracts, errata, citation practice, presentation)}

Consensus review: There are proper abstracts for all articles. The quality of English is variable, as is the tone (e.g. some of the papers are less formal). There is no evidence of the publication of errata. The editor's questionnaire states that errata are published when necessary; perhaps it has not yet been necessary. The citation practice is variable. In general, the quality of the layout and design is appropriate, and diagrams are used in an ethical manner. It appears that there are careful copy-editing interventions.

\section{Usefulness in capacity development, and international comparability:}

Consensus review: The journal does not publish articles from a specific discipline, and it is thus not feasible to assess whether it is suitable as an ongoing stimulus for local graduates or young staff in a particular discipline. However, it is possible that young scholars would find individual articles of relevance to their own scholarly research. There seems to be limited comparability with leading international journals, and given the extremely wide scope of the journal, direct comparison is limited. It is therefore difficult to gauge the international standing of the journal among leading international journals that address interdisciplinary and transdisciplinary research.

\section{Business aspects:}

\section{(Business-related criteria; Bibliometric assessments)}

The journal is owned by North-West University and published by AOSIS. There is no regular print run, as the journal is open access. Production and distribution are outsourced by AOSIS. The journal carries unpaid advertising for conference notices. There is no financial sponsorship.

There are no paying subscribers, as the journal is open access. The article-processing charge for this journal is R1114.00 (excluding VAT) per A4 output page in PDF format. The average length of articles is 10 pages. The journal uses an online management system for the management of editorial workflow. It is freely accessible online without password protection, and it is part of a non-commercial e-publication mechanism.

There have not been any offers from multinational publishers to purchase the journal. Authors retain copyright of work published by AOSIS unless specified otherwise, but are required to grant AOSIS unlimited rights to publish the definitive work in any format, language or medium, for any lawful purpose. AOSIS requires journal authors to publish their work in open access under a CC BY 4.0 licence. Authors retain the non-exclusive right to do anything they wish with a published article, provided that attribution is given to the original publication, as set out in the official citation of the article published in the journal. The retained right specifically includes the right to post the article on a website of the authors or their institution, or in an institutional repository.

The journal is accredited by DHET; DOAJ; Gale Cengage Learning; Norwegian Register for Scientific Journals, Series and Publishers Level 1; ProQuest; and ESCI. The journal has an impact factor of 6 based on Google Scholar (as at 9 February 2018). There are altmetric indicators. The 'front details' for papers and English abstracts are mandatory. The journal was independently peer reviewed by DHET in 2007. 


\section{Suggested improvements:}

Consensus review: The precise focus of the journal in contributing to the emerging field of transdisciplinarity at an international level is unclear and not evident. It is thus recommended that consideration be given to rethinking the purpose and focus of the journal, and perhaps even renaming it.

Based on some of the published research, it appears that some authors may need more assistance to improve the quality of their scholarship. A double-blind peer-review system should be considered for the journal if it is not already in place, as this would assist in elevating the quality of published papers.

The editorial board needs to be refreshed. Depending on the future orientation of the journal, it might be necessary to reorganise the methodological orientation of the editorial board. Expanding the editorial board to include members from other SADC states might be considered.

The journal considers a wide variety of MIT research for publication. It is recommended that the way in which this variety is presented should be reconsidered to improve the focus and standing of the journal, with the inclusion, for example, of special issues on specific topics.

\section{Panel's consensus view:}

i. The journal should continue to be listed on the DHET-accredited list.

ii. The journal should be invited to join the SciELO SA platform.

iii. The journal should seriously consider the recommendations of this review. In particular, the senior editors should refrain from publishing in 'their own journal', as this represents a conflict of interest.

\subsubsection{South African Journal of Chemistry}

\section{Focus and scope:}

(Purpose of journal, positioning, focus, scope, readership)

The South African Journal of Chemistry (SAJC) publishes short communications, full research papers and review articles in all branches of chemistry. It caters broadly for chemistry research and accepts papers within interdisciplinary fields (for example, synthesis, analysis and theoretical methods; synthesis and microbial/viral testing/bioassays; synthesis and materials research).

Most of the authors and papers are from South Africa. Papers are derived (in order of decreasing numbers) from South Africa, Iran, India, China, the USA, the UK, Germany and Australia. Authors from at least 19 other African countries publish in the journal. Citations for SAJC publications (in decreasing order) come from South Africa, the USA, the UK, China, Germany, Iran, India and France.

\section{Editing functions:}

\section{(Standing, local institutional spread, international participation)}

Consensus review: The editorial board of the SAJC is composed of two editors-in-chief, three assistant editors and 17 subject editors. The editor-in-chief and members of the editorial board are highly rated and respected researchers, both nationally and internationally, in their respective areas of specialisation. The 17 subject editors are professors appointed from seven subject areas of chemistry.

\section{Questionnaire:}

\section{(Editorial process-related criteria)}

The journal was established in 1918. Papers appear online as they are approved, and about 30 papers are published each year. The content of the journal is available online through Sabinet at https:// www.sabinet.co.za/sajchem/. Issues are not pre-scheduled to appear on given dates. There have been no significant interruptions. 
The number of full articles published between 2013 and 2015 was 177. Three review articles were also published over this period. The total number of manuscripts received during this period was 672 . The number of manuscripts rejected without peer review was 169 for 2014 and 2015. A total of 165 manuscripts were rejected after peer review between 2014 and 2015. The proportion of peer-reviewed papers that had at least one author with a non-South African address was 97 out of a total of 180.

Between three and 12 peer reviewers are usually approached for each submitted manuscript. Peer reviewers are selected from among those who have published in the particular field and who do not have a close relationship with the author(s). Peer review is not conducted in a 'blind way'. $\checkmark$ alid reviewer critique and article improvement are rigorously implemented. Peer reviewers receive follow-up information. Reviewer performance is assessed, and information is captured in a database. Between six and eight reviewers were used for papers not rejected at pre-screening. Most of the peer reviewers were not South African. The peer-review reports were accessibly retained in the journal's records. The average period between receipt of a manuscript and its publication online was 100 days.

The current editor-in-chief has been in office since 2017 and was not appointed competitively. The period of appointment is unlimited. The editorial board (scientific editors) oversee the review process. They can be used as reviewers if they are formally invited. They also advise on editorial policies and practices. The term of office of members of the editorial board and the editorial advisory board is five years on average. Most members serve for at least five years, and some for much longer. Members of the editorial board are all from South Africa, while the advisory board comprises only international members.

Editorial guidelines are published and can be accessed at https://www.sabinet.co.za/sajchem/chem aut.html. The journal does not have a conflict-of-interest policy. The guidelines of the journal are not fully aligned with ASSAf's Code of Best Practice in Scholarly Journal Publishing and Peer Review. Errata are published. The journal does not publish any value-added features. The percentage of pages in each issue representing peer-reviewed original material is $100 \%$.

\section{Content:}

\section{(Quality, focus, spread within domain, sample of best work in SA, enrichment features)}

Consensus review: In general, the quality of the articles is good, with adequate literature review, clear descriptions of methods, and results presented in a logical manner. The journal publishes about 30 articles per year. This is consistent with the capacity of the chemistry community to sustain on a voluntary basis. In 2014 and 2015 , only about $25 \%$ of the received manuscripts were published. The articles published in the SAJC are from a number of different South African universities. Some articles have multiple authors from different South African academic and research institutions, and others have joint authorship from South Africa and abroad. Due to the nature of chemistry, the research focus is completely international. The SAJC does not carry editorials, topical reviews, book reviews or scholarly correspondence other than regular articles (short communications, review articles and full research articles).

\section{Essential technical features:}

\section{(English abstracts, errata, citation practice, presentation)}

Consensus review: The English-language usage and the quality of abstracts for all articles are satisfactory. Only one erratum has been published in the last three years. Citation practices are in line with international standards. The overall layout is of the highest quality and comparable with international journals.

\section{Usefulness in capacity development, and international comparability:}

Consensus review: The journal plays a significant role in providing a forum for postgraduate students and young staff to publish their research. The fact that all articles are published online and open access is a significant advantage for local students and staff, as well as for researchers across Africa. The journal is comparable with similar (relatively low impact) journals internationally. 


\section{Business aspects:}

\section{(Business-related criteria; Bibliometric assessments)}

The owner and publisher of the journal is the South African Chemical Institute (SACI). The journal only appears online and is not printed. Production is done by Isteg Scientific Publications. Distribution is online through Sabinet. The journal does not carry advertising. SACl pays for the production costs.

The journal is open access, and there are no article-processing charges. The journal uses an online management system for the management of editorial workflow.

There have been no offers from multinational publishers to purchase the journal. The journal has a CC BY copyright licence.

The journal is indexed by DOAJ and SciELO SA, abstracted by the Chemical Abstracts Service (CAS) and listed in Current Contents Connect, Web of Knowledge and Scopus. There are impact factors, which can be accessed on Web of Knowledge. Altmetric indicators are administered by Sabinet. 'Front details' for papers and English abstracts are mandatory. The journal has not been independently peer reviewed before.

\section{Suggested improvements:}

Consensus review: The journal should consider inviting some of the leading academic chemists in South Africa to contribute reviews. This might encourage a wider readership and further citations. If successful, invitations to some leading international scholars with whom these local authors have close ties could follow.

\section{Panel's consensus view:}

i. The journal should continue to be listed on the DHET-accredited list.

ii. The journal is already on the SCiELO SA plafform.

\subsubsection{South African Journal of Science}

\section{Focus and scope:}

(Purpose of journal, positioning, focus, scope, readership)

The South African Journal of Science (SAJS) aims to publish original research with an African focus or relevance, and to provide a forum for the discussion of news and developments in research and higher education. The SAJS is multidisciplinary both in the sense of considering papers from a wide range of disciplines (with a focus on southern Africa and Africa as a whole) and in the sense that the journal aims to publish papers that will be of interest to readers from more than one discipline.

Manuscripts first undergo an assessment by the editor-in-chief to determine their scope, and the criteria of regional relevance and interest to non-specialists are strictly applied. Although only $40 \%$ of the manuscripts submitted are from South Africa, more than $80 \%$ of those published are from South Africa.

Hard-copy distribution comprised about $50 \%$ national and $50 \%$ international institutions (mostly university libraries), and as of December 2015, only four individual subscribers. Hard copies were discontinued with effect from January 2016. At the culmination of each issue, the table of contents, summaries of featured articles and links to full digital issues are sent in a 'Highlights of the latest issue' email to over 15000 recipients comprising mostly local and international scholars, as well as government, policy advisory councils and local media. 


\section{Editing functions:}

\section{(Standing, local institutional spread, international participation)}

Consensus review: The editor-in-chief, associate editors and editorial advisory board members are locally based researchers, with high national and international standing in their disciplines. The associate editors are, for the most part, researchers with an NRF rating, indicating some degree of national or international standing. Editorial standards are high and comparable to those of international journals.

\section{Questionnaire:}

\section{(Editorial process-related criteria)}

The SAJS was established in 1903 as the annual proceedings of the South African Association for the Advancement of Science. Since 2001, the journal has been published bimonthly (i.e. six issues per year). It is freely accessible online at www.sajs.co.za. The number of visits was 73000 in 2017, 73 500 in 2016 and 50600 in 2015. The journal is read in 196 countries, including all 54 African countries. It is pre-scheduled to appear on the last day of each publication month (i.e. January, March, May, July, September and November). There have been no significant interruptions since ASSAf became the publisher of the journal in 2002.

Over the three-year review period, 173 full articles, 18 letters, 37 review articles and 51 book reviews have been published. Other published papers include 49 commentaries, two obituaries, one research brief, 10 scientific correspondences, 26 news and views articles and 18 leaders. The total number of manuscripts received over the review period was 1090 full articles, 64 letters and 187 review articles. The number of manuscripts rejected without peer review was 790 full articles, 40 letters and 119 review articles. The number of manuscripts rejected after peer review was 77 full articles, eight letters and 12 review articles. The proportion of peer-reviewed papers that had at least one author with a non-South African address, excluding secondary affiliations, was 18\% in $2017,34 \%$ in 2016 and $24 \%$ in 2015.

At least three peer reviewers are usually approached for each submitted manuscript. A minimum of two reports are required. Reviewers are selected by discipline-specialist associate editors, who may use a variety of sources for assistance: Reviewer Locator on ScholarOne Manuscripts provides a list of recommended reviewers based on the keywords of the manuscript; associate editors can search various databases on PubMed, HighWire, Google Scholar as well as the journal's reviewer database using the manuscript metadata; and authors recommend three reviewers (the associate editors ensure that the selection includes reviewers not suggested by the authors). Peer review is conducted in a 'double-blind way'. Valid reviewer critique and article improvement are rigorously implemented. Peer reviewers do not individually receive follow-up information, but they have access to the outcome of the manuscripts they have reviewed on the content management system. Reviewer performance is assessed, and information is captured in a database. In 2017, 821 reviewers were invited to review, 368 agreed to review and 322 completed a review. The proportion of these who had a non-South African address was $24 \%$. The peer-review reports were accessibly retained in the journal's records. The average period between receipt of a manuscript and its publication online is three to 12 months (on average 9.5 months from submission to publication); in 2015, the print edition appeared two to three weeks after online publication.

The editor-in-chief was appointed competitively with effect from April 2019. The period of appointment was three years, renewable for a second three-year term. Peer review is handled by 10 disciplinespecific associate editors who comprise the editorial board. The associate editors and members of the editorial advisory board advise on editorial policies and practices. The editorial board has been in effect since the editorial model was changed in 2008 from a single editor to an editor-in-chief and discipline-specific associate editors. The term varies for each current associate editor. The name of the editorial advisory board was changed in 2014 from 'editorial board' to 'editorial advisory board' 
to reflect its advisory status, whereas 'editorial board' now refers to the group of associate editors. The positions of advisory board members are not advertised, but the process of invitation is competitive. Appointments to the editorial board are ratified by the editorial advisory board, and appointments to the editorial advisory board are ratified by the ASSAf Council. Associate editors are appointed on one-year contracts, which can be renewed for up to 10 years. Elected members of the editorial advisory board serve a three-year term, renewable once, and the member nominated by the South African Young Academy of Science (SAYAS) serves a fixed three-year term. As of 2020, members of the editorial advisory board are drawn from SAYAS (one member), ASSAf membership (six members) and international scholars with African connections (four members).

All editorial policies and processes are published on the journal website at https://www.sajs.co.za/ navigationMenu/view/editorial-policies. Authors and reviewers are asked to disclose any conflicts in specific fields during submission and review, respectively. The guidelines are aligned with ASSAf's Code of Best Practice in Scholarly Journal Publishing and Peer Review. Errata and corrigenda are published at the discretion of the editor-in-chief. A correction will be published if a paper contains a significant error that affects, for example, the accuracy of the article; minor errors, such as typographical errors, will generally not be corrected after publication.

The journal publishes value-added features such as critical editorials, news and views, analyses of articles being published, critical topical reviews, analytical book reviews and correspondence on published articles. The percentage of pages in each issue that represents peer-reviewed original material was $77 \%$ in $2017,81 \%$ in 2016 and $88 \%$ in 2015 .

\section{Content:}

\section{(Quality, focus, spread within domain, sample of best work in SA, enrichment features)}

Consensus review: The journal publishes articles that are of a generally high quality. There are an adequate number of articles each year, with a good split between research articles, review articles and commentaries. There seem to be a fair number of original papers in each issue. The journal faces the challenge of attracting the 'best' local work per discipline for publication, given that the best research in science would usually be published in international flagship journals where the focus is on the impact factor. Currently, most papers would be labelled as 'good' rather than the 'best'. However, it does appear that some significant results in fields such as environmental sciences and palaeontology are published in this journal.

The journal has a clear and established regional focus, as evidenced by the topics covered and the spread of authors. The focus is on interdisciplinary research with a regional focus. This may also explain why some significant results are not reported here but are submitted to more focused journals. All university and research institutions in South Africa are represented by authors over the last few of years. International authors are represented to a lesser extent. The focus on various topical matters such as, for example, women in science, is particularly good. The journal includes useful commentaries and book reviews, while also publishing topic reviews and traditional research articles.

\section{Essential technical features:}

\section{(English abstracts, errata, citation practice, presentation)}

Consensus review: English-language abstracts are provided for all articles. The journal differentiates between errata and corrigenda, suggesting an open policy towards correcting mistakes. Errata, where applicable to significant errors in the article, are published by the journal. The journal conforms to good citation practice. This is also an item on the checklist for submitting authors. The journal seems serious about giving credit where it is due. The design and layout are professional. All images are fully cited and used in an ethical manner. 
Usefulness in capacity development, and international comparability:

Consensus review: The journal provides a particularly suitable platform for the publication of exceptional work by students and young academics, although young researchers may also opt for the wide range of international field-specific journals that would attract more international interest in their research. In the field of palaeontology, several instances were noted where commentaries were published that refuted previous publications, or where authors defended their results. This suggests the existence of healthy debate, and that the journal gives authors the freedom to express their thoughts. These are excellent examples for younger colleagues, who should be encouraged to participate in these types of commentary.

\section{Business aspects:}

\section{(Business-related criteria; Bibliometric assessments)}

ASSAf is both the title owner and publisher of the journal. Hard copies were discontinued with effect from January 2016. The print run in 2015 was 100, having been gradually decreased with the discontinuation of complimentary copies from 2014 onwards. Layout, printing and postage are outsourced. Copy-editing and proofreading, as well as electronic distribution and various publishing functions such as DOI deposition and XML creation, are done in-house. The journal carries both paid and unpaid advertising. It receives financial sponsorship from the DSI.

Subscriptions were discontinued with effect from January 2016. There were 61 subscriptions in 2015 before the print distribution was discontinued. There are no page fees or article-processing charges, but colour reproduction charges were applied for colour printing in 2015 (these charges became redundant from January 2016). The editorial workflow is managed using the online management system. The journal migrated to OJS with effect from January 2018. It is freely accessible online without password protection, and is part of a commercial e-publication service (Sabinet) and a noncommercial open-access e-publication mechanism (SciELO SA).

There have been offers from multinational publishers to purchase, but they have been refused. Authors retain the copyright and grant the publisher a licence to publish by signing the publishing agreement. Papers are published under a Creative Commons attribution licence.

The journal is included in Google Scholar, ProQuest, SciELO SA, ScienceOpen, Scopus, WoS and other indices, including several discipline-specific indices. The latest WoS impact factors are 1.191 for 2017, 0.960 for 2016 and 0.902 for 2015 . Website visits and social media reach are monitored monthly. Article views, downloads and social media shares are available on all article pages. The 'front details' for papers and English abstracts are mandatory. The journal has not been independently peer reviewed before, but quality was assessed for inclusion and retention in WOS and SciELO SA.

\section{Suggested improvements:}

Consensus review: The journal accepts manuscripts only in an MSWord template, despite many journals in the natural sciences accepting or requiring Latex format, which has become the de facto standard in many fields such as physics.

Compared with international science journals, the SAJS has a rather low impact factor (1.19 in 2017). Although this is not an indication of the scientific quality of the journal, it is a reflection of the rather low citation rate of articles that appear in the journal. In addition, authors are often strongly encouraged (by their institutions) to publish in journals with high impact factors. However, given that the SAJS is completely open access and available online, the international readership is likely to increase along with the corresponding impact factor. A strategy should be implemented to increase the impact factor, which would improve the international standing of the journal. 
Fields such as space and astrophysics appear to be underrepresented in the journal. The journal could do more to advertise to the research community in underrepresented fields, for example, by visiting (in person) research institutions and being present during national conferences. The onus should be on the associate editors to increase the reach of the journal in their fields.

The editorial team could also consider partnerships with other African societies. The editorial team might consider the introduction of thematic issues, soliciting manuscripts from leading national and international (African) scholars. This concept could be expanded to invited contributions from talented early-career researchers under specific themes (e.g. Young Investigator Awards), providing a platform to showcase research of up-and-coming researchers based in Africa.

\section{Panel's consensus view:}

i. The journal should continue to be listed on the DHET-accredited list.

ii. The journal is already on the SciELO SA platform.

iii. The journal should make an effort to address the recommendations in this review.

\subsubsection{South African Journal for Science and Technology}

\section{Focus and scope:}

(Purpose of journal, positioning, focus, scope, readership)

The main objective of the South African Journal of Science and Technology/Suid-Afrikaanse Tydskrif vir Natuurwetenskap en Tegnologie is to advance science and technology, especially in South Africa, by open-access peer-reviewed publications. At the same time, it provides an opportunity for Afrikaans-speaking scientists to publish their results in their mother tongue. This enables the continued existence and advancement of scientific language in Afrikaans. The journal focuses on the broad field of science and technology, incorporating interdisciplinary publications.

The journal is not restricted to the Afrikaans-speaking scientific community; since 2017 authors are allowed to submit English manuscripts that are published online. All articles are published once a year in hard copy in Afrikaans. The journal also publishes reviewed abstracts for all student symposia in the natural sciences held under the auspices of the Suid-Afrikaanse Akademie vir Wetenskap en Kuns (Akademie). Because there is strong financial support for scientific publications in Afrikaans, there are no page charges. The primary target audience is South African scientists. The South African Journal of Science and Technology is an open-access journal, published by MedPharm. The journal has a worldwide audience.

\section{Editing functions:}

\section{(Standing, local institutional spread, international participation)}

Consensus review: The editor-in-chief is an experienced senior scientist and researcher. The editorial board is comprised mostly of South African members. It was not possible to access the process for selection, but it would seem that the language criterion (Afrikaans) constrains the pool from which the editorial board members are selected. The academic standing of the editorial board members, apart from the editor-in-chief, appears to be rather weak.

\section{Questionnaire:}

\section{(Editorial process-related criteria)}

The South African Journal of Science and Technology was established in 1981 and publishes one issue each year. Individual articles are published online as soon as they are ready for publication by adding them to the table of contents of the 'current' volume and issue. In this way, the journal aims to speed up the process of manuscript publication from submission to becoming available on the website. 
Articles are available online at http://www.satnt.ac.za. There are 83491 visit records and 1089178 download records. The journal is read in 176 countries worldwide, including 40 African countries. Issues are not pre-scheduled to appear on given dates, and there have been no significant interruptions.

During the three-year review period, 57 full articles, one book review and 60 conference papers have been published. Other published papers include one reviewer acknowledgement and three corrections. A total of 167 manuscripts were received. A total of 26 manuscripts were rejected without peer review, and 21 were rejected after peer review. About $5 \%$ of the authors of peer-reviewed papers in 2017 had a non-South African address.

A minimum of two peer reviewers are usually approached for each submitted manuscript. Reviewer selection is critical to the publication process, and the editor bases his choice on many factors, including expertise, reputation, specific recommendations and the previous experience of the reviewer. Peer review is conducted in a 'double-blind way'. Valid reviewer critique and article improvement are rigorously implemented. The editor has the discretion to provide reviewers with the reports of other reviewers for the manuscript under review. Reviewer performance is assessed, and information is captured in a database. In 2017, 41 reviewers were used. About 2.5\% of the reviewers used in 2017 had a non-South African address. The peer-review reports were accessibly retained in the journal's records. The average period between receipt of a manuscript and its publication online is 71 days. The printed edition of the journal is compiled annually at the end of a volume.

The current editor has been in office since 2017 and was not appointed competitively. The period of appointment is three years. The members of the editorial board handle peer review and advise on editorial policies and practices. The term of office of members of the board is three years. At the end of the term of the previous board, all members of the Akademie were invited to serve on the editorial panel by submitting their CV. Only some were approved. Where gaps existed, leading scientists from South Africa and abroad who understood Afrikaans were invited to serve. The board was appointed from inside and outside the country with the aim of providing specific topical expertise.

The journal has editorial guidelines that are accessible at http://www.satnt.ac.za/index.php/satnt/ about/submissions. There is a conflict-of-interest policy for authors and reviewers. The guidelines are aligned with ASSAf's Code of Best Practice in Scholarly Journal Publishing and Peer Review. Errata are published in the journal. The value-added features published in the journal include critical topical reviews. The percentage of pages in each issue that represents peer-reviewed original material was $81.7 \%$ in 2017.

\section{Content:}

\section{(Quality, focus, spread within domain, sample of best work in SA, enrichment features)}

Consensus review: Across the three-year review period, the articles published were of fair quality and covered a range of topics. Some articles are considered generally good, although quite a number are average.

The science in most of the articles is of high standard and consistent with what would be expected of a 'good' journal on the international scale. It should be noted that this assessment was based on the limited or low proportion of papers that were written in the English language. Since the bulk of the papers are in Afrikaans, the content could not be objectively evaluated. It is also noted that there has been an undertaking since 2017 to present an English version of each paper, or at least most of the papers in the journal. 
The journal produced an adequate number of articles annually between 2016 and 2018 , compared to other journals with similar coverage. The variety of papers in science and technology is commendable, covering a range of aspects in relevant disciplines. However, there also appear to be published articles on a variety of topics and research disciplines without any direct link to natural science and technology. In some volumes, there appear to be multiple papers emanating from the same authors or institution, which tends to overemphasise one area in the volume. It would also appear that some authors are perpetual publishers in the journal, at least over the three-year period of this review.

Given the mandate of the journal to provide publishing opportunities for Afrikaans-speaking scientists, the focus of most of the published articles appears to be local, sometimes with regional interest. The issues being investigated address the South African context well, while a large proportion of the papers have an international flavour. The work reported in the journal is of reasonable quality, but it certainly cannot be described as the 'best' work done in the country. This is informed by the scope of the technologies and science reported, which in most cases is not at the cutting edge, although there are pockets of high-quality scholarship displayed in some (albeit few) papers in the journal. Generally, the articles are short (mostly two pages) and thus do not display or expose particular depth. This has also resulted in some reduction in the total page numbers. A single volume was produced each year over the three-year review period.

The number of international authors was very limited. Most authors are South African, from a limited number of research and higher learning institutions. This is a real weakness of the journal and gives the impression of the journal being an 'exclusive' project. As the editor-in-chief has indicated, this has implications for patronage and subscription, and raises issues of future subsidy by DHET. In this respect, the content of papers in the journal does not adequately represent the domains and scope of science and technology in the country.

The journal has limited scholarly features. Only one review paper has been published in three years. The formats most encountered during the review period include editorials, conference abstracts and symposium outcomes and reports.

\section{Essential technical features:}

(English abstracts, errata, citation practice, presentation)

Consensus review: The journal articles show a general increase in the number of abstracts in English. Hopefully, this will become mandatory for all articles, which could increase the readership of the journal. The publication of errata was not observed in the volumes under review. There is evidence of proper citation and acknowledgements, consistent with scholarly principles and format. However, the degree and extent of referencing was generally relatively poor, or brief compared to other similar journals. This is not surprising, considering that most of the papers are in Afrikaans and might be limited in the extent to which they can source literature in this language.

The journal presentation, style, and layout are good. The images used in the papers are generally clear and of high quality. The design, layout, style and copy-editing during the review period were generally consistent, although some articles that were not of the expected standard were noted. Ethical considerations are adhered to in the use of most of the images in the journal, although there were some instances where informed consent was unclear.

\section{Usefulness in capacity development, and international comparability:}

Consensus review: The editor-in-chief presents the journal as a vehicle to stimulate young and upcoming graduate students and staff to publish, but the authorship of most of the papers in the volumes assessed did not seem to reflect this. Apart from abstracts of conference presentations by 
students, most of the papers appear to be by well-established senior researchers. The journal has the potential to provide a suitable platform for emerging natural science and technology scientists and researchers in relevant disciplines, particularly those who prefer to publish in Afrikaans.

Compared to other South African journals on science and technology, the editorial board of this journal is composed mainly of local researchers. In this respect, the journal differs from international journals in similar disciplines, where editorial boards are usually composed of researchers from multiple different countries and institutions, allowing for diverse scholarly perspectives. The number of articles published in this journal each year is limited by the annual publication frequency compared to international journals in similar disciplines, which have a higher number of issues each year. The journal compares well with similar international journals in terms of the topics covered, but the depth and scope are limited.

\section{Business aspects:}

\section{(Business-related criteria; Bibliometric assessments)}

The title owner of the journal is the Suid-Afrikaanse Akademie vir Wetenskap en Kuns, and the publisher is MedPharm. There is no regular print run, as the journal is open access. Each member scientist of the Akademie receives a free print copy. Production and distribution are outsourced by MedPharm. The journal does not carry advertising. The journal is sponsored by the Akademie and the Hiemstra Trust.

There are no paying subscribers, and no page fees or article-processing charges. The editorial workflow is managed through an online management system. The journal is free online, without password protection, as part of a non-commercial e-publication mechanism though DOAJ.

There have not been any offers from multinational publishers to purchase the journal. The ownership of copyright of the content of manuscripts is vested with the authors. They retain the non-exclusive right to do anything they wish with the published article, provided attribution is given to the Suid-Afrikaanse Tydskrif vir Natuurwetenskap en Tegnologie, and the details of original publication are given, as set out in the official citation of the article published in the journal. The retained right specifically includes the right to post the article on a website or in an institutional repository associated with the author or their institutions. Articles are published under a CC BY 4.0 licence.

The journal is accredited by DHET; DOAJ; AOSIS Library Index; EBSCOhost; Gale Cengage Learning; Google Scholar; Norwegian Register for Scientific Journals, Series and Publishers Level 1; ProQuest; Sabinet; and Clarivate Analytics WOS BIOSIS Previews. There are no impact factors. Altmetric indicators are determined. 'Front details' for papers and English abstracts are mandatory. The journal has been reviewed by Clarivate Analytics WoS and DOAJ.

\section{Suggested improvements:}

Consensus review: It is recommended that an attempt be made to diversify the editorial board in terms of country and institutional representation, in order to introduce international standards and approaches and expand the editorial team to better reflect the multidisciplinary nature of the journal.

The journal should implement a strategy to expand its target audience beyond South African scientists. This would necessitate increasing the contribution of papers in English, which could be achieved without reducing the Afrikaans articles but simply publishing English translations.

Increasing the number of issues each year would make the journal more comparable with similar international journals. Improvements in the quality of the papers in terms of depth and presentation would benefit the standing of the journal. 
The inclusion of guest editors on a regular basis in special issues on thematic areas would add considerable strength. This would attract a wider audience from South Africa and abroad, and extend the reach of the journal not only within the academic sector but also to industry.

\section{Panel's consensus view:}

i. The journal should continue to be listed on the DHET-accredited list.

ii. The journal should be invited to join the SciELO SA platform.

iii. The journal should seriously consider the recommendations of this review.

\subsubsection{Transactions of the Royal Society of South Africa}

\section{Focus and scope:}

(Purpose of journal, positioning, focus, scope, readership)

The Transactions of the Royal Society of South Africa, published on behalf of the Royal Society of South Africa (RSSA) since 1908, comprise a rich archive of original scientific research in and beyond South Africa. Since 1878, when the journal was founded as Transactions of the South African Philosophical Society, its strength has depended on its multidisciplinary and interdisciplinary orientation, aimed at "promoting the improvement and diffusion of science in all its branches" (original Charter). Today, this includes the natural, physical, medical, environmental and earth sciences, as well as any other topics that may be of interest or importance to the people of Africa. Transactions publishes original research papers, review articles, special issues, feature articles, Festschriften and book reviews. While southern Africa is emphasised in the coverage, submissions concerning the rest of the African continent are encouraged.

The primary target audiences are both local and international scholars and researchers. The journal also has a large membership subscription base within the RSSA, as all members receive the journal as part of the benefits of membership. With the recent inclusion of the Transactions in the Scopus database, the journal hopes to increase its international visibility and improve its scientific standing.

Transactions is available to readers both in print and online, and through various subsidiaries. Approximately 20 libraries in South Africa and 350 institutions in Africa, as well as 2400 international institutions and libraries, have access to the journal as part of sales deals with Taylor \& Francis. In addition, more than 8000 institutions in developing regions have access to the journal through initiatives such as INASP, AGORA and OARE.

\section{Editing functions:}

\section{(Standing, local institutional spread, international participation)}

Consensus review: The editorial board members are highly reputable researchers nationally and internationally. However, the records of the editorial board need to be updated (e.g. Prof Priscilla Kincaid-Smith, who passed away several years ago, is still listed). The journal is well managed and publishes good-quality work, although the reputation of the editorial board may have exceeded the reputation of the journal itself.

\section{Questionnaire:}

\section{(Editorial process-related criteria)}

Transactions was established in 1908, and three issues are published each year. It is available on the Taylor \& Francis platform at www.tandfonline.com/ttrs. In 2017, the journal received more than 83200 page views (including the issues list, table of contents, abstracts and references page views) and over 9830 full-text downloads. The journal was read in 98 countries in 2017, 24 of which were African countries. The journal is pre-scheduled to appear in February, June and November. According to the 
previous editor-in-chief, there were occasions in the past when the journal did not appear at regular intervals. However, since the journal joined the Taylor \& Francis catalogue, deadlines have been met and publication has occurred regularly without exception.

During the three-year review period, 62 full articles, six review articles and 16 book reviews have been published. According to ScholarOne Manuscripts records, Transactions received a total of 139 original article submissions between January 2015 and December 2017. About 5\% of all 139 manuscripts submitted in the three-year review period were rejected before peer review, and $30 \%$ after peer review. The proportion of papers published during the same period with at least one author with a non-South African address was close to $50 \%$.

All manuscript submissions are subject to initial appraisal by the editor, and, if found suitable for further consideration, are passed on for peer review by anonymous independent expert reviewers. Two to three peer reviewers are usually approached for each submitted manuscript. A decision is made on the basis of two reviews, with a third review included in cases of disagreement. Peer review is conducted in a 'double-blind way'. Valid reviewer critique and article improvement are rigorously implemented. Peer reviewers receive follow-up information. Reviewer performance is assessed, and information is captured in a database. In 2014, up to 100 reviewers were used. Approximately $40 \%$ had a non-South African address. The peer-review reports are accessibly retained in the journal's records. The average period between receipt of a manuscript and its publication in print is four months.

The editor-in-chief has been in office since the beginning of 2015. The position was advertised, and the term of office is for three years, with the opportunity to serve for a second term. The members of the editorial advisory board handle peer review, but do not provide advice on editorial policies and practices. Some members of the board have been in office for many years, and the term of office is not specified. Editorial board members were invited from inside and outside the country, but most are fellows of the RSSA.

There are instructions for authors on the journal webpage. Conflict of interest is dealt with on a caseby-case basis, and in consultation with Taylor \& Francis where necessary. All authors are required to sign a publishing agreement with Taylor \& Francis, as are guest editors. It is also generally accepted that the editor-in-chief cannot publish in the journal. The guidelines are aligned with ASSAf's Code of Best Practice in Scholarly Journal Publishing and Peer Review and were reformulated at the end of 2014. It is the publisher's policy to publish errata according to the guidelines.

The journal publishes book reviews as a value-added feature. The percentage of pages in each issue that represents peer-reviewed original material is more than $90 \%$. A variable number of pages is used for book reviews and obituaries of deceased fellows of the RSSA.

\section{Content:}

\section{(Quality, focus, spread within domain, sample of best work in SA, enrichment features)}

Consensus review: Articles published by the journal are scholarly and in general appear to be of average quality, with occasional good-quality reviews. This is probably because Transactions might not be the first choice when regional scientists plan to publish their quality work.

The journal publishes a small number of articles each year: roughly 30 articles or reviews, with an average of eight original articles per issue. This is perhaps one of the weakest aspects of the journal. This is not comparable with similar interdisciplinary open-access journals that might publish more than 1000 articles each year (e.g. Proceedings of the National Academy of Sciences USA, Proceedings/ Philosophical Transactions of the Royal Society A and B, Scientific Reports or PLoS One). 
The journal does not represent a sample of the best work done in any field in South Africa. The number of original articles is small. The impact of published articles is low according to the citation metrics. This is probably because the journal does not have a WoS impact factor, and the reality that much of the best research done in the country is published in top-tier international journals with both a high reputation and a high impact factor. It is noted that none of the editorial board members publish their best work in this journal.

The focus of the journal is on local and regional issues and systems, as evident in the articles published. The authors were generally from various different institutions in South Africa, with a mix of international authors. A number of invited topical reviews and book reviews appear in each issue, making up $30-50 \%$ of the published articles. Obituaries are also featured.

\section{Essential technical features:}

(English abstracts, errata, citation practice, presentation)

Consensus review: This is an English-language journal, and all abstracts are presented in English of suitable academic standard. Errata are published as necessary, approximately one each year. The citation practices are good, and most articles cite only relevant references. The layout and presentation of journal articles is excellent. The images are professional, as the journal is managed by Taylor \& Francis and maintains the standards of the publisher.

\section{Usefulness in capacity development, and international comparability:}

Consensus review: In terms of its publication standards and quality, Transactions may serve to encourage local graduate students and young staff to publish. However, the limited number of original research articles in each issue might deter many from regularly viewing the journal.

The journal is not comparable with other leading international interdisciplinary journals.

\section{Business aspects:}

\section{(Business-related criteria; Bibliometric assessments)}

Transactions is the official publication of the Royal Society of South Africa, and copyright is vested in the RSSA. Taylor \& Francis holds the licence to publish the journal. The production of the journal is done by Unisa Press in collaboration with Taylor \& Francis. Hard-copy distribution in Africa is managed by NISC, whilst electronic distribution is done by Taylor \& Francis, which also uses subscription agencies such as EBSCOhost. Libel checks and legal services are offered by Taylor \& Francis. The journal carries no advertising and does not receive any financial sponsorship.

Subscriptions to Transactions are mostly from institutions, and individual subscriptions represent a negligible fraction. Sales and marketing do not necessarily target individual subscribers but focus instead on institutions and libraries. There are no page fees or article-processing charges. The journal uses an online management system. The management of editorial workflow includes uploading articles to the internet. The journal is not open access and is part of a commercial e-publication service.

There is a co-publishing partnership with Unisa Press and Taylor \& Francis, but the RSSA retains ownership and copyright of the journal. The RSSA holds full copyright of Transactions, and Taylor \& Francis is licensed to publish the journal. Upon publication, authors are asked to sign a copyright agreement transferring copyright to the RSSA. This enables Taylor \& Francis, on behalf of the RSSA, to ensure protection against infringement.

The journal is indexed by Scopus and Google Scholar. The Scopus impact factor for 2016 was 0.39 . Altmetric indicators are administered by Taylor \& Francis. The 'front details' for papers and English abstracts are mandatory. The journal has not been independently peer reviewed before. 


\section{Suggested improvements:}

Consensus review: Transactions faces similar problems and challenges to any typical local journal, notwithstanding that it has a highly reputable editorial board. The low Scopus impact factor and the absence of a WoS impact factor are obvious issues. It is recommended that the editors engage with the Taylor \& Francis group to ensure that the journal is indexed by WoS as soon as possible.

The journal should aim to increase the annual number of published articles. This would assist the journal in being indexed by WoS, which would further increase its visibility.

The editorial board should consider expanding the remit of the journal to cover publications from all over the world. The members of the editorial board are usually fellows of the RSSA with stature in their respective research fields, and the journal could potentially increase its impact by including invited reviews from fellows and leading scientists such as those working at NRF Centres of Excellence or in SARChl chairs.

Similarly, the journal should consider publishing special issues on specific topics, with the objective of attracting more regional authors and broadening its coverage.

The journal should embark on an advertising campaign targeting national university academic departments and libraries to increase awareness and visibility among staff and student bodies.

The journal content could be made available to a wider readership by means of e-contents and abstracts. The essay competition for schools, with the top-ranked essays being published in the journal, is an excellent feature. This could be replicated for graduate students, with the publication of papers from master's and doctoral degrees.

\section{Panel's consensus view:}

i. The journal should continue to be listed on the DHET-accredited list.

ii. The journal should be invited to join the SciELO SA platform should the relationship with its publishers change and it becomes open access.

iii. The journal should address the recommendations of this review.

\subsection{General Science}

\subsubsection{Annals of the Ditsong National Museum of Natural History}

\section{Focus and scope:}

(Purpose of journal, positioning, focus, scope, readership)

The focus of the Annals of the Ditsong National Museum of Natural History is on the terrestrial zoology of southern Africa, concentrating mainly on taxonomy and systematics, as well as contributions on Plio-Pleistocene palaeontology and southern African archaeozoology. The disciplines of taxonomy and systematics underpin all biological sciences and are thus of international relevance; within this context, entomology has traditionally played a larger role than vertebrate groups.

The primary target audience is users of taxonomic and systematic information globally. The archaeozoological articles appear to be of more local interest than the palaeontological papers. There are 42 local subscribers to the online version of the journal. The Ditsong National Museum of Natural History has exchange agreements with approximately 350 entities, 50 of which are South African institutes and individuals, while the rest are international research institutes. 


\section{Editing functions:}

\section{(Standing, local institutional spread, international participation)}

Consensus review: Until 2019, the journal was managed by a single editor (who was also the senior curator of the Ditsong National Museum of Natural History) and lacked an editorial board. Although the editor was a well-published and well-recognised entomologist, this was a cause for concern. Sadly, the editor passed away in 2019 and has subsequently been replaced by an independent editor from the Polish Academy of Sciences.

\section{Questionnaire:}

\section{(Editorial process-related criteria)}

The journal was established in 1908 and is published annually. It is available online through the Sabinet platform at http://reference.sabinet.co.za/sa epublication/hfi ditsong. The visit and download records were not available at the time of the review. The journal is read by users from nine countries globally, four of which are other African countries. Issues are not pre-scheduled to appear on given dates. The journal was experiencing problems in appointing service providers for layout and printing, which has led to substantial delays. The matter is being addressed. There was a four-year gap between 1942 and 1945 during the Second World War.

During the three-year review period, 20 full articles, one book review and two scientific notes were published. The number of manuscripts received was 23. No manuscripts were rejected with or without peer review. Of the 20 full articles published over three years, at least 12 of the authors had a nonSouth African address.

Two peer reviewers are approached to review each submitted manuscript. The selection of peer reviewers is based on a list that is kept up to date; in addition, authors are invited to make suggestions. Peer review is not conducted in a 'blind way'. All major issues raised by the reviewers are dealt with by the editor. Peer reviewers receive follow-up information on request. Reviewer performance is assessed informally. No database is maintained in this regard, given the comparatively small number of contributions. In 2016, 22 reviewers were used, 12 of whom had a non-South African address. The records of peer-review reports were accessibly retained. The journal takes an average of six months between receipt of a manuscript and its publication.

Prior to his death in 2019, the editor held the position for 13 years and was not appointed competitively. The period of appointment of the editor is unspecified. There is currently no editorial or advisory board.

There are no editorial guidelines or conflict-of-interest policy. Although there is no policy in place with regard to errata, these are published if necessary. The journal publishes analytical book reviews as value-added features. About $95 \%$ of the pages in each issue represent peer-reviewed original material.

\section{Content:}

\section{(Quality, focus, spread within domain, sample of best work in SA, enrichment features)}

Consensus review: The reviewers expressed concern about the small number of articles published in each annual issue and questioned the viability of the journal in both academic and economic terms. It was noted that most of the papers have at least one author from the host institution, but generally a good range of co-authors from other institutions. One reviewer noted that journals such as this were originally established specifically to publish work for the host institution. The quality of the articles was thought to be good, although the panel noted with some concern that submitted manuscripts are never rejected. Nevertheless, despite the rather narrow focus of the published material, the taxonomical studies were considered as representing valuable datasets, particularly for the local scientific community. 
The journal reflects an adequate sample of the best work done in the country in the relevant fields. The focus is on local and regional issues, since that is the rationale for the journal. Most the content comprises research articles, with an occasional book review or scientific note.

\section{Essential technical features:}

(English abstracts, errata, citation practice, presentation)

Consensus review: The technical (design, layout, style, copy-editing) and grammatical aspects of the published articles were generally noted to be good to excellent. Images were generally of high quality, and referencing was appropriate and consistent. One reviewer commented that the journal is attractively laid out and illustrated. There were proper abstracts in English for all articles. The journal publishes errata if necessary. The citation practice is good.

\section{Usefulness in capacity development, and international comparability:}

Consensus review: Reviewers had mixed opinions of the value of the journal to young researchers. It was noted that the highly specialised taxonomic content was not appropriate for a wider audience, and that the absence of impact metrics and altmetric indicators might make the journal less attractive to younger readers. Conversely, it was noted that a museum journal such as this could provide a useful vehicle for developing researchers and postgraduate students to publish their work.

In comparing the Annals with similar journals, it was noted that a local and highly focused journal such as this cannot compete effectively with larger international online journals. Leading international journals, particularly in taxonomy (e.g. Zootaxa, ZooKeys) are large online enterprises that might publish thousands of articles each year from across the globe.

\section{Business aspects:}

\section{(Business-related criteria; Bibliometric assessments)}

The journal is owned and published by the Ditsong National Museum of Natural History. The regular print run is 500 copies. The layout, design, technical editing and production of the journal are handled by Isteg Scientific Publications. Hard copies of the journal are distributed by the museum, and the digital issues are hosted and distributed by Sabinet. The journal does not carry advertising and is not financially sponsored.

Three institutions subscribe to the journal in hard copy, and 53 institutions to the online version. All the subscribers are organisations or institutions. Page charges may be levied on all papers on a sliding scale from $25 \%$ to $100 \%$, although this is currently not enforced. The journal makes use of a manual system to manage its editorial workflow. All issues older than five years are free to access, while the most recent five volumes are available only to subscribers through a commercial e-publication service.

There have been no offers to purchase the journal. The Ditsong National Museum of Natural History owns the copyright to the content of the journal. There is currently no licensing agreement with authors. The journal is accredited by DHET. There is no impact factor, and altmetric indicators have not been determined. It is mandatory to include 'front details' for papers and to publish English abstracts. The journal has not been independently peer reviewed.

\section{Suggested improvements:}

Consensus review: The panel recommends that the journal needs to address a range of issues to ensure its future viability. Such interventions should include broadening the range of articles and increasing both the number of issues each year and the number of articles from researchers outside the host institution. 
Until recently, the journal was managed by an editor who had been in this position for 13 years and was not supported by an editorial board; this does not constitute good practice. An editorial board, if established, could consist of national and international scientists whose inputs could contribute to strengthening the standing of the journal.

If the new editor wishes to refine the policies and quality of the journal and its peer-review process, ASSAf's Code of Best Practice in Scholarly Journal Publishing, Editing and Peer Review would be a valuable resource to consult. The editor might also consider working towards an impact factor, performance analytics and indicators.

The scope of the journal should be expanded. The journal should also consider open access for visibility.

The journal does not consistently publish on time and does not adhere to its stipulated periodicity. This is a cause for concern and must be addressed.

The lack of an editorial board, and the high proportion of articles that include an author from the host institution, are both incompatible with current DHET specifications.

\section{Panel's consensus view:}

i. The journal should continue to be listed on the DHET-accredited list, on condition that the suggested improvements are implemented by the end of 2022.

ii. The journal should not be invited to join the SciELO SA platform.

iii. The panel notes that, in its current form and with its current mode of management and production, this journal does not meet the requirements for DHET accreditation.

iv. However, the panel also notes that the new editor is committed to implementing most of the suggested changes and improvements which, when completed, would align the journal with the requisites for DHET accreditation.

\subsubsection{Durban Natural Science Museum Novitates}

\section{Focus and scope:}

(Purpose of journal, positioning, focus, scope, readership, etc.)

The Durban Natural Science Museum Novitates publishes papers dealing with the natural sciences, with an emphasis on the geographical area of south-eastern Africa. Most of the papers are on topics in zoology, especially mammalogy, ornithology, herpetology, entomology and palaeontology. Three important biogeographical regions represented in the area covered by the scope of the journal are Maputaland, Pondoland and Drakensberg-Maloti. With the demise of Lammergeyer, the former journal of the Natal Parks Board/Ezemvelo KZN Wildlife, and the recent restriction of subject matter by the journal of the KwaZulu-Natal Museum to invertebrates only, Novitates now provides the only local outlet for vertebraterelated museum-based research papers in this geographical region. Two recent monographs (Vol. 33 on butterflies and Vol. 35 on birds) illustrate the value of catering for manuscripts based on long-term museum investigations that would struggle to find an outlet elsewhere due to their length.

The target audience is both local and international. The journal is exchanged with a wide variety of exchange partners. The print run is 350 copies, most of which are posted as part of exchange agreements with both international (59\%) and local (41\%) partners, mostly institutions with a high representation of other museums. 


\section{Editing functions:}

(Standing, spread, international participation, peer review, etc.)

Consensus review: The editor and associate editors are well-established researchers, and the editorial board is composed of well-established local researchers with a good range of relevant fields of expertise. It is noted that the editor, who has served for 19 years, was not appointed competitively; the post of editor was a condition of employment at the museum.

\section{Questionnaire:}

\section{(Editorial process-related criteria)}

The journal was established as the Annals of the Durban Museum in 1914 and continued under this title until 1952, when the name was changed to the Durban Museum Novitates. The journal underwent rebranding in 2008, and the name was changed again to the Durban Natural Science Museum Novitates. One edition is produced each year. Editions from 1914 to 2007 are available on the Sabinet platform (African Journal Archive) at http://reference.sabinet.co.za/sa epublication/admn, and editions since 2008 are available on the eThekwini municipal website at http://www.durban.gov. za/City Services/ParksRecreation/museums/nsm/Pages/Publications.aspx or http://www.durban. gov.za/City Services/ParksRecreation/museums/nsm/publications/Pages/Novitates.aspx.

The contents of the journal are included on the broader municipal website; this practice is mandatory at present but could possibly soon change due to changes in municipal policy. This puts the journal somewhat at the mercy of the municipal IT web department, which is not under the journal's direct control. At the time of writing, the journal is working with the municipality to implement significant improvements: (a) Novitates will no longer share a webpage with the museum's popular magazine (Thola) but will have its own webpage, and (b) each paper will be presented in a separate PDF document rather than the entire content of an edition being presented as a single PDF.

Neither the visit and download records, nor information on the number of countries in which the journal is read, were available. Each annual edition is printed and delivered by the end of June, which is the end of the museum's financial year. Publication was intermittent during the period 1914-1951. During the period 1952-1989, papers were produced as individual separates at fairly high frequency during the course of each year. From 1990 onwards, a single consolidated annual edition was produced, with the exception of the three-year period 2008-2010, when a single extremely lengthy monograph was produced (Vol. 33), between four and five times the usual length of a single edition, and essentially covering the life's work of a long-time museum employee.

Over the three-year review period, 16 full articles, one review article and one book review have been published. The number of manuscripts received over the same period was 18. Only one full article was rejected without peer review. Five out of $16(31 \%)$ of the peer-reviewed papers had at least one author with a non-South African address.

Two peer reviewers are usually approached for each submitted manuscript. Peer reviewers are selected in three ways: (a) authors are asked to suggest potentially suitable peer reviewers; (b) the editor or members of the editorial board with experience in the field of expertise in question select peer reviewers; (c) where peer reviewers are unable to assist, the editor asks them to suggest potentially suitable alternative reviewers. Peer review is not conducted in a 'blind way'. Valid reviewer critique and article improvement are rigorously implemented. Authors are asked to address all reviewers' comments and to provide explicit reasons where they disagree. Peer reviewers receive follow-up information. There is no formal procedure for assessing 'reviewer performance'. All reviews and associated material are stored permanently and electronically. Nineteen peer reviewers were used in one year over the review period. Eight of these reviewers had a non-South African address. The peerreview reports were accessibly retained in the journal's records. The average period between receipt of a manuscript and its publication in print and online is six months. 
The editor, who has been in office for 19 years, was not appointed competitively. It was a condition of employment as part of the editor's broader responsibility as curator of birds at the museum. The appointment will continue for as long as the editor remains the curator of birds. Members of the editorial board handle peer review and advise on editorial policies and practices. Two older members of the editorial board were replaced with the other two curators at the museum when the journal underwent rebranding and improvement for the 2008-2010 edition. With the 2014 edition, the editorial board was expanded by an additional three members from outside the museum. The journal is in the process of appointing an additional (sixth) editorial board member from outside the museum to meet the necessary requirements of the DHET subsidy policy. The members of the editorial board who are museum staff members were appointed by the museum management, and the members from outside the museum were selected by museum staff in the relevant field based on their knowledge and experience of the individuals and their past and current involvement with the museum. The period of appointment is indefinite. All members of the editorial board are currently from South Africa and were appointed to provide specific topical expertise, particularly to cover the museum's key research fields of mammalogy, ornithology and entomology.

The publication policy is printed on the inside back cover of each edition of the journal. There is currently no conflict-of-interest policy. The editorial guidelines of the journal are broadly aligned with ASSAf's Code of Best Practice in Scholarly Journal Publishing, Editing and Peer Review, but in several areas the guidelines are not aligned with the code. It has been indicated that the necessary amendments and additions to the guidelines will be implemented for the next edition and will be fully discussed in an editorial devoted to the subject. The journal publishes errata.

The journal publishes value-added features such as critical editorials and analytical book reviews. In each issue, $100 \%$ of the pages represent peer-reviewed original material.

\section{Content:}

(Quality, focus, spread within domain, sample of best work in SA, enrichment features, etc.)

Consensus review: The quality of the published papers is described as average to good, with the usual proviso that potential authors are unlikely to publish high-profile studies in such a low-impact journal. The focus of the studies is, quite deliberately, locally focused (essentially KwaZulu-Natal). Many of the articles are published by museum staff members, but with a good range of national (and even international) co-authors. The number of articles published annually is low, but the journal does include a range of enrichment features such as editorials and book reviews.

\section{Essential technical features:}

\section{(English abstracts, errata, citation practice, presentation)}

Consensus review: The technical (design, layout, style, copy-editing) and grammatical aspects of the published articles were generally noted to be good to excellent. None of the reviewers reported any weaknesses in these elements of the journal.

\section{Usefulness in capacity development, and international comparability:}

Consensus review: Reviewers had rather divergent views with respect to the usefulness of the journal for capacity development: one noted that the reach of the journal to graduate students might be limited due to the specialised and local nature of the research, while another commented that the published material would be valuable to young researchers working in the relevant areas.

As a low-key and local journal, this journal cannot compete with larger, higher-profile international publications. Nevertheless, it was noted that the standards of publication are comparable with those of more highly ranked journals. 


\section{Business aspects:}

(Business-related criteria; Bibliometric assessments)

The Durban Natural Science Museum (essentially eThekwini Municipality) is the owner and publisher. The regular print run is one edition each year. Layout and printing are outsourced to commercial service providers. All editorial work and distribution activities occur in-house. Editorial responsibilities are performed by the editor and the editorial board, while distribution, including management of the list of exchange partners and subscribers, is the responsibility of the museum library and librarian. The journal does not carry advertising. The costs of the journal are met entirely by the annual budget provided by eThekwini Municipality to the museum as a municipal entity.

The number of paying subscribers is about 300 , about $90 \%(270)$ of which are organisations. There are no page or article-processing charges to authors. The editorial workflow is managed manually. Access is free online, without password protection.

There have not been any offers from multinational publishers to purchase the journal. The museum retains copyright of the material in the journal, although this is not explicitly stated. A statement to this effect will be added to future editions. There is no licensing agreement with authors. As the journal is essentially completely open access, this has not been deemed necessary.

The journal is accredited by DHET. There is currently no impact or altmetric factors. The 'front details' for papers and English abstracts are mandatory. The journal previously underwent independent peer review by DHET and ASSAf in 2004/2005.

\section{Suggested improvements:}

Consensus review: It is recommended that the journal seek to improve its outreach, and work on issues that might hinder its growth. For example, the journal should consider broadening the range of interest and subject areas beyond those dictated by the narrow focus of the museum. If the journal is to increase its reach, agreements with additional institutions should also be considered.

The editor has indicated that the journal is considering aligning the guidelines more closely with those of ASSAf. This would benefit the journal, the quality of the published work, as well as the quality of reviews. It is therefore recommended that this initiative indeed be implemented.

\section{Panel's consensus view:}

i. The journal should not continue to be listed on the DHET-accredited list.

ii. The journal should not be invited to join the SciELO SA plafform.

iii. The panel recommends that the journal should address issues that do not currently comply with the requirements for either DHET accreditation or inclusion on the SciELO SA platform. These are, specifically, the number of annual published articles, and the high proportion of publications that emanate (with or without external co-authors) from the host institution.

iv. In addition, the panel believes that, as indicated by the editor, it is critically important to expand the breadth of content of the journal both geographically and in terms of the subject matter. Whether the journal could remain viable without these changes remains an issue of considerable concern.

\subsubsection{Indago}

Focus and scope:

(Purpose of journal, positioning, focus, scope, readership)

The journal publishes articles on topics related to the approved research disciplines of the National Museum, Bloemfontein, or based on the study collections of the museum, or studies undertaken in the Free State. The journal covers natural science and human science (cultural history) topics, with a 
focus on the biogeography, taxonomy and ecology of African plants and animals, and the history and culture of the Free State, particularly Bloemfontein. Manuscripts that involve interdisciplinary or multidisciplinary approaches are also considered.

The primary target audiences are local and international researchers working on African plants and animals, and southern African culture and history, especially that of the Free State. Journals are posted to 266 institutions or individuals and are also available free online.

\section{Editing functions:}

\section{(Standing, local institutional spread, international participation)}

Consensus review: The editor and members of the editorial board are all local, and are scientists of good national and, in some cases, international standing, although it was noted that many are retired rather than active scientists. The membership of the editorial board reflects the breadth of focus of the journal in both the humanities and natural sciences. The absence of international representatives was noted, together with the fact that the affiliation details of members of the editorial board on the journal website were out of date (by as much as 10 years in some cases).

The editorial advisory committee has only three members, the standing of two of whom is uncertain (they are not natural scientists), while the third member was the director of the museum and was recognised as a manager but not as a scientist.

\section{Questionnaire:}

\section{(Editorial process-related criteria)}

The journal was established in 1952 as the Navorsinge van die Nasionale Museum. In 2016, the editorial board changed the name of the journal to Indago (a Latin word meaning 'to investigate'). Indago (containing one or more articles per issue) appears at least once a year, but may be published more frequently, depending on contributions submitted and accepted. It is freely available online through the National Museum website at http://www.nasmus.co.za/museum/library/publications/scientificjournal. Records of visits and downloads were not available at the time of the review. It is not prescheduled to appear on given dates. There have been certain periods when the journal was not issued: 1959-1961, 1963-1964, 1966, 1968, 1970-1971 and 1982. This appears to have been simply due to a lack of submissions at those times.

Nine full articles were produced over a three-year period between 2016 and 2018. Eleven full-article manuscripts were received, and one was rejected after peer review. The proportion of peer-reviewed papers that had at least one author with a non-South African address was $22 \%$ (two out of the nine papers). Two, or occasionally three, peer reviewers are approached (up to five may be approached). In the case of a manuscript requiring considerable revision, a consulting editor has been used as a third reviewer. Authors are asked to send a list of five potential reviewers, including at least one international reviewer if possible. However, the editor may request advice about potential reviewers from other members of the editorial committee, or may independently choose alternative reviewers if it is considered appropriate.

Peer review is conducted in a 'blind way'. There is rigorous implementation of valid reviewer critique and article improvement. Peer reviewers receive follow-up information. Reviewer performance is not currently assessed, and there is no database of reviewers. Nine peer reviewers were used in one year, five of whom (56\%) had a non-South African address. Peer-review reports were accessibly retained in the journal's records. The average period between receipt of a manuscript and its publication was 18 months, but this was due largely to the fact that a new format for the journal was being developed. Articles are usually uploaded to the National Museum website about a week after the hard copies are posted. 
The editor has held the position since 2010 and was invited to serve; the appointment was not competitive. The period of appointment is undetermined. The editorial board handles peer review and advises on editorial policies and practices. Editorial board members are not appointed competitively but selected by the existing editorial board and then approached by the chief editor. Editorial board members are appointed from among the ranks of National Museum scientists and are South African. The board provides specific topical expertise. The editorial advisory board members (consulting editors) have been in office for more than 10 years. Members of the editorial advisory board include South African scientists and researchers of high standing in their fields of expertise. The period of appointment is indefinite.

There are editorial guidelines, which are published at the back of each issue of the journal. The guidelines are not currently aligned with ASSAf's Code of Best Practice in Scholarly Journal Publishing, Editing and Peer Review. There are no policies or guidelines regarding conflict of interest or errata.

There are no value-added features such as book reviews or topical reviews. A general editorial was published in the first issue of the new-look journal, Indago. All pages represent peer-reviewed original material.

\section{Content:}

\section{(Quality, focus, spread within domain, sample of best work in SA, enrichment features)}

Consensus review: The published articles, particularly the science articles, were considered to be of sound to good quality, but generally not of high impact. As always, it was felt that the best work from South Africa would be published in higher-impact international journals. Serious concerns were expressed about the small number of articles published annually (four each year between 2016 and 2018), and the variability between years: with the current publication volume constituting a barely marginal, or sub-marginal, level of sustainability. This issue might reflect the narrow self-defined scientific and regional scope of the journal (i.e. the focus is national, with an emphasis on human sciences papers from the local region).

The high proportion of national authors was noted. The fact that the editor-in-chief was the lead author of one and the co-author of another of the four papers published in 2018 is a cause for concern. There are no useful additional scholarly features such as editorials, topical reviews, book reviews or scholarly correspondence.

\section{Essential technical features:}

\section{(English abstracts, errata, citation practice, presentation)}

Consensus review: The technical (design, layout, style, copy-editing) and grammatical aspects of the articles were generally noted to be good. All articles have English abstracts. No errata were published during the years under review; the editor-in-chief reported that no errata were identified during this period. Images were generally of high quality (although one reviewer noted several specific examples where tables and figures were below the expected publication quality). Referencing was appropriate and consistent. One reviewer commented that much effort goes into correct presentation, copyediting and proof-reading.

Usefulness in capacity development, and international comparability:

Consensus review: The reviewers had mixed views of the suitability of the journal for younger researchers. One reviewer noted that the journal, despite its limited publication volume and parochial nature, might provide a useful platform for local postgraduate students. 
In comparison with international journals, it was noted that researchers are unlikely to publish their best work in such a local and low-impact journal, and that the content of this journal might be seen as weak in comparison with international journals in similar subject areas (e.g. ZooKeys, Zootaxa, Biodiversity Data Journal). One reviewer commented that the diverse content (human and natural sciences) and the weak online visibility means that Indago papers are unlikely to be well cited and would be largely invisible to an international audience. Another commented that "the publication of Indago may be more of a tradition than a rational practice in a $21^{\text {st }}$ century environment".

\section{Business aspects:}

\section{(Business-related criteria; Bibliometric assessments)}

Indago is owned and published by the National Museum, Bloemfontein. The journal's regular print run is 350 copies. All typesetting and editorial work are done by the editorial board and other National Museum staff. Printing is done by private companies in Bloemfontein or Kimberley. The distribution of hard copies is done by National Museum staff. The journal does not carry advertising and is not financially sponsored.

There are no paying subscribers as such, but there are 266 exchange members or individuals (173 international, 65 South African and 28 from elsewhere in Africa). About $90 \%$ of the subscriptions are held by institutions. Copies of papers are also available from the museum library at low cost. There are no page charges, but in the case of an article that is not authored or co-authored by a researcher from the National Museum, the senior author(s) may be asked to pay for the cost of colour printing of plates or figures. Workflow is managed manually. All issues since 2009 are freely downloadable on the museum website. There have been no offers to purchase the journal. There is no specific statement on copyright arrangements, and no formal licensing agreement with authors.

The journal is indexed in American Museum of Natural History, Biosciences, Ecological Abstracts, Entomology Abstracts, BioSciences Information Service of Biological Abstracts (BIOSIS) and The Zoological Record. The journal does not currently have an impact factor, and altmetric indicators are not determined. There are mandatory 'front details' for papers and English abstracts. The journal has not been independently peer reviewed before.

\section{Suggested improvements:}

Consensus review: Increasing the numbers of submissions and published papers is considered critical for the journal to have any impact or value to the scientific community.

Attention should also be paid to the proportion of publications that emanate (with or without external co-authors) from the host institution. There also needs to be a clearly stated approach to the editorial process when the editor-in-chief or any of the consulting editors are authors of papers.

Indago might consider reinventing itself and changing or expanding its scope to be more broadly relevant (as African Invertebrates has done), for example, by including neighbouring provinces to the Free State (e.g. several articles in the last three years refer to the Northern Cape or Eastern Cape) or expanding the scope to include taxonomic descriptions (e.g. of mites or reptiles).

In order for the journal to survive, it is recommended that the editors consider partnering with a suitable publishing house that can present the journal in a modern and accessible online open-access format.

The turnaround time needs to be drastically reduced if the journal is to increase submissions. Where necessary, the presentation quality of images and tables in articles should be improved. 


\section{Panel's consensus view:}

i. The journal should continue to be listed on the DHET-accredited list on condition that the suggested improvements are implemented by the end of 2022.

ii. The journal should not be invited to join the SciELO SA platform.

iii. The panel recommends that the journal should address the issues that do not currently comply with the requirements for DHET accreditation. The panel also notes that the current editor, in response to a range of criticisms, has committed to addressing most of these issues. Once completed, such changes would align the journal with the requisites for DHET accreditation.

\subsubsection{Palaeontologia Africana}

\section{Focus and scope:}

(Purpose of journal, positioning, focus, scope, readership)

This journal covers the broad scope of research of palaeontological interest in Africa or related to African palaeontology. Palaeontologia Africana is the foremost journal for local palaeontological research. Researchers who publish in the journal are generally working in southern Africa (although palaeontological research from anywhere in Africa falls within the scope of the journal), and often (but not exclusively) on Karoo or Karoo-age deposits. The journal also attracts international members of the palaeontological community, often those collaborating with African-based researchers. The primary target audiences are local and international palaeontologists.

\section{Editing functions:}

\section{(Standing, local institutional spread, international participation)}

Consensus review: The editor and members of the editorial board are mostly scientists of considerable international stature. There are also international consulting editors, including leading researchers from Europe, and North and South America.

\section{Questionnaire:}

\section{(Editorial process-related criteria)}

Palaeontologia Africana was established in 1953 and is an annual publication. The journal has recently made the transition to an online-only journal, accessible at http://wiredspace.wits.ac.za/ handle/10539/13253. There is currently little information available on the readership and subscribers due to the transition to an online-only journal. The most recent statistics, from 2018, show that, on average, 300 people per month logged on to the website to download one or more articles. Of the visitors, about $36 \%$ were from the USA, 20\% from European Union countries, $18 \%$ from South Africa, $8 \%$ from China, $5 \%$ from the UK and $4 \%$ from Brazil. The journal was accessed from at least 25 countries around the world, as well as about 10 African countries. Issues are pre-scheduled to be published in April each year, and have appeared on the scheduled dates. Papers are published on a rolling basis, however, and appear intermittently throughout the year. There were significant interruptions in publication in 1970-1972 and 1981-1984. The reasons for the interruptions were unknown at the time of the review.

Fifteen full articles were published during the three-year review period. Other articles included three sets of approximately 60 peer-reviewed abstracts. A total of 23 manuscripts were received over the same period. Three manuscripts were rejected without peer review, and no papers were rejected after peer review. Fifty per cent of the peer-reviewed papers had at least one author with a non-South African address.

Two peer reviewers are approached to review each manuscript. Reviewers are either selected from a pool of candidates or solicited by the editor or sub-editors. Peer review is not conducted in 
a 'blind way'. At least two reviewers and the handling editor are required to make comments on the manuscript. If the reviewers are in dispute, a third reviewer is appointed. Records of every step of this process have been kept since 2012. Peer reviewers receive follow-up information. Reviewer performance is not assessed, and there is no reviewer database. Approximately 15 reviewers were used in one year during the review period. The proportion of these reviewers who had a non-South African address was $70 \%$. Peer-review reports were accessibly retained in the journal records. There is a three-month period between receipt of a manuscript and its publication online.

The editor-in-chief has held the position for six years. The appointment was not competitive, and the period is indefinite. Manuscripts are received by the editor and distributed to the appropriate member(s) of the editorial board for peer review. Editorial board members also advise on editorial policies and practices at an annual meeting. Members of the editorial board and editorial advisory board have been in office for five years. The appointments were not competitive, and the period of appointment is indefinite. Members are appointed from both inside and outside South Africa, with the aim of providing specific topical expertise.

Editorial guidelines are available on the journal website. They are not aligned with ASSAf's Code of Best Practice in Scholarly Journal Publishing and Peer Review. There are currently no policies or guidelines dealing with conflict of interest or errata. The journal publishes errata in all cases where errors are apparent. The journal does not publish additional features such as editorials, book reviews or correspondence. Ninety per cent of the pages in each issue represent peer-reviewed original material.

\section{Content:}

\section{(Quality, focus, spread within domain, sample of best work in SA, enrichment features)}

Consensus review: All reviewers noted that the quality of the research published in the journal is consistently high. One reviewer noted that Palaeontologia Africana is the top journal for southern African research in the field of palaeontology, and another observed that despite its local focus, the articles published in the journal would be welcomed in any major international palaeontological journal. The journal focuses on palaeontology, but also includes papers from the related fields of palaeoanthropology and palaeobotany.

Most of the articles are by South African authors. The number of articles published each year has been very variable (from two articles in 2017 to 11 articles in 2018), suggesting that, at least periodically, the journal struggles to receive sufficient submissions. The journal is applauded for implementing a continuous publication schedule, with papers appearing online as they are completed. This ought to encourage increased submission rates. It was thought that the best research in the relevant fields is probably not submitted to this journal, with higher-impact international journals being the favoured targets.

The authorship is dominated by researchers from the host institution, the University of the Witwatersrand (Wits), which is perhaps not surprising since a high proportion of researchers in the relevant fields are based at this institution. However, other national institutions, and a good number of international authors (from at least 12 countries) are represented in the publications. In most cases, international authors that publish in the journal are working in collaboration with researchers at Wits.

The journal also publishes topical reviews, technical reports (focusing on new methodologies) and conference proceedings. However, there are no other scholarly features, and it was noted that regular editorials would be particularly useful. 


\section{Essential technical features:}

(English abstracts, errata, citation practice, presentation)

Consensus review: The journal maintains the highest technical standards in its publications. All papers have suitable abstracts and keywords for indexing. All aspects of the design, presentation and content are 'exemplary'. The publication of errata does not appear to have occurred recently, although the editor indicates that the journal will publish errata as needed. The citation practices are appropriate and follow the best international standards in the field. The journal should be commended on the clarity of the scope and guidelines for submission, and the availability of an EndNote template for referencing is a useful feature.

\section{Usefulness in capacity development, and international comparability:}

Consensus review: There was consensus that the journal provides a useful resource for younger researchers, particularly those in the relevant fields. The journal is well placed and clearly plays an important role in providing a venue for the publication of work by early-career researchers in South Africa.

In terms of comparison with leading international journals, Palaeontologia Africana may be a regional journal, but its quality of content and presentation is often entirely comparable with leading international journals. It is noted that the regional focus means that the journal will inevitably have relatively low impact. However, the full open access and author retention of copyright are attractive properties that are not present in many of the leading palaeontological journals.

\section{Business aspects:}

\section{(Business-related criteria; Bibliometric assessments)}

The journal is owned and published by the Wits Evolutionary Studies Institute. There is no print run, as the journal is published online. Production is done by Isteg Scientific Publications, and distribution is done by the Evolutionary Studies Institute. The journal does not carry advertising. Financial sponsorship comes from the Palaeontological Scientific Trust (PAST) and the NRF (for some articles).

There are no subscribers, and there are no page charges unless there are excessive error corrections. Editorial workflow is managed manually. Online accessibility is free and open. The journal has received offers to purchase from multinational publishers, although no details were provided. Copyright is retained by the authors, and material is published under a CC BY 4.0 licence. There is no formal licensing agreement with authors.

The journal is indexed by Google Scholar and WoS. Impact factors have not been determined for the journal. Palaeontologia Africana monitors altmetric indicators through the DSpace archive. It is mandatory that 'front details' for papers and English abstracts are provided. This is the journal's first independent peer review.

\section{Suggested improvements:}

Consensus review: It is recommended that the journal ensure that the pre-print policy is clear to potential authors. An explicit policy on open data or the availability of underpinning data is advised.

Efforts should be made to ensure that the number of annual publications is increased and stabilised. More work could be done to promote the visibility of Palaeontologica Africana. The editorial board might also consider soliciting submissions from international researchers, and perhaps including significant and timely reviews of topics relevant to southern African palaeontology. These could be tied to keynote presentations given at conferences of the Palaeontological Society of Southern Africa or other significant conferences. 
In addition, the panel supports the editor's efforts to acquire an impact factor. Even a low impact factor might have a positive effect on the objectives outlined above.

\section{Panel's consensus view:}

i. The journal should continue to be listed on the DHET-accredited list.

ii. The journal should be invited to join the SciELO SA platform.

iii. The panel recommends that the number of articles published annually be increased and stabilised.

\subsubsection{South African Archaeological Bulletin}

\section{Focus and scope:}

(Purpose of journal, positioning, focus, scope, readership)

The South African Archaeological Bulletin publishes archaeological research findings from southern Africa and other related geographical regions. The Bulletin was established in 1945 with the aim of informing a wide audience about important new research findings on all aspects of African archaeology. The Bulletin strives to raise the profile of African archaeological research and to demonstrate the key importance of archaeology in post-colonial Africa.

The primary target audience is Africanist archaeologists in Africa and beyond, as well as those with a general interest in the discipline. The publication is disseminated to members of the South African Archaeological Society (SAAS) and the Association of Southern African Professional Archaeologists (ASAPA). University libraries subscribe to the journal through institutional membership of SAAS.

\section{Editing functions:}

\section{(Standing, local institutional spread, international participation)}

Consensus review: The editorial board appears to comprise well-established senior researchers who have, at least, a sound reputation at national level, and who come from the various fields of archaeology. The expertise of the board members covers a wide and relevant range of archaeological and palaeontological disciplines. Four members of the board are South African, and the remaining four are from the Netherlands, Sweden, the UK and the USA.

\section{Questionnaire:}

\section{(Editorial process-related criteria)}

The Bulletin is published biannually. It is available online through the JSTOR and EBSCOhost platforms. The tables of contents are available on the SAAS website at https://www.archaeology.org.za/. Visit and download records were not available at the time of the review. Readers who access the journal are mainly from southern Africa, but some are based in Europe, America or Australasia. Issues are prescheduled to appear in June and December. Issues have appeared regularly, and there have been no significant interruptions in publication.

During the review period, 45 full articles, 18 book reviews and six discussion forum articles were received and published. No manuscripts were rejected without peer review, and three were rejected after peer review. About 15 peer-reviewed papers had at least one author with a non-South African address.

Two peer reviewers are usually approached to review each manuscript, and a third reviewer is approached in the event that another opinion is needed. Peer reviewers are identified based on compatibility between the content of the manuscript and the expertise of the reviewer. A double-blind review process is used, and a rigorous process of valid reviewer critique and article improvement is followed. Peer reviewers do not receive follow-up information. Reviewer performance is not assessed, although there are plans to implement such a system in the near future. About 35 peer reviewers 
were used in one year over the review period. About 14 of these had a non-South African address. Records of peer-review reports were accessibly retained. The average period between receipt of a manuscript and its publication in print was 12 months.

The editor-in-chief was appointed in 2015 after the position had been advertised. The editor and members of the editorial team were appointed for five years, with the possibility of extension. The editorial board deals with peer review and advises on editorial policies and practices. The members of the editorial board have served for varying periods, the longest being for 10 years. Editorial board members are appointed by the ASAPA council on the recommendation of the editor-in-chief. The council can also identify editorial board members. One editorial team member is based in the USA, while all the others are based in South Africa. All board members provide expertise on various aspects of archaeology.

The journal publishes guidelines in each volume, and these are updated as required. There is a conflict-of-interest policy, and if an editorial team member should wish to publish in the journal, an independent review process is applied. The guidelines are aligned with ASSAf's Code of Best Practice in Scholarly Journal Publishing, Editing and Peer Review. Errata are published if necessary.

The journal publishes additional features such as critical editorials, critical topical reviews and analytical book reviews. About 80 of the approximately 120 pages of each issue represent peerreviewed original material.

\section{Content:}

\section{(Quality, focus, spread within domain, sample of best work in SA, enrichment features)}

Consensus review: Articles published in the Bulletin are of good to high quality. Noting that the best work is usually published in higher-impact international journals, some of the best South African scholarship is presented in the Bulletin. There are a good number of articles each year, and the number of papers published in each volume has been consistent. The geographical focus of the published studies is, perhaps not surprisingly, almost entirely on the southern African region, but the diversity of articles makes for interesting reading.

While most of the authors are local or locally affiliated, there is a good representation of international contributors, mostly as co-authors. One reviewer noted the rather weak representation of authors from neighbouring SADC countries, most studies from these regions being authored by international (non-African) researchers. Reviewers noted that the number of articles published, and the historical reliability of the issue publication schedule, were entirely appropriate and commendable.

One reviewer commented positively on the editorials in each issue, which are a useful means of informing the readership of current and topical issues. All volumes carry book reviews, but topical reviews and scholarly correspondence are not published regularly. One reviewer commented that letters to the editor did not appear to be encouraged, and suggested that the editor might consider this mode of communication.

\section{Essential technical features:}

(English abstracts, errata, citation practice, presentation)

Consensus review: The technical (design, layout, style, copy-editing) and grammatical aspects of the published articles were generally noted to be good to excellent. Images were generally of high quality, and referencing was appropriate and consistent. One reviewer suggested that the editor might allow greater variation in the cover design. Errata were not common, but some examples were noted. 
Usefulness in capacity development, and international comparability:

Consensus review: It was generally agreed that the journal content was entirely suitable as a means of stimulating graduate student interest and research. The journal also provides a good platform for recent graduates to publish their work.

While the scientific content of the journal was deemed to be strong, it was noted that local journals such as this, with their regional focus, cannot compete with higher-profile, higher-impact international journals with broader geographical scope. One reviewer nevertheless noted that the Bulletin is a 'trusted and credible' journal.

\section{Business aspects:}

(Business-related criteria; Bibliometric assessments)

The owner is SAAS, and the journal is published in collaboration with ASAPA, which is responsible for appointing the editorial team and managing the publication process. Until December 2019, the regular print run was between 1000 and 1100 copies. In June 2020, the Bulletin switched to a hybrid distribution mode, whereby subscribers can opt to receive a digital copy only, or both a digital and hard copy. The print run thus varies according to demand (approximately 300). Technical layout and printing are outsourced, and distribution is done through the South African Post Office. The journal does carry advertising. Limited funding is received for the journal. There are about 1000 paying subscribers, 60 of which are institutions as opposed to individuals. Article-processing fees are charged only if authors exceed the recommended word length or wish to publish images in colour. Manual systems are used to manage the workflow. The journal is not open access.

There have been many offers from multinational publishers to purchase the journal. The authors own the copyright to their material and are required to sign a copyright agreement.

The Bulletin is indexed by Google Scholar, Scopus and WoS. The impact factor was not provided at the time of the review. Altmetric indicators have not been determined yet. English abstracts and 'front details' for papers are required. The Bulletin has not been independently peer reviewed before.

\section{Suggested improvements:}

Consensus review: The editorial board could benefit from the involvement of younger researchers. Staggering the period of office of members of the editorial board, as well as the selection of individuals from different career levels, would improve continuity.

The journal might actively attempt to attract more authors from neighbouring southern African countries.

The panel supports the journal in its assessment of the possibility of future online publication, and the implementation of an online management system. The editor could also consider publishing articles online ahead of publication, which would enable the release of current or cutting-edge discoveries in advance of the traditional publication dates.

Extended abstracts from the biennial ASAPA conferences could be published.

\section{Panel's consensus view:}

i. The journal should continue to be listed on the DHET-accredited list.

ii. The journal should be invited to join the SciELO SA plafform if it becomes open access.

iii. The panel recommends that the journal might actively attempt to attract more authors from neighbouring southern African countries.

iv. The panel believes that the editorial board could benefit from the involvement of younger researchers. 


\section{Appendix A: Questionnaire Sent to Editors of Journals Under Review}

[Note: The questionnaire was revised in 2018 before the reviews took place.]

\section{Purpose of journal, positioning, focus, scope, readership, etc.:}

1.1 What is the focus and scope of the journal (i.e. what does it say about this in your masthead)?

1.2 Is the journal's aim to focus on a specific discipline or field, or does it (also) include an interdisciplinary focus?

1.3 How does the journal serve the South African research community in relation to its focus and scope?

1.4 Who are your primary target audiences (predominantly local scholars or also further afield)?

1.5 What is the journal's reach and how is the readership composed (i.e. international subscribers, institutions, and/or individuals in terms of numbers and/or percentages)?

\section{Editorial process-related criteria:}

1.1 When was the journal established?

1.2 What is the publication frequency of your journal, per year?

1.3 If online,

\subsubsection{What is its URL?}

1.3.2 What is the visit and download record?

1.3.3 In how many countries is the journal read?

1.3.4 In how many African countries is the journal read?

\subsection{Scheduled issues:}

2.4.1 Are issues of your journal pre-scheduled to appear on given dates?

1.1.2 If scheduled, do the issues in fact appear regularly on the scheduled dates?

1.4 Have there been significant interruptions in publication since the journal's inception? If so, provide details.

1.5 Peer-reviewed original papers:

2.6.1 How many peer-reviewed original papers have you published during the last three years:

a. Full articles?

b. Letters? 
c. Review articles?

d. Book reviews?

e. 'Conference papers'?

f. Other?

1.5.1 How many manuscripts in each of the above categories were received in the last three years?

1.6 Rejection rate:

2.7.1 Approximately how many manuscripts in each category were rejected without peer review (as a pre-peer review decision)?

1.6.1 How many were rejected after peer review?

1.7 What proportion of peer-reviewed papers of all kinds that you published had at least one author with a non-South African address?

1.8 Peer reviewers:

2.9.1 How many peer reviewers are usually approached for each submitted manuscript?

1.8.1 How are peer reviewers selected?

1.9 Is peer review conducted in a 'blind way', i.e. authors and institutions blanked out?

1.10 How rigorous is the implementation of valid reviewer critique and article improvement?

1.11 Do peer reviewers receive follow-up information, e.g. outcomes of the reviews?

1.12 Is reviewer performance assessed and is such information captured in a database?

1.13 Total of peer reviewers:

1.1.1 How many peer reviewers were used in total, in any one of the last three years?

1.1.2 What proportion of these had non-South African addresses?

1.14 Are peer review reports accessibly retained in your records?

1.15 What is the average period between receipt of a manuscript and its publication:

- In print?

- Online?

1.16 Editor/editor-in-chief:

1.16.1 How long have you been editor/editor-in-chief of this journal?

1.16.2 Were you appointed competitively (i.e. following advertisement and a selection process)?

1.16.3 For what period have you been appointed?

1.17 Do members of your editorial board and/or editorial advisory board: 
1.17.1 Handle peer review of individual manuscripts?

1.17.2 Advise on editorial policies/practices?

1.17.3 How long have they been in office:

$>$ Editorial board?

$>$ Editorial advisory board?

1.17.4 Are they appointed competitively (i.e. following advertisement and a selection process)?

1.17.5 For what period?

1.17.6 From inside and outside the country?

1.17.7 To provide specific topical expertise?

1.18 Policies:

1.18.1 Do you have published editorial/policy guidelines? What is the policy? (Please send us a copy)

1.18.2 Is there a conflict-of-interest policy? If so, please provide details.

1.18.3 Have your editorial/policy guidelines been aligned with ASSAf's Code of Best Practice in Scholarly Journal Publishing, Editing and Peer Review?

1.19 Do you publish errata in all cases where errors have become apparent? What is your policy?

1.20 Does your journal contain value-added features such as:

- Critical editorials?

- 'News and views' analyses of articles being published?

- Critical topical reviews?

- Analytical book reviews?

- Correspondence on published articles?

- Other?

1.21 What is the percentage of pages in each issue that represents peer-reviewed original material?

\section{Business-related criteria:}

1.1 Who is the actual title owner (legally) of the journal? And the publisher(s)?

1.2 What is the regular print run of your journal, if it is printed?

1.3 Are production and distribution outsourced? If so, provide details.

1.4 Do you carry advertising which is:

- Paid?

- Unpaid?

1.5 Do you receive financial sponsorship(s)? If so, please list the sponsors and provide details.

1.6 What is the number of paying subscribers? 
1.7 How many of the subscribers are organisations as opposed to individuals?

1.8 Do you impose page charges or article-processing charges on authors? If so, provide details.

1.9 How is the editorial workflow of the journal managed?

- Online management system

- Loading of articles on to web

- Manual system

- Other

1.10 If your journal appears online:

- Is it free online (open access)?

- Is it free online but password protected?

- Is it part of a commercial (pay-to-view and/or pay-to-subscribe) e-publication service?

- Is it part of a non-commercial e-publication mechanism (i.e. MEDLINE)?

1.11 What is the journal's estimated total cost each year?

1.12 Has the journal had offers to purchase from multinational publishers?

1.13 What are your copyright arrangements?

1.14 What licensing agreement do you have with authors?

\section{Bibliometric assessments:}

1.1 Could you provide us with a list of the indices in which the journal is indexed (including Web of Science and/or the IBSS, Google Scholar, Scopus as well as others)?

1.2 Have impact factors (e.g. Google Scholar, WoS or Scopus) ever been determined for your journal? If so, what were they?

1.3 Do you use any altmetric indicators (number of visits to journal website, number of downloads, citations on social media) to monitor the journal's 'performance'?

1.4 Are 'front details' for papers like titles, authors, addresses, affiliations and English abstracts mandatory?

1.5 Has your journal ever been independently peer reviewed before and by whom?

\section{General:}

1.1 Is there any other information or do you have any comments that may be useful to the panel?

1.2 What do you regard as the main challenges that your journal and editorial team face? 


\section{Appendix B: Requests to Independent Peer Reviewers}

1. Do the hard copies of the last 2-3 years of issues of the journal reflect:

1.1 high national/international disciplinary reputations/standing of the editor-in-chief/ associate editors/members of the editorial board?

1.2 a high/good (general/average) quality of the articles accepted/published?

1.3 a (contextually) adequate/good number of articles each year?

1.4 an (adequate/good) sample of the best work done in the country in the discipline/ field?

1.5 a focus on local/regional kinds of materials/problems?

1.6 publication of articles by authors from across the country, and internationally?

1.7 useful additional scholarly features such as editorials, topical reviews, book reviews, scholarly correspondence?

1.8 appropriate (English-language) abstracts for all articles?

1.9 suitable publication of errata?

1.10 good citation practice?

1.11 good presentation, design, layout, style, copy-editing interventions, images are used in an ethical manner?

1.12 suitability as a general ongoing stimulus for local graduate students and young staff in the discipline concerned?

1.13 some kind of comparability with leading international journals in the field?

2. Please list your suggestions for an improvement programme for the journal. 
Notes 
1st Floor Block A, The Woods 41 De Havilland Crescent Persequor Park - Meiring Naude Road - Lynnwood Pretoria - South Africa

PO Box $72135 \cdot$ Lynnwood Ridge 0040

Pretoria, South Africa

Switchboard: +27 $123496600 / 21 / 22$

Tel: +27 123456789 • Fax: +27 123456789 
Report on Grouped Peer Review of

\section{Scholarly Journals in Mathematics and Science}

\section{Academy of Science of South Africa (ASSAf)}

Academy of Science of South Africa (ASSAf)

Please cite as: Academy of Science of South Africa (ASSAf), (2021). Report on Grouped

Peer Review of Scholarly Journals in Mathematics and Science. [Online] Available at: DOI http://dx.doi.org/10.17159 http://hdl.handle.net/20.500.11911/216

Downloaded from ASSAf Research Repository, Academy of Science of South Africa (ASSAf) 